\title{
Glutamine Supplementation in Sick Children: Is It Beneficial?
}

\author{
Elise Mok ${ }^{1,2,3}$ and Régis Hankard1,2 \\ ${ }^{1}$ INSERM Centre D'Investigation Clinique 802, Centre Hospitalier Universitaire de Poitiers, 86021 Poitiers Cedex, France \\ ${ }^{2}$ Pédiatrie Multidisciplinaire-Nutrition de l'Enfant, Centre Hospitalier Universitaire de Poitiers, 86021 Poitiers Cedex, France \\ ${ }^{3}$ Child Health Clinical Research Centre, The Montréal Children's Hospital, McGill University Health Centre, \\ Montréal, QC, Canada H3H 1 P3
}

Correspondence should be addressed to Régis Hankard, regis.hankard@free.fr

Received 1 August 2011; Accepted 28 September 2011

Academic Editor: Johannes B. van Goudoever

Copyright (C 2011 E. Mok and R. Hankard. This is an open access article distributed under the Creative Commons Attribution License, which permits unrestricted use, distribution, and reproduction in any medium, provided the original work is properly cited.

\begin{abstract}
The purpose of this review is to provide a critical appraisal of the literature on Glutamine (Gln) supplementation in various conditions or illnesses that affect children, from neonates to adolescents. First, a general overview of the proposed mechanisms for the beneficial effects of Gln is provided, and subsequently clinical studies are discussed. Despite safety, studies are conflicting, partly due to different effects of enteral and parenteral Gln supplementation. Further insufficient evidence is available on the benefits of Gln supplementation in pediatric patients. This includes premature infants, infants with gastrointestinal disease, children with Crohn's disease, short bowel syndrome, malnutrition/diarrhea, cancer, severe burns/trauma, Duchenne muscular dystrophy, sickle cell anemia, cystic fibrosis, and type 1 diabetes. Moreover, methodological issues have been noted in some studies. Further mechanistic data is needed along with large randomized controlled trials in select populations of sick children, who may eventually benefit from supplemental Gln.
\end{abstract}

\section{Introduction}

Glutamine (Gln) is the most abundant amino acid in the muscle and plasma of humans [1]. Although Gln is a nonessential neutral amino acid, it is necessary for optimal growth of mammalian cells in tissue culture [2] and has important physiological functions. Apart from providing nitrogen for protein synthesis, Gln is a precursor for nucleic acids, nucleotides [3], hexosamines [4], the nitric oxide precursorarginine (Arg) [5], and the major antioxidant-glutathione $[4,6]$. Gln is also an important oxidative fuel for rapidly proliferating cells such as those of the gastrointestinal tract [7] and immune system [3], reticulocytes [8], fibroblasts [9], and so on. It plays a central role in nitrogen transport between tissues [10], specifically from muscle to gut, kidney, and liver. In addition to its role as a gluconeogenic substrate in the liver, kidney [11], and intestine [12], Gln is involved in the renal handling of ammonia, serving as a regulator of acidbase homeostasis [13]. Present data also indicate that Gln functions as a signalling molecule [14], particularly under catabolic conditions.
Traditionally Gln is considered a nonessential amino acid, because it is synthesized by most tissue (skeletal muscle being the main producer and storage site) [15]. Gln synthetase catalyzes the terminal step in Gln de novo synthesis and is a key enzyme in Gln metabolism [16, 17]. In mammals, Gln synthetase expression is regulated by transcriptional and posttranscriptional mechanisms, that is, increasing Gln synthetase mRNA in response to stress (e.g., glucocorticoids) and regulation of Gln synthetase protein turnover in response to its product (Gln concentrations) [18]. The importance of Gln at the whole body level is highlighted by the report of severe brain malformation resulting in multiorgan failure and neonatal death in 2 unrelated newborns with congenital Gln synthetase deficiency, in whom Gln was largely absent in plasma, urine, and cerebral spinal fluid [19].

Under normal conditions, Gln is released into circulation for consumption by other tissue, whereas during catabolic stress the production of Gln may be insufficient to meet the increased requirements by the gut, immune system/inflammatory cells, liver, and kidneys. Demands are 
partly met by skeletal muscle proteolysis and release of large amounts of Gln to maintain normal concentrations in the plasma, resulting in depletion of Gln stores. Based on this abundant evidence, Lacey and Wilmore [10] suggested that Gln may become a conditionally essential amino acid for the critically ill.

In paediatrics, several researchers have studied the efficacy of supplemental Gln in premature infants of low birth weight (LBW), who are highly stressed and have low energy and protein reserves [20]. Similar to premature neonates, Gln supplementation may also be beneficial for other childhood conditions including gastrointestinal disease, malnutrition, cancer, severe burns/trauma as well as chronic diseases of childhood. However, less data is available on the effects of supplemental Gln in older infants and children with various diseases.

In addition to being sick and highly stressed, children are also in the process of growth and development. Hence, specific research on the role of Gln in pediatric patients is necessary. The main purpose of this manuscript is to provide a critical review of the literature on Gln supplementation in various conditions/illnesses that affect children (from neonates to adolescents). First the proposed mechanisms of Gln action are reviewed in a general context, followed by a detailed description and critique of the clinical research on Gln supplementation in children.

1.1. Glutamine Mechanisms of Action. While it is well established that Gln is a protein precursor as well as a major fuel and nucleotide substrate for rapidly proliferating cells (e.g., gut and immune system) [3, 7], additional mechanistic data has emerged to explain the apparent benefits of Gln. Gln can regulate the expression of many genes related to metabolism, signal transduction, cell defense, and repair and can activate intracellular signaling pathways [14]. In brief, Gln seems to affect antioxidant capacity, tissue protection, immune, and metabolic function [21] as well as protein synthesis and degradation [14] (Figure 1). The postulated mechanisms remain speculative and are by no means mutually exclusive, since Gln can provoke a number of different effects that interact with one another.

\subsection{Antioxidant Capacity}

1.2.1. Glutathione. Gln is a precursor of the glutamate (Glu), for glutathione (L- $\gamma$-glutamyl-L-cysteinyl-glycine) synthesis, an important antioxidant in many cell types [22]. Glutathione is present in the cell in reduced (GSH) and oxidized (GSSG) forms. The ratio of reduced-to-oxidized glutathione is the major regulator of the cellular redox potential that determines the antioxidant capacity of the cell [14, 22, 23]. The effectiveness of glutathione protection in individual tissue depends on the tissue concentration of glutathione as well as the capacity of the tissue to import GSH and to export GSSG [24].

In vivo experiments in rats demonstrate that administration of Gln before ischemia/reperfusion injury or surgical manipulation can enhance GSH concentrations and provide

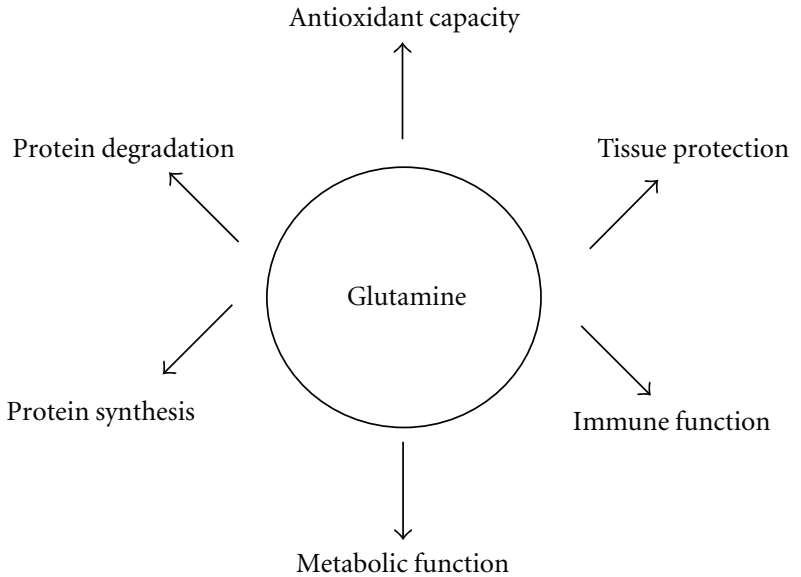

FIGURE 1: Schematic representation of the mechanism of glutamine action.

protection against oxidative stress in various tissues (e.g., cardiac, intestinal, and lung) $[25,26]$. Further, the effectiveness of Gln in preventing liver damage in neonatal sepsis appears to be mediated via glutathione synthesis [27]. In humans, Gln supplementation can attenuate GSH depletion in skeletal muscle following surgical trauma [28].

During critical illness, muscle concentrations of GSH decrease and a change in the redox status occurs, indicative of an elevated GSSG [24]. Moreover, there is a correlation between the concentrations of Gln and GSH [24]. Shifting the GSH/GSSG redox toward oxidizing conditions activates several signaling pathways, such as c-Jun $\mathrm{N}$-terminal kinase (JNK), apoptosis signal-regulated kinase-1 (ASK-1), mitogen-activated protein kinase (MAPK), and the transcription factor nuclear factor-kappaB (NF- $\kappa \mathrm{B}$ : a stimulator of the synthesis of proinflammatory cytokines and adhesion molecules) [22, 23, 29]. Evidence also implicates oxidative stress as a potential regulator of NF- $\kappa \mathrm{B}$ transactivation by MAPKs (in particular extracellular signal-regulated kinase $1 / 2$ (ERK1/2) and p38) [30] which could lead to increased proteolysis in muscle [31]. Moreover, the cellular redox status seems to be related to the degree of muscle protein degradation [32, 33]. Likewise, there is significant literature on the role of inflammatory cytokines (interleukin-1, -6, tumour necrosis factor-alpha (TNF- $\alpha)$ ) and muscle wasting [34].

Gln metabolism via entry into the citric acid cycle may allow the activation of malic enzyme which will result in an increase in NADPH [15] and subsequently increase the GSH/GSSG ratio [14]. Administration of Gln leads to an increased ratio of GSH/GSSG and reduces the activity of redox sensitive kinases subsequently preventing NF- $\kappa \mathrm{B}$ activation and thus inhibiting the inflammatory response [23].

Experiments from our group in the $m d x$ mouse model of muscular dystrophy (a condition associated with severe muscle wasting) showed that in vivo Gln administration can reduce GSSG in dystrophic skeletal muscle, hence, increasing the ratio of GSH/GSSG [35]. This was associated 
with decreased activation of MAPK (ERK1/2) pathway [35]. Similar effects were observed in muscle of control mice; however, the magnitude was less [35]. Thus, in muscle tissue, Gln might affect the cellular redox state involving MAPK pathway.

\subsection{Tissue Protection}

1.3.1. Heat Shock Protein (HSP). The HSPs serve as molecular chaperones that appear to repair denatured/injured proteins or promote their degradation following irreparable injury. Gln has cell-protective effects, as a potent enhancer of the expression of HSP25, HSP70, HSP72, and hemeoxygenase-1 in cell culture [36], in multiple organs of both stressed and unstressed animal models [37], as well as in humans $[38,39]$. However, Gln depletion during the stress response can impair the expression of the major inducible HSP (HSP70), as shown in human lymphocytes [40]. And recent evidence suggests that HSP70 expression is required for Gln's protection against tissue injury and for attenuation of NF- $\kappa \mathrm{B}$ activation and proinflammatory cytokine release [41].

In rats, preoperative administration of Gln induces HSP70 expression and attenuates the inflammatory response by regulating nitric oxide synthase (NOS) activity in heart, lung, and liver [42]. Gln is a well-known precursor for Arg [5], which can increase nitric oxide formation as a result of enhanced NOS activity [6]. However, in various models of human intestinal cells, Gln does not further increase nitric oxide production or inducible NOS mRNA following proinflammatory cytokine stimulation [43]. Thus, Gln's effects on NOS activity might be tissue- or conditionspecific.

The survival-promoting effects of HSP70 can also be attributed in part to the suppression of apoptosis, since reduced HSP expression in Gln-deprived cells together with their impaired antioxidant capacity may make them more susceptible to apoptosis [29].

1.3.2. Apoptosis. Gln starvation has been shown to induce apoptosis in intestinal epithelial cells [44] and also renders human monocytic cells more susceptible to apoptosis induced by Fas ligand, heat shock, or TNF- $\alpha$ stimulation [45]. In HeLa cells, Gln might also suppress ASK-1 and JNK/stress-activated protein kinase (SAPK) activation by Fas ligand [46]. The effect of Gln in delaying spontaneous apoptosis in neutrophils may be mediated by the antioxidant effects of glutathione [47]. Furthermore, Gln may protect activated $\mathrm{T}$ cells from apoptosis, partially by upregulating glutathione and $\mathrm{Bcl}-2$ expression and inhibiting Fas [48].

1.3.3. Intestinal Barrier Function. As an important fuel for intestinal tissue and gut-associated lymphoid tissue, Gln may contribute to gut barrier function [49]. Experimental data from neonatal animal models also support the beneficial effects of Gln on gastrointestinal development and function [50-59]. Gln is also involved in the biosynthesis of hexosamines which are important for maintaining gut wall integrity via surface mucin and glycoprotein-forming intracellular tight junctions and thus may protect against bacterial translocation $[4,60]$.

1.4. Immune Function. As a major fuel for immune cells, Gln is known to modulate immune function. More recently, Gln has also been shown to have anti-inflammatory effects, modulating cytokine production, both in vitro $[36,61-63]$ and in vivo $[41,51,64]$, possibly through decreased NF- $\kappa \mathrm{B}$ activation $[41,62]$, a major transcription factor regulating immune and inflammatory responses. In neonatal mice and rats with experimental NEC, Gln reduces intestinal injury $[54,55]$, via mechanisms inhibiting inflammatory cytokine release [54].

Gln's anti-inflammatory effects may also be related to enhanced HSP expression [36, 41]. The induction of HSP response can attenuate proinflammatory cytokine release, which in turn depends on the cellular redox potential and consequently is regulated by the intracellular GSH/GSSG ratio [14] (as previously described).

1.5. Tissue Metabolic Function. Gln can preserve tissue-metabolic function in stress states. For instance, Gln enhances myocardial tissue-metabolic function after ischemia/ reperfusion injury in rats [26]. Gln can also enhance ATP levels in oxidant stressed endothelial cells [65].

1.5.1. Glucose Metabolism. While Gln plays an important role in gluconeogenesis $[11,12,66]$, evidence also suggests that Gln can improve insulin sensitivity and glucose disposal in patients suffering from critical illness [21, 67], a condition frequently associated with insulin resistance and subsequent hyperglycemia. Gln also plays a role as a signaling molecule in amino acid- and glucose-stimulated insulin secretion [68]. Interestingly in rats with diet-induced obesity, Gln supplementation induces insulin resistance in adipose tissue and reduces adipose mass, consequently attenuating insulin resistance and activation of JNK and inhibitory kappaB kinase subunit beta in liver and muscle, thus improving insulin signaling [69]. These data suggest that Gln can beneficially influence insulin-dependent glucose metabolism.

1.6. Protein Synthesis and Degradation. Gln appears to regulate protein turnover in cultured rat skeletal myotubes, stimulating protein synthesis in stressed myotubes while inhibiting protein degradation in long-lived proteins. This may be related to the increase in HSP70 [70]. There is also abundant literature to suggest that amino acids affect protein turnover via the mammalian target of rapamycin (mTOR) pathway $[71,72]$.

1.6.1. Protein Synthesis. Amino acids, particularly branched chain amino acids, for example, leucine (Leu) stimulate skeletal muscle protein synthesis via the activation of mTOR which in turn activates p70 ribosomal S6 kinase $\left(\mathrm{p} 70^{\mathrm{S} 6 \mathrm{~K}}\right)$ and dephosphorylates eukaryotic initiation factor 4E-binding protein 1 (4E-BP 1), stimulating translation and protein synthesis $[71,72]$. Gln can induce growth and maturation of neonatal rat cardiomyocytes, which is associated with 
an increase in the mRNAs-encoding contractile proteins and metabolic enzymes via the activation of protein kinase A and mTOR [73]. However, the action of Gln seems to be cell-type specific. For instance, in C2C12 myogenic cells, Gln and Leu have opposite effects on the mTOR pathway [74]. Whereas Leu activates this pathway, Gln inhibits it by decreasing the phosphorylation states of mTOR (on serine (Ser)2448), p70 $56 \mathrm{~K}$, and 4E-BP1, with no effect on protein synthesis [74].

1.6.2. Protein Degradation. The major proteolytic pathways in organs such as the liver, muscle, and intestine include the autophagic/lysosomal (cathepsins), the calcium activated (calpains), and the ATP-ubiquitin-proteosome pathway [14, $34]$. The proteosome system (26S) is a highly selective proteolytic pathway [71]. In visceral tissues (e.g., liver), autophagy is, however, the major proteolytic pathway and the only pathway known to be regulated by plasma amino acids (in liver and skeletal muscle) $[71,72]$. In autophagic proteolysis, several amino acids have direct regulatory potential, possibly via a plasma membrane amino acid receptor/sensor and subsequent intracellular signaling [71].

Another line of evidence suggests that amino acids activate mTOR pathway which in turn suppresses protein breakdown by the autophagy/lysosomal pathway [71, 72]. Amino acids can also control autophagic lysosomal proteolysis by inhibiting MAPK (ERK1/2) phosphorylation [75]. Gln may cause its antiproteolytic effect through osmotic swelling [76], involving p38 MAPK pathway [77]. An increase in cellular hydration acts as an anabolic signal, whereas cell shrinkage is catabolic, and there is a close relation in the regulation of cell volume, Gln, and protein catabolism [23].

On the other hand in the human gut, enteral Gln may attenuate ubiquitin-dependent proteolysis as demonstrated by decreased ubiquitin mRNA, whereas mRNAs encoding for cathepsins or calpains were not affected [78]. Furthermore, in lung and muscle, Gln can also regulate its own production through a posttranscriptional mechanism in which Gln regulates Gln synthetase protein degradation [16, 17, 79], by facilitating its degradation by the $26 \mathrm{~S}$ proteosome [18]. Thus, the presence of Gln could have a protein-sparing effect, sparing amino acids for protein accretion [80-82].

1.7. Glutamine in the Neonatal Period. Gln is the predominant amino acid supplied to the fetus through the placenta and is specifically suited for its rapid development [83, 84]. While normally present in the enteral diet, Gln has been excluded from parenteral nutrition (PN) because of low solubility and instability in solution. In the first weeks of life, however, premature infants receive most of their nutrients from PN which is Gln-free [85]. The sudden cessation of Gln supply from the mother to premature infants, who are already stressed and undergoing rapid growth, may be detrimental [86]. Whereas plasma Gln concentrations normally increase during the first days of life in newborn infants breastfed ad libitum [87], selective amino acid deficiencies have been reported in neonates suffering from acute illness, including reductions in serum Gln and Arg in infants who have necrotizing enterocolitis (NEC) that may predispose them to the illness [88]. It has been suggested that in catabolic conditions premature infants are not able to synthesize sufficient Gln to meet demands, and in these conditions Gln may become a conditionally essential amino acid [10].

1.8. Glutamine in Breast Milk. In addition to providing an ideal nutritional composition for the neonate, breast milk contains specific nutrients such as Gln that may influence gastrointestinal development and can modulate immune, metabolic, and inflammatory responses [89]. Deprivation of dietary or endogenously synthesized Gln results in a breakdown in the intestinal epithelium of artificially reared neonatal rats, whereas Gln supplementation may help to maintain intestinal integrity [59].

In extremely low birth weight (ELBW) infants, the beneficial effects of breast milk ingested in the neonatal intensive care unit (NICU) on developmental outcomes at 18 months of age [90] persist at 30 months [91]. While $\mathrm{PN}$ is Gln-free, Agostoni et al. [92] reported lower free Gln concentrations in standard infant formulas compared to breast milk collected from 40 healthy lactating mothers after delivery of term infants at age 1 month. And similar to previous reports [93], they observed that glutamic acid and Gln accounted for most of the free amino acids in breast milk [92]. Moreover, heat sterilization of infant formulas can further lower the concentrations of Gln by more than $60 \%$ [94]. Thus, suggesting that enrichment of infant formulas with nonprotein nitrogen components (particularly Gln and glutamic acid) could be beneficial. The same group followed 16 healthy exclusively breastfeeding mothers after delivery of term infants and showed that the concentrations of free glutamic acid and Gln increased by 2.5 and 20 fold, respectively, with progressing lactation, representing $>50 \%$ of total free amino acids by 3 months [95]. To assess the potential influence of gestational age and duration of lactation, Jochum et al. [96] measured the content of free and protein-bound Gln in transitional and mature breast milk of 40 healthy mothers after term and preterm delivery. While the time of delivery had no influence on the free Gln or total Gln concentration, free Gln concentrations increased during maturation of lactogenesis, similar to previous reports $[95,97,98]$. In contrast, total Gln and protein-bound Gln concentrations decreased with the duration of lactation, and this correlated with the decrease in total protein concentration in mature breast milk [96]. These data highlight the need to better define the role of Gln in the neonatal period and the possible benefit of supplemental Gln.

\section{Materials and Methods}

The following sections describe the clinical studies that examined the effects of parenteral and enteral Gln supplementation in premature neonates as well as older infants and children with various diseases. The search methods for identification of studies consisted of searches of PubMed 
(1966-June 2011). The database was searched using the search term: "glutamine." The search output was limited with the search filter for ages: all children $0-18$ years. There were no language restrictions. References in previous reviews and studies were examined also. The title and abstract of all studies identified by the above search strategy were screened, and the full text for all potentially relevant studies published in English was obtained. The full text of any potentially relevant studies was assessed by the first author. Studies that included only adult participants were excluded. The same author extracted data from the published studies.

\section{Results and Discussion}

\subsection{Parenteral Glutamine Supplementation in Premature Neonates}

3.1.1. Clinical Outcomes. The first evidence to suggest that parenteral Gln appears safe and may be considered a conditionally essential amino acid in premature infants was put forth more than a decade ago by Lacey et al. [99] (Table 1). Although efficacy was not demonstrated in the entire cohort of very low birth weight (VLBW) infants $(N=44)$, subgroup analysis in the infants with birth weight $<800 \mathrm{~g}(n=24)$ showed that those supplemented with Gln $(20 \%$ of amino acids) had fewer $\mathrm{d}$ on PN (13 versus $21 \mathrm{~d}, P<0.05)$, required less time to full feeds ( 8 versus $14 \mathrm{~d}, P<0.05$ ), and needed less time on a ventilator ( 38 versus $47 \mathrm{~d}, P<0.05$ ) compared to standard isonitrogenous isocaloric PN. The positive results, however, were based on subgroup analyses, followup of recruited infants was incomplete, and intentionto-treat analysis was not performed. Thompson et al. [100] further demonstrated that parenteral Gln may reduce the time to establish full feeds and appears to be well tolerated and safe in a group of 35 ill ELBW neonates randomized to standard PN supplemented with Gln (16\% of amino acids) or standard PN containing an isocaloric isonitrogenous amino acid solution. The primary outcome (median $\mathrm{d}$ to achieve full enteral nutrition (EN)) was significantly shorter in the Gln group (Gln: $13 \mathrm{~d}$ versus control: $21 \mathrm{~d}, P<0.05$ ), whereas other clinical outcomes (growth, infection, number of episodes of sepsis, NEC, or age at discharge) did not differ. The study, however, did not achieve the calculated sample size of 120 infants. It is also not clear whether groups differed with respect to enteral feeding with either breast milk or preterm formula (that was started on d-3 of life). Although sample sizes were small, both trials were generally of good quality and provided evidence for improved feeding tolerance with parenteral Gln.

More recently, Li et al. [101] have examined the effects of PN supplemented with alanyl-Gln dipeptide for more than 2 weeks in 53 premature infants of LBW. Gln-supplemented infants required fewer $\mathrm{d}$ on $\mathrm{PN}(24.8$ versus $30.8 \mathrm{~d}, P<0.05)$, had shorter hospital stays $(32.1$ versus $38.6 \mathrm{~d}, P<0.05)$ and fewer episodes of hospital-acquired infections ( 0.96 versus 1.84 times, $P<0.0001)$ compared to infants who received routine PN. They also regained birth weight sooner (8.1 versus $10.4 \mathrm{~d}, P<0.05$ ), whereas there were no differences between groups for body weight or head circumference.
The results should be interpreted with caution due to limitations in the methodology. It was not clear whether treatment allocation was randomized or whether care givers or assessors were blinded to the intervention. In addition, followup of recruited infants was incomplete. Although 68 infants were enrolled, 15 infants were excluded from the analysis because of insufficient time on PN ( $<2$ weeks) and intention-to-treat analysis was not performed.

Poindexter et al. [102] performed the largest multicentre trial to determine whether early PN supplemented with Gln reduces the risk of mortality or late onset sepsis in ELBW infants. Within $72 \mathrm{~h}$ after birth, 1433 infants were randomly assigned to receive either a standard IV amino acid solution (control) or an isonitrogenous amino acid solution with 20\% Gln, whenever they received PN, up to $120 \mathrm{~d}$ of age, death, or discharge from hospital. Safety was also assessed in a subset of 141 ELBW infants by measuring plasma concentrations of amino acids and ammonia after infants had received study PN $(2.3 \pm 1.0 \mathrm{~g} / \mathrm{kg} / \mathrm{d}$ amino acids $)$ for approximately $10 \mathrm{~d}$ [103]. While parenteral Gln supplement increased plasma Gln concentrations with no apparent biochemical risk in ELBW infants, Gln did not reduce the incidence of death or late onset sepsis (Gln: $51 \%$ versus control: $48 \%$; RR [95\% CI]: 1.07 [0.97-1.17]). There were no differences between groups in the number of episodes of late onset sepsis, NEC, d on ventilator, length of hospital stay, $d$ to first and full enteral feeds, feeding intolerance, or growth. Moreover, infants who received Gln required more d of PN support. Although apparently safe in ELBW infants, the authors concluded that parenteral Gln supplementation does not reduce mortality or late onset sepsis, and its routine use cannot be recommended. The lack of significant effect could be explained by a number of factors. Firstly, the primary outcome (death or late onset sepsis) could be influenced by other factors during the clinical course. In addition, as in previous studies [99-101] that used isonitrogenous controls (to ensure the specific effect of Gln), the overall amino acid intake may have been inadequate in the Gln group, as a consequence of the substitution of $20 \%$ of the standard amino acids with Gln. Specifically, in order to make the supplements isonitrogenous, amino acids (including essential) were removed from the Gln-containing supplement, which could exacerbate specific amino acid deficiencies (especially if the PN period is prolonged). And although plasma amino acids were similar between groups, comparing plasma amino acid concentrations may not represent a valid marker for nutrient equivalence, since plasma amino acids may not reflect whole body amino acid concentrations or tissue concentrations. Furthermore, because infants in both groups did not receive the targeted amino acid intake of $3.0 \mathrm{~g} / \mathrm{kg} / \mathrm{d}$ until $10 \mathrm{~d}$ of age and most had also received small volumes of EN, the delivery of a sufficient dose of Gln may have been inconsistent. Moreover, differences in enteral intake (formula or breast milk) may limit comparability of nutrient intakes between study groups.

More recently, a double blind randomized trial in VLBW infants found no difference in mortality with parenteral Gln supplementation $(0.3 \mathrm{~g} / \mathrm{kg} / \mathrm{d})$ versus control [104]. The trial, however, was not powered to study rare outcomes 
TABLE 1: Glutamine-supplemented parenteral nutrition in premature neonates.

\begin{tabular}{|c|c|c|c|c|c|c|}
\hline Reference & Subjects & Design & Gln & Control & Outcomes & Results \\
\hline $\begin{array}{l}\text { Lacey et al. } \\
1996 \text { [99] }\end{array}$ & $\begin{array}{l}44 \mathrm{VLBW} \\
\text { premature } \\
\text { neonates age }<4 \mathrm{~d} \\
\text { receiving PN for } \\
<3 \mathrm{~d} \text {; birth wt: } \\
530-1250 \text { g; GA } \\
<32 \mathrm{wk}\end{array}$ & $\begin{array}{l}\text { Randomized } \\
\text { double blind }\end{array}$ & $\begin{array}{l}\text { Isonitrogenous } \\
\text { isocaloric PN } \\
\text { supplemented } \\
\text { with Gln } \\
(15-25 \% \text { of AA } \\
\text { mix) for } 14 \pm 6 \mathrm{~d} \\
(n=22)\end{array}$ & $\begin{array}{l}\text { Standard PN for } \\
16 \pm 10 \mathrm{~d} \\
(n=22)\end{array}$ & $\begin{array}{l}\text { Time to full EN, d } \\
\text { on PN, d on } \\
\text { ventilator, LOS, } \\
\text { other clinical } \\
\text { outcomes and } \\
\text { safety monitored } \\
\text { throughout } \\
\text { hospitalisation }\end{array}$ & $\begin{array}{l}\text { No differences for } \\
\text { entire cohort; birth wt } \\
<800 \text { g subgroup had } \\
\text { fewer d on PN, fewer d } \\
\text { to full feeds, fewer d on } \\
\text { ventilator, higher } \\
\text { lymphocyte count, no } \\
\text { difference in NICU } \\
\text { LOS, safe }\end{array}$ \\
\hline $\begin{array}{l}\text { Des Robert } \\
\text { et al. } 2002 \\
{[105]}\end{array}$ & $\begin{array}{l}13 \mathrm{LBW} \text { age }<3 \mathrm{~d} \\
\text { receiving } \\
\text { exclusive PN; } \\
\text { birth wt: } \\
820-1650 \mathrm{~g} \text {; GA: } \\
28-30 \mathrm{wk}\end{array}$ & $\begin{array}{l}\text { Randomized } \\
\text { double blind }\end{array}$ & $\begin{array}{l}\text { Gln- } \\
\text { supplemented } \\
0.5 \mathrm{~g} / \mathrm{kg} / \mathrm{d} \\
\text { exclusive PN } \\
\text { started on } \mathrm{d} 3 \text { of } \\
\text { life for } 24 \mathrm{~h}, \mathrm{AA} \\
\text { intake at } \\
1.5 \mathrm{~g} / \mathrm{kg} / \mathrm{d} \text { by d } 3 \\
(n=6)\end{array}$ & $\begin{array}{l}\text { Isonitrogenous } \\
\text { Gln-free AA } \\
\text { (Primène) } \\
\text { supplemented } \\
\text { exclusive PN } \\
\text { started on } \mathrm{d} 3 \text { of } \\
\text { life for } 24 \mathrm{~h}, \mathrm{AA} \\
\text { intake at } \\
1.5 \mathrm{~g} / \mathrm{kg} / \mathrm{d} \text { by d } 3 \\
(n=7)\end{array}$ & $\begin{array}{l}\text { Whole body } \\
\text { protein } \\
\text { metabolism/Leu } \\
\text { kinetics (IV } \\
\text { infusions of } \\
\text { NaH13CO3 and } \\
\text { L- }[1-13 \mathrm{C}] \text { Leu) } \\
\text { on d4 of life } \\
\text { during } \\
\text { continuous PN } \\
\text { (fed state) }\end{array}$ & $\begin{array}{l}\text { Decreased rates of Leu } \\
\text { release from protein } \\
\text { breakdown and Leu } \\
\text { oxidation, decreased } \\
\text { rates of nonoxidative } \\
\text { Leu disposal (an index } \\
\text { of whole-body protein } \\
\text { synthesis), safe }\end{array}$ \\
\hline $\begin{array}{l}\text { Thompson } \\
\text { et al. } 2003 \\
{[100]}\end{array}$ & $\begin{array}{l}35 \text { ELBW ill } \\
\text { premature } \\
\text { neonates age } \\
<1 \text { d; birth wt: } \\
<1000 \text { g }\end{array}$ & $\begin{array}{l}\text { Randomized } \\
\text { double blind }\end{array}$ & $\begin{array}{l}\text { Standard } \\
\text { isonitrogenous } \\
\text { isocaloric PN } \\
\text { supplemented } \\
\text { with } 16 \% \text { of AA } \\
\text { as Gln started on } \\
\text { d } 1 \text { of life, AA } \\
\text { intake started at } \\
1.0 \mathrm{~g} / \mathrm{kg} / \mathrm{d} \text { to } \\
\leq 3.0 \mathrm{~g} / \mathrm{kg} / \mathrm{d} \\
(n=17)\end{array}$ & $\begin{array}{l}\text { Standard PN } \\
\text { started on d } 1 \text { of } \\
\text { life, AA intake } \\
\text { started at } \\
1.0 \mathrm{~g} / \mathrm{kg} / \mathrm{d} \text { to } \\
\leq 3.0 \mathrm{~g} / \mathrm{kg} / \mathrm{d} \\
(n=18)\end{array}$ & $\begin{array}{l}\text { (1) Feeding } \\
\text { tolerance; } \\
\text { (2) growth, age at } \\
\text { discharge, } \\
\text { infection, } \\
\text { number of } \\
\text { episodes of } \\
\text { culture-positive } \\
\text { sepsis or NEC, } \\
\text { metabolic } \\
\text { tolerance and } \\
\text { safety monitored } \\
\text { until expected } \\
\text { date of delivery, } \\
\text { discharge or } \\
\text { death (whichever } \\
\text { came first) }\end{array}$ & $\begin{array}{l}\text { (1) Fewer d to reach } \\
\text { full EN; (2) no } \\
\text { differences in gastric } \\
\text { residuals, d to regain } \\
\text { birth wt, wt gain, } \\
\text { infection, total white } \\
\text { cell count, episodes of } \\
\text { low white cell count, } \\
\text { number of episodes of } \\
\text { culture-positive sepsis } \\
\text { or NEC, age at } \\
\text { discharge or death, well } \\
\text { tolerated and safe }\end{array}$ \\
\hline $\begin{array}{l}\text { Poindexter } \\
\text { et al. } 2004^{*} \\
{[102]}\end{array}$ & $\begin{array}{l}1433 \text { ELBW } \\
\text { ( } \leq 72 \mathrm{~h} \text { after } \\
\text { birth); birth wt: } \\
401-1000 \mathrm{~g} ; \mathrm{GA}: \\
26 \pm 2 \mathrm{wk}\end{array}$ & $\begin{array}{l}\text { Multicentre- } \\
\text { randomized } \\
\text { double blind }\end{array}$ & $\begin{array}{l}\text { Isonitrogenous } \\
\text { study AA solution } \\
\text { with } 20 \% \text { of AA } \\
\text { as Gln in PN until } \\
120 \mathrm{~d} \text { of age, } \\
\text { death, or } \\
\text { discharge } \\
\text { (whichever came } \\
\text { first), AA intake } \\
\leq 3-3.5 \mathrm{~g} / \mathrm{kg} / \mathrm{d} \\
(n=721)\end{array}$ & $\begin{array}{l}\text { Standard AA } \\
\text { solution without } \\
\text { Gln } \\
\text { (TrophAmine) in } \\
\text { PN until } 120 \mathrm{~d} \text { of } \\
\text { age, death or } \\
\text { discharge } \\
\text { (whichever came } \\
\text { first), AA intake } \\
\leq 3-3.5 \mathrm{~g} / \mathrm{kg} / \mathrm{d} \\
(n=712)\end{array}$ & $\begin{array}{l}\text { (1) Death or late } \\
\text { onset sepsis; } \\
\text { (2) number of } \\
\text { episodes of late } \\
\text { onset sepsis, } \\
\text { NEC, d on } \\
\text { ventilator, LOS in } \\
\text { hospital, } \\
\text { tolerance of } \\
\text { enteral feeds, } \\
\text { feeding } \\
\text { intolerance, } \\
\text { growth, d of PN, } \\
\text { safety }\end{array}$ & $\begin{array}{l}\text { (1) No differences in } \\
\text { death or late onset } \\
\text { sepsis (culture after } \\
72 \mathrm{~h} \text { of age), (2) no } \\
\text { differences in number } \\
\text { of episodes of late onset } \\
\text { sepsis, NEC, d on } \\
\text { ventilator, LOS in } \\
\text { hospital, d to first/full } \\
\text { enteral feeds, } \\
\text { incidence/number of } \\
\text { episodes of feeding } \\
\text { intolerance, d to reach } \\
\text { 1500 g or wt at } 36 \text { wk } \\
\text { postmenstrual age, } \\
\text { increased d of PN, well } \\
\text { tolerated and safe }\end{array}$ \\
\hline
\end{tabular}


Table 1: Continued.

\begin{tabular}{|c|c|c|c|c|c|c|}
\hline Reference & Subjects & Design & Gln & Control & Outcomes & Results \\
\hline $\begin{array}{l}\text { Poindexter } \\
\text { et al. } 2003^{*} \\
{[103]}\end{array}$ & $\begin{array}{l}141 \text { ELBW }(\leq 72 \mathrm{~h} \\
\text { after birth); birth } \\
\text { wt: } 401-1000 \mathrm{~g} ; \\
\text { GA: } 26 \pm 2 \mathrm{wk}\end{array}$ & $\begin{array}{l}\text { Multicentre- } \\
\text { randomized } \\
\text { double blind }\end{array}$ & $\begin{array}{l}\text { Isonitrogenous } \\
\text { study AA solution } \\
\text { with } 20 \% \text { of AA } \\
\text { as Gln in PN for } \\
\sim 10 \mathrm{~d}, \mathrm{AA} \text { intake } \\
\leq 3-3.5 \mathrm{~g} / \mathrm{kg} / \mathrm{d} \\
(n=72)\end{array}$ & $\begin{array}{l}\text { Standard AA } \\
\text { solution without } \\
\text { Gln } \\
\text { (TrophAmine) in } \\
\text { PN for } \sim 10 \mathrm{~d} \text {, AA } \\
\text { intake } \\
\leq 3-3.5 \mathrm{~g} / \mathrm{kg} / \mathrm{d} \\
(n=69)\end{array}$ & $\begin{array}{l}\text { Safety as assessed } \\
\text { by plasma } \\
\text { concentrations of } \\
\text { AA and ammonia } \\
\text { after infants had } \\
\text { received study PN } \\
(2.3 \pm 1.0 \mathrm{~g} / \mathrm{kg} / \mathrm{d} \\
\text { AA) for } \sim 10 \mathrm{~d}\end{array}$ & $\begin{array}{l}\text { Increased plasma Gln } \\
\text { (Gln group only) with } \\
\text { no apparent } \\
\text { biochemical risk, } \\
\text { increased plasma } \\
\text { essential AA (both } \\
\text { groups) whereas Phe } \\
\text { and Tyr decreased with } \\
\text { greater decrease in Tyr } \\
\text { (Gln group), no change } \\
\text { in plasma ammonia }\end{array}$ \\
\hline
\end{tabular}

Isonitrogenous

AA mixture

20 LBW clinically

Kalhan et al. stable (24-48 h

2005 [80] after birth); birth

wt: 694-1590 g;

$\mathrm{GA} \leq 32 \mathrm{wk}$

Randomized double blind with Gln for 3-5 d, AA intake
53 LBW

premature infants

Li et al. (48-72 $\mathrm{h}$ after

2007 [101] birth); birth wt: $<2000$ g; GA $<37$ wk
Prospective intervention supplemented $0.6 \mathrm{~g} / \mathrm{kg} / \mathrm{d}$ in $\mathrm{PN}$ $\sim 3.0 \mathrm{~g} / \mathrm{kg} / \mathrm{d}$ $(n=10)$

Isonitrogenous AA solution with $20 \%$ of AA content as Alanyl-Gln dipeptide in PN until $>2$ wk, AA intake started at $0.5-1.0 \mathrm{~g} / \mathrm{kg} / \mathrm{d}$ to $\leq 3.0 \mathrm{~g} / \mathrm{kg} / \mathrm{d}$ $(n=28)$

$6 \%$ pediatric $\mathrm{AA}$ compound injection, average AA dosage $1.7 \mathrm{~g} / \mathrm{kg} / \mathrm{d}$ with Gln $0.3 \mathrm{~g} / \mathrm{kg} / \mathrm{d}$, $\mathrm{PN}$ decreased when EN increased and PN withheld when $>70 \%$ of recommended intake from $\mathrm{EN}$ $(n=13)$
Whole body protein and Gln kinetics (IV infusions of

Routine PN until randomized double blind [2H5]Phe, L-[113C,15N]Leu, [15N2]urea, L-[5-15N]Gln) on $\mathrm{d} 6$ or $\mathrm{d} 7$ of life while receiving AA mixture continuously after 3-5 d $>2 \mathrm{wk}$, AA intake started at $0.5-1.0 \mathrm{~g} / \mathrm{kg} / \mathrm{d}$ to $\leq 3.0 \mathrm{~g} / \mathrm{kg} / \mathrm{d}$ $(n=25)$

AA mixture PN for 3-5 d, AA intake $(n=10)$

Growth, biochemical indices, feeding tolerance, and infective episodes throughout hospitalization for $\geq 7 \mathrm{~d}$; mean $\mathrm{GA}(\mathrm{wk}) \pm \mathrm{SD}$ : $31.3 \pm 1.5(\mathrm{Gln})$ and $30.5 \pm 1.8$ (control)

Lower endogenous rates of appearance of Phe and Leu N (indices of proteolysis), lower Gln de novo synthesis, no differences in rate of appearance of Leu C, urea turnover or plasma AA concentrations
Fewer d to regain birth wt, no differences in wt or head circumferences, fewer d on PN, fewer episodes of hospital-acquired infection, shorter LOS in hospital, safe
(1) Mortality and changes in hepatic function (bile acid, ALT, AST, total bilirubin, direct bilirubin, prealbumin, albumin), (2) time to full EN (d), episodes of gastric residual, total duration of PN (d), wt gain $(\mathrm{g} / \mathrm{d})$, head circumference (cm), LOS, d on ventilator
(1) Decreased AST and direct bilirubin, no differences in bile acid, ALT, total bilirubin, prealbumin, or albumin, (2) no differences in time to full EN, episodes of gastric residual, total duration of $\mathrm{PN}$, wt gain, head circumference, LOS or $\mathrm{d}$ on ventilator

VLBW: very low birth weight; PN: parenteral nutrition; wt: weight; GA: gestational age; AA: amino acid; EN: enteral nutrition; LOS: length of stay; NICU: neonatal intensive care unit; LBW: low birth weight; IV: intravenous; ELBW: extremely low birth weight; NEC: necrotizing enterocolitis; AST: aspartate aminotransferase; ALT: alanine aminotransferase.

* Originating from the same cohort. 
(such as mortality) or multiple endpoints. Furthermore, no deaths occurred and only 28/30 infants randomized completed the study and thus analysis was not by intention to treat. Interestingly, hepatic function improved as assessed by serum aspartate aminotransferase and direct bilirubin, which both decreased after PN in the Gln-supplemented group $(P<0.05)$. It should be noted, however, that no differences were observed for other measures of hepatic function (bile acid, alanine aminotransferase, total bilirubin, prealbumin, or albumin) or other secondary outcomes (time to full EN, episodes of gastric residuals, total duration of PN, weight gain, head circumference, length of stay, or days on ventilator).

3.1.2. Protein Metabolism. Two small randomized controlled trials in LBW infants examined the effects of Glnsupplemented PN on whole body protein metabolism using primed continuous IV infusions of essential amino acid tracers [80, 105] (Table 1). Des Robert et al. [105] studied 13 LBW neonates on postnatal $\mathrm{d}-3$, while they received exclusive PN that was supplemented with Gln $(0.5 \mathrm{~g} / \mathrm{kg} / \mathrm{d})$ or an isonitrogenous Gln-free amino acid solution for $24 \mathrm{~h}$. Compared to an isonitrogenous amino acid supplement, Gln decreased the rate of plasma Leu appearance, Leu release from protein breakdown (an index of whole body proteolysis; $-16 \%, P<0.05$ ), and rate of Leu oxidation $(-35 \%, P<0.05)$. There was also, however, a decrease in nonoxidative Leu disposal (an index of whole body protein synthesis; $-20 \%, P<0.05$ ), and, thus, net Leu balance (protein balance) did not differ between groups. Plasma Gln concentrations were higher in Gln versus control, whereas plasma ammonia did not differ. Although parenteral Gln failed to enhance estimates of protein synthesis, Gln may preserve body protein as it suppressed Leu oxidation and protein breakdown in LBW infants. In addition to the small sample size, the failure to enhance protein synthesis may have also been due to insufficient amino acid availability since whole body protein kinetics were assessed on $\mathrm{d}-4$ of life (when amino acid intake was $2 \mathrm{~g} / \mathrm{kg} / \mathrm{d}$ in both groups) before infants received an optimal amino acid intake of $3 \mathrm{~g} / \mathrm{kg} / \mathrm{d}$ [106].

Kalhan et al. [80] examined the effect of $0.6 \mathrm{~g} / \mathrm{kg} / \mathrm{d}$ Gln-supplemented PN for 3-5d on whole body protein and Gln kinetics in a carefully selected population of 20 clinically stable LBW infants, between d-1 and -2 after birth. Compared to an isonitrogenous control, Gln-supplemented PN resulted in significantly lower rates of appearance of phenylalanine (Phe) and Leu nitrogen and a nonsignificant decrease in the rate of appearance of Leu carbon. Gln also suppressed the endogenous rate of Gln synthesis. There was no significant difference in urea turnover between the 2 groups. The results suggest that parenteral Gln supplementation at $0.6 \mathrm{~g} / \mathrm{kg} / \mathrm{d}$ decreases whole body protein breakdown and Gln de novo synthesis in clinically stable LBW infants and may be beneficial in selected populations of LBW infants. The carefully selected population of clinically stable infants limits the application of the results to other groups of premature neonates. Moreover, the use of a higher dose of Gln makes comparisons with other studies difficult.
Interestingly, the same group demonstrated that the suppression of proteolysis and protein oxidation in response to an acute increase in parenteral amino acids (without Gln) was not evident when the amino acid infusion was continued for a prolonged period in both acutely ill [81] and clinically stable LBW infants [82]. The only exception was when amino acids were supplemented with Gln, whereby a prolonged infusion resulted in a sustained inhibition of whole body proteolysis and reduced Gln de novo synthesis. Taken together with previous studies [80, 105], Gln supplementation may have a protein-sparing effect in premature infants decreasing whole body protein breakdown and Gln de novo synthesis thereby "sparing" the increased amino acids for protein synthesis.

\subsection{Enteral Glutamine Supplementation in Premature Neonates}

3.2.1. Clinical Outcomes. Neu et al. [107] conducted a double-blind randomized trial to test whether enteral Gln supplementation for VLBW infants decreases morbidity (Table 2). Sixty-eight premature neonates were assigned to a Gln-supplemented premature formula or a nonsupplemented standard premature formula between postnatal d3 to d-30. The Gln supplemented group initially received a dose of $0.08 \mathrm{~g} / \mathrm{kg} / \mathrm{d}$ Gln which was increased to a maximum of $0.31 \mathrm{~g} / \mathrm{kg} / \mathrm{d}$ Gln by $\mathrm{d}-13$. The Gln group had better tolerance to enteral feedings (fewer \% of d with no oral intake in Gln: $8.8 \%$ versus controls: $23.8 \%, P<0.01$ ). Episodes of hospital-acquired sepsis were 4/35 and 10/33 in Gln and control group, respectively. Moreover, when controlling for birth weight, the estimated odds of developing sepsis was 3.8 times higher for control versus Gln (95\% CI: 1.0114.18). Analysis of T cell subsets showed a blunting of the rise in HLA-DR+ and CD16/CD56 in the Gln group. There were, however, no significant differences between groups for cases of NEC, growth, or length of stay. Whereas the plasma concentrations of alanine (Ala), glycine (Gly), Ser, threonine (Thr), Phe, and total nonessential amino acids were lower in the Gln-supplemented infants after 2-week supplementation, there were no differences between groups for plasma concentrations of Gln, Glu, or ammonia [108]. The authors speculated that the lower plasma amino acid concentrations in infants fed Gln were the result of enhanced uptake of these amino acids for gluconeogenesis and provide evidence of reduced tissue catabolism. A secondary analysis of the initial trial also provided evidence for decreased hospital costs [109]. While the control used is comparable to routine clinical practice, the study design cannot ensure the specific effect of Gln as the differences between feeding groups might result from higher intakes of nitrogen or energy with Gln supplementation. The authors, however, chose not to use a third group with an isonitrogenous control due to recruitment constraints. Although the trial was small, these initial results provided evidence for better tolerance to enteral feedings and lower sepsis rates in VLBW infants receiving enteral Gln supplementation.

Barbosa et al. [110] conducted a randomized controlled pilot study to evaluate the tolerance and clinical impact of 


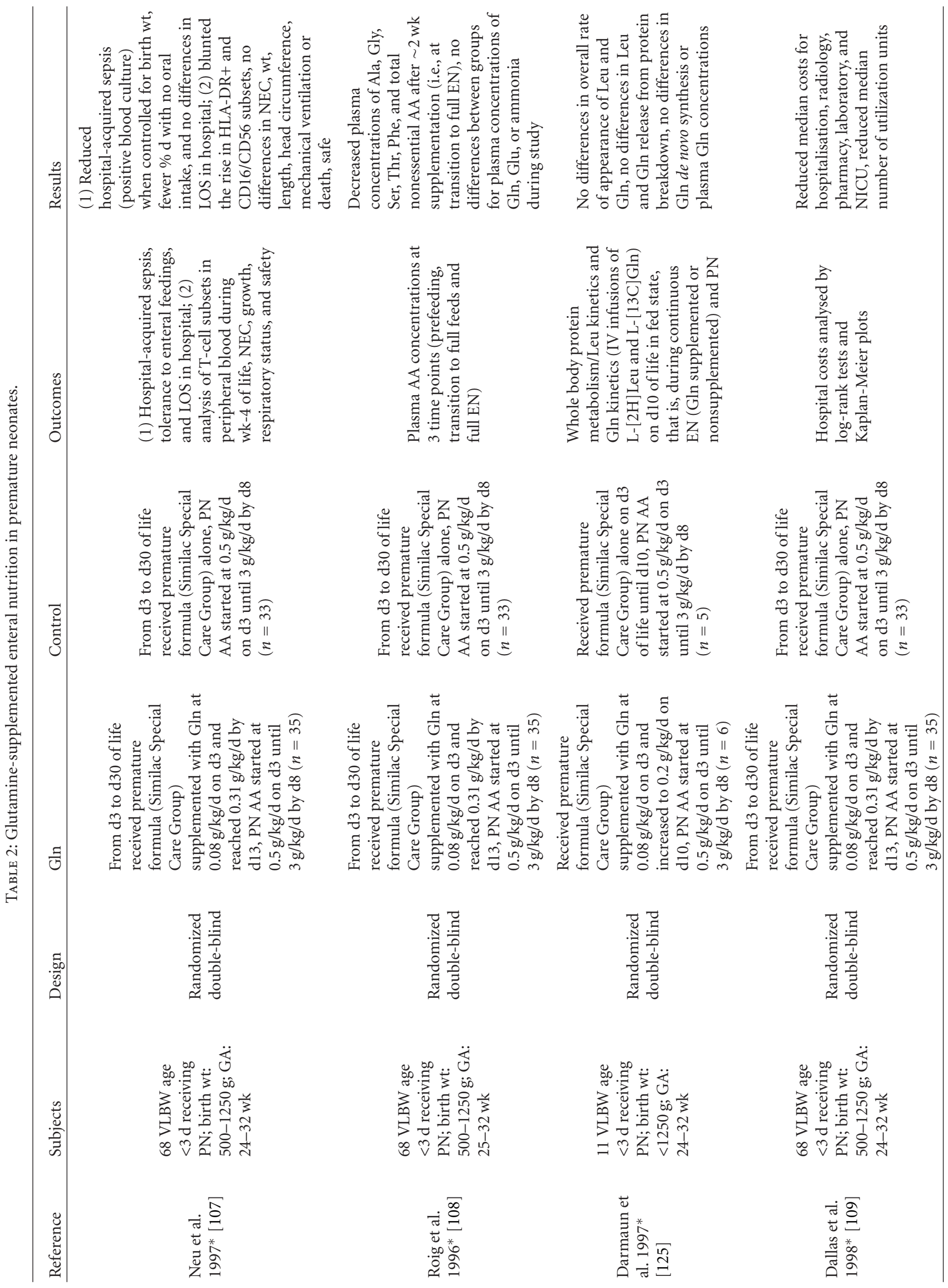




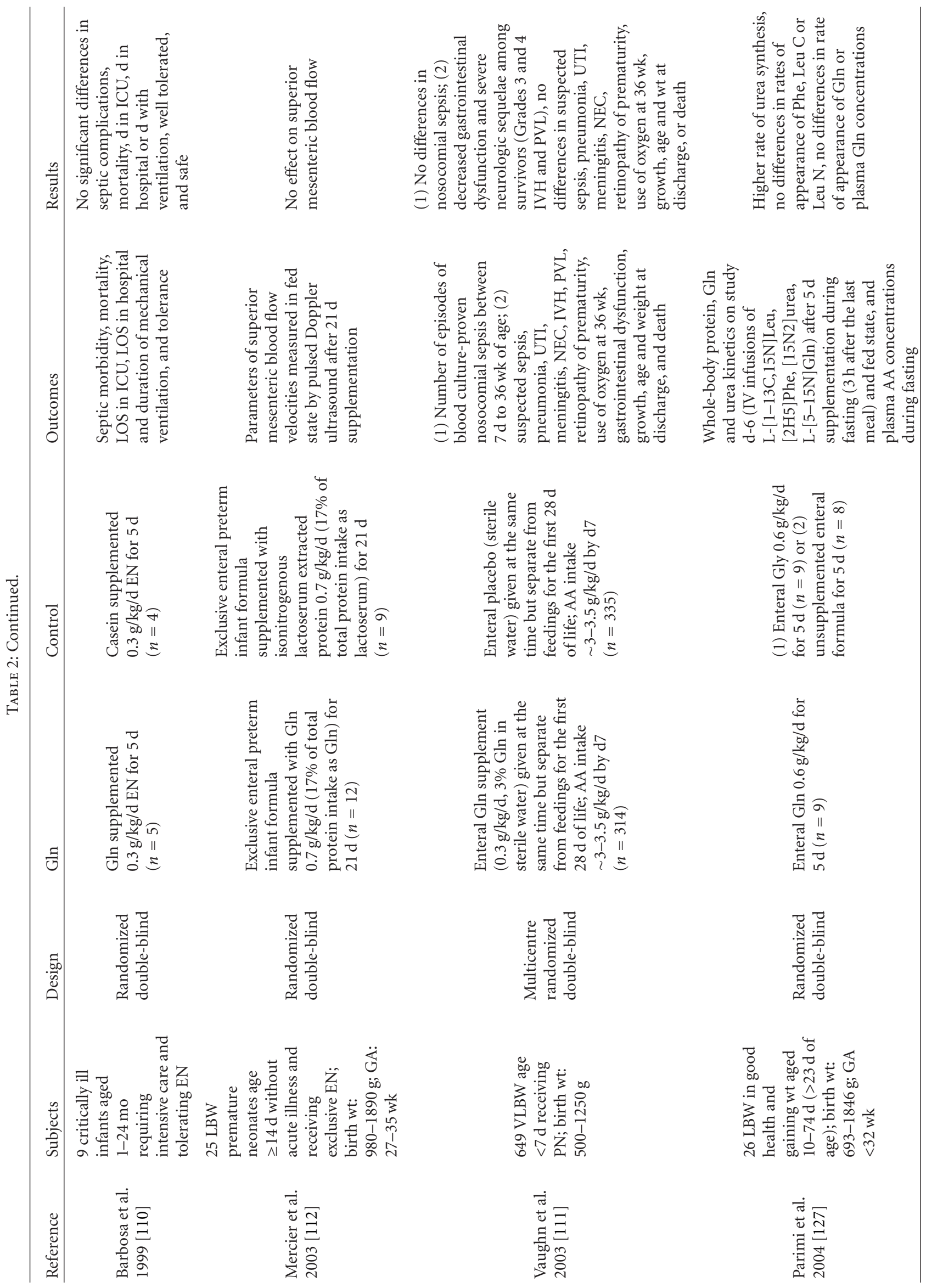




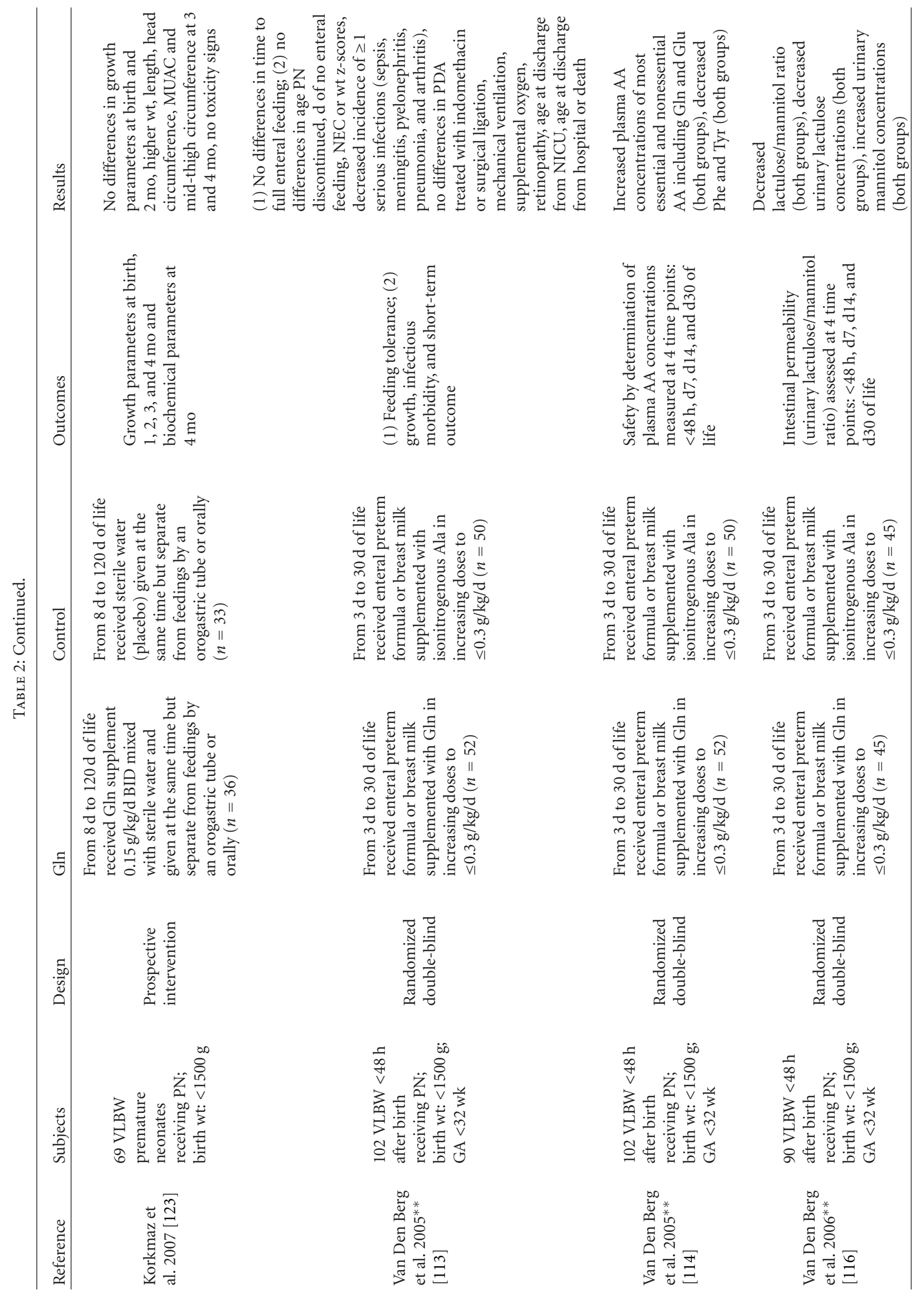




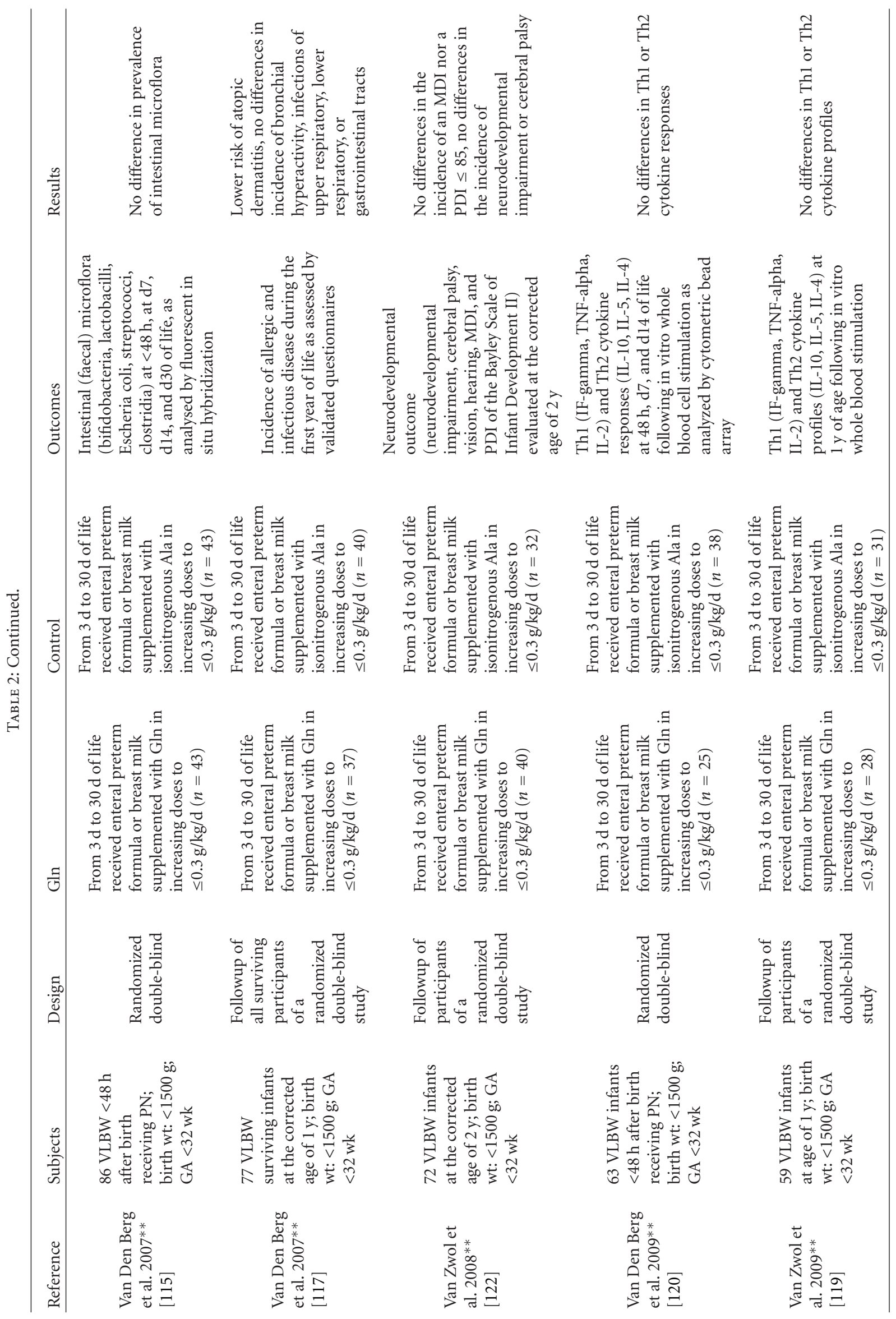




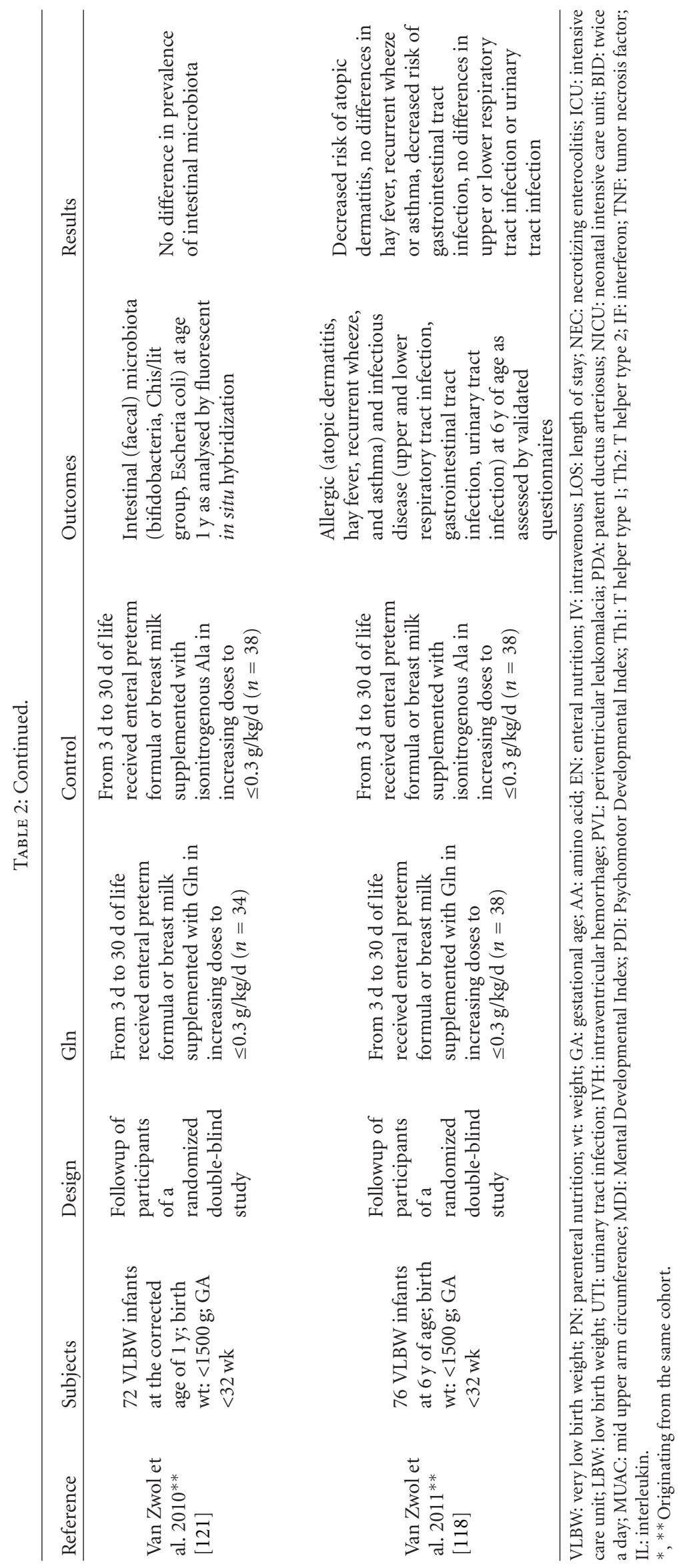


enteral formula supplemented with $0.3 \mathrm{~g} / \mathrm{kg} / \mathrm{d}$ Gln for 5 days versus an equal dose of casein in 9 critically ill infants aged 124 months. Although Gln was well tolerated, the study was underpowered to detect differences in septic complications (control: $3 / 4$ versus Gln: $1 / 5, P=0.10$ ), mortality (control: 2/4 versus Gln: 0/5, $P=0.10$ ) or other outcomes (ventilator use, length of stay in intensive care unit (ICU) or in hospital). It was also not reported in the inclusion criteria whether the study population of infants were premature or term.

Vaughn et al. [111] conducted a large multicentre trial to test whether enteral Gln supplement decreases the incidence of hospital-acquired infection and other morbidities in 649 VLBW infants. Within the first $7 \mathrm{~d}$ of age, infants were randomly assigned to enteral Gln supplement $(0.3 \mathrm{~g} / \mathrm{kg} / \mathrm{d}$, $3 \%$ Gln in sterile water) or placebo (sterile water) given at the same time but separate from feedings for the first $28 \mathrm{~d}$. There were no differences between groups for the primary outcome (nosocomial sepsis between $7 \mathrm{~d}$ and 36 weeks postmenstrual age; Gln: 30.9\% versus control: 33.7\%). However, gastrointestinal dysfunction (2.5 versus $7.5 \%, P<0.01$ ) and severe neurological sequelae among survivors (Grades 3 and 4 intraventricular hemorrhage and paraventricular leukomalacia; 10.4 versus $15.1 \%, P=0.08$ ) were less frequent in Gln versus control, respectively. There were no differences in the occurrence of suspected sepsis, pneumonia, urinary tract infection, meningitis, NEC, retinopathy of prematurity, oxygen use at 36 weeks, or mortality. Growth, age, and weight at discharge were also similar. Whereas enteral Gln does not appear to decrease nosocomial sepsis in VLBW infants, the study may have been underpowered to detect a significant difference, as dropout rate was higher than anticipated (i.e., 105 infants exited the study before completion). Also the centre-to-centre variation in this and other multicentre trials [102] may have blunted differences in outcomes (e.g., sepsis), since nutrition and infection control practices may differ among centres and may mask some of the differences that might be apparent in a single facility. While the study provides further evidence to suggest that enteral Gln improves feeding tolerance and may prevent central nervous system (CNS) morbidity, these positive results are based on secondary endpoints and subgroup analyses. Furthermore, the Gln dose was based on birth weight and was not adjusted for interval changes in weight. Therefore, the dose administered may have been inadequate due to rapid growth during the early neonatal period.

The apparent improved feeding tolerance in VLBW infants receiving enteral Gln in previous studies $[107,111]$ cannot be explained by enhanced mesenteric blood flow [112]. It seems that, in premature infants without acute illness and tolerating exclusive EN, mesenteric blood flow remains stable after $14 \mathrm{~d}$ of age and does not appear to be influenced by enteral Gln.

In contrast to previous reports on Gln-enriched EN in VLBW infants [107, 111], Van Den Berg et al. [113] found no improvement in feeding tolerance, as assessed by the median $\mathrm{d}$ to reach full enteral feeds (Gln: $13 \mathrm{~d}$ versus control: $13 \mathrm{~d}$; hazard ratio [95\% CI]: 1.19 [0.79-1.79]). In this randomized controlled trial, 102 VLBW infants received either enteral Gln supplementation or an isonitrogenous control (Ala) added to breast milk or preterm formula in increasing doses from d-3 to d-30 of life to a maximum dose of $0.3 \mathrm{~g} / \mathrm{kg} / \mathrm{d}$ Gln. There were also no differences between groups for other variables of feeding tolerance (age at which PN was discontinued, d of no enteral feeding), NEC, or growth. However, the Glnsupplemented group had a lower incidence of $\geq 1$ serious infections (sepsis, meningitis, pyelonephritis, pneumonia, and arthritis) compared with the isonitrogenous control group (Gln: 50\% versus control: 76\%; OR [95\% CI]: 0.32 [0.14-0.74]. Other short-term outcomes (patent ductus arteriosus treated with indomethacin or surgical ligation, mechanical ventilation, supplemental oxygen, retinopathy, age at discharge from NICU, age at discharge from hospital, or death) were not significantly different. Gln did not alter plasma concentrations of Gln, Glu, or other amino acids [114]. Although safe at the dose provided, Gln-enriched EN did not improve feeding tolerance or other shortterm outcomes in VLBW infants. However, because Gln reduced infectious morbidity, the use of Gln-enriched EN in VLBW infants deserves further consideration. Comparison, however, with other studies is made difficult because of the use of different feeding guidelines for the introduction or withholding enteral feeds. Whereas the choice of isonitrogenous control prevented the removal of amino acids from the Gln supplement in the present study, groups were made isonitrogenous by adding more amino acid (Ala) to the control group. The control group then received additional amino acid/nitrogen, which is not representative of daily practice. However, given the limited sample size, a third comparison group (enteral formula routinely used in an NICU) was not feasible. The beneficial effect of enteral Gln on infection rate could not be explained by an increased number of bifidobacteria or lactobacilli in the intestinal microflora as demonstrated by a secondary analysis in a subset of 86 VLBW infants [115]. Furthermore, Gln did not enhance the postnatal decrease in intestinal permeability, as assessed by the urinary lactulose/mannitol ratio in a subset of 90 VLBW infants. Specifically, supplementation with Gln or isonitrogenous control equally decreased urinary concentrations of lactulose and increased urinary mannitol [116]. More recently, followup of all surviving participants $(n=77)$ revealed that Gln-enriched EN in VLBW infants may lower the incidence of atopic dermatitis (OR [95\% $\mathrm{CI}]: 0.13$ [0.02-0.97]) during the first year of life but has no effect on the incidence of bronchial hyperactivity or infectious diseases [117]. Further followup of this cohort of VLBW infants $(n=76)$ at $6 \mathrm{y}$ of age also found a decreased risk of atopic dermatitis (adjusted OR [95\% CI]: $0.23[0.06-0.95]$ ) and gastrointestinal infections (adjusted OR [95\% CI]: 0.10 [0.01-0.93]) in the Gln-supplemented group [118]. Although outcomes were assessed by validated questionnaires in these 2 followup studies, parental report of physician diagnosis of disease could be subject to reporting/information bias. Furthermore, the lower incidence of atopic dermatitis and infection rates with Gln were not related to changes in cytokine profiles [119]/responses [120] or to changes in intestinal bacterial species at age $1 \mathrm{y}$ [121]. Finally, the same group studied neurodevelopmental outcome at $2 \mathrm{y}$ corrected age in a subgroup of 72 VLBW 
infants and found no beneficial effect of Gln-enriched EN during the neonatal period [122].

The effect of Gln supplementation on long-term outcome of VLBW infants has also been reported by Korkmaz et al. [123] who studied the effect of 4-month enteral Gln supplementation on growth. From d-8 through d-120 of life, 69 VLBW infants were assigned to enteral Gln $(0.3 \mathrm{~g} / \mathrm{kg} / \mathrm{d})$ supplement or placebo (sterile water) according to the order of admission to the NICU. Whereas growth parameters did not differ during the first 2 months of life, by the end of the third and fourth month, infants treated with Gln showed higher weight, length, head circumference, mid-upper-arm circumference, and midthigh circumference compared to controls. The authors concluded that long-term enteral Gln in VLBW infants may lead to improvements in growth in a time-dependent manner without any signs of Gln toxicity. Although this was a prospective interventional study, a complete description of masking, blinding, or randomization procedures was not provided. Also, because the placebo (sterile water) was neither isocaloric nor isonitrogenous to the Gln treatment, the enhanced growth could have resulted from the effect of increased amino acid/nitrogen, since early provision of parenteral amino acids (without Gln) has been shown to improve growth parameters in VLBW infants [124].

3.2.2. Protein Metabolism. Darmaun et al. [125] determined the effect of enteral Gln on Leu and Gln metabolism in a subset of 11 VLBW neonates from the larger trial [107] (Table 2). Enteral Gln supplementation provided at low doses $(\leq 0.2 \mathrm{~g} / \mathrm{kg} / \mathrm{d})$ from d-3 to d-10 of life did not inhibit whole-body protein breakdown in VLBW infants. Leu release from protein breakdown (an index of whole-body protein breakdown) was slightly but not significantly lower in the Gln group versus controls. Plasma Gln concentration, Gln release from protein breakdown, or Gln de novo synthesis did not significantly differ between groups. However, there was a trend toward lower rates of Gln de novo synthesis in infants receiving Gln supplement. Although the number of patients was small, the failure to detect a significant effect of Gln on its own metabolism or on whole-body protein breakdown could also be due to the different effects of enteral and parenteral Gln supplementation. Importantly, the majority of enteral Gln is used in first pass in premature infants [126]. This is likely a significant factor in the different effects of enteral and parenteral Gln. Moreover, the dose of Gln used in the current study was lower than that $(0.5 \mathrm{~g} / \mathrm{kg} / \mathrm{d}$ Gln $)$ previously shown to inhibit proteolysis in LBW infants [105].

Parimi et al. [127] examined the effect of enteral Gln on whole-body Gln and nitrogen kinetics in healthy growing LBW infants during the fasting $(3 \mathrm{~h}$ after the last meal) and fed state. This study was the only to have 3 groups, where Gln-supplemented group was compared with an isonitrogenous control and enteral formula routinely used in the NICU. Between 10 and $74 \mathrm{~d}$ of age, infants were randomly assigned to formula supplemented with Gln $(0.6 \mathrm{~g} / \mathrm{kg} / \mathrm{d} ; n=9)$, isonitrogenous amounts of Gly $(n=$ $9)$, or unsupplemented formula $(n=8)$ for $5 \mathrm{~d}$. During fasting, the rate of appearance of Phe, Leu carbon, and Leu nitrogen (measures of proteolysis) were not significantly different between groups. Compared with controls, enteral Gln resulted in an increased rate of urea synthesis, no change in Gln rate of appearance, or plasma Gln concentrations. Similar effects were observed with Gly supplement, but the magnitude was less. The authors concluded that enteral Gln does not affect Gln rate of appearance or whole-body protein turnover in a specific group of healthy growing LBW infants, thus, suggesting that Gln is primarily metabolized in the gut (and liver) [126] and is associated with an increased rate of urea synthesis. Alternatively, because, in healthy premature newborns, there is already a high rate of Gln turnover $(85 \%$ of which is contributed by de novo synthesis) [128], this specific population of neonates could have been less sensitive to enteral Gln. This is in contrast to premature neonates with acute illness, whereby catabolic stress may provoke a greater need for exogenous Gln.

In summary, although methodologically sound randomized trials consistently demonstrate safety in VLBW infants $[80,99,100,102,105,107,111,113,127]$, parenteral or enteral Gln supplementation does not appear to affect mortality $[100,102,104,107,111,113]$, NEC $[100,102,107$, $111,113]$, length of stay $[99,100,102,104,107,111,113]$, or growth $[100,102,104,107,111,113]$. Moreover, the results are conflicting for other short-term clinical outcomes such as feeding tolerance $[99,100,102,104,107,111,113]$, serious infections/sepsis [100,102, 107, 111, 113], ventilator use $[99,102,104,107,113]$, and severe neurological sequelae [111]. Few data have been reported for the effects of Gln supplementation in VLBW infants on long-term clinical outcomes such as growth at 4 months [123], allergic and infectious morbidity at $1 \mathrm{y}$ [117] and 6y [118], and neurodevelopmental outcomes at 2 y corrected age [122]. Larger well-controlled studies are needed. A systematic review of 7 randomized controlled trials showed that parenteral or enteral Gln supplementation in premature infants of VLBW does not affect mortality (RR [95\% CI]: 0.98 [0.80-1.20]) or other clinical outcomes including invasive infection, NEC, time to achieve full EN, duration of hospital stay, growth, or neurodevelopmental outcomes at 18 months corrected age [129].

In contrast, studies on protein metabolism showed that parenteral Gln may have a protein-sparing effect decreasing whole body proteolysis and Gln de novo synthesis in premature infants of LBW $[80,105]$. However, the beneficial effects on whole-body protein metabolism have not been reproduced for enteral Gln [125, 127]. Hence, the route of administration (enteral versus parenteral) should be considered in interpreting the effect of Gln on outcome in premature infants [126].

Parenteral and enteral Gln supplementation is apparently safe in premature neonates; however, the lack of any consistent benefit(s) does not support its routine use in this population as a whole. It is possible that any beneficial effects of Gln are limited to specific subgroups of premature infants suffering from acute stress (e.g., NEC, who are perhaps Gln or Arg deficient [88]) whereby increased Gln utilization exceeds the body's synthetic capacity [10]. Future studies 
are needed to better define the role of Gln in the neonatal period and its mechanism of action. Large prospectively stratified trials are needed to identify the specific subgroups of premature neonates, who may have a greater need for Gln and who may eventually benefit from Gln supplementation.

\subsection{Glutamine Supplementation in Pediatric Patients with Gastrointestinal Disease}

3.3.1. Glutamine Supplementation in Infants with Surgical Gastrointestinal Disease. While several trials have been conducted in VLBW infants, only 2 small double-blinded randomized trials tested whether supplemental Gln might be of benefit in critically ill infants with surgical gastrointestinal disease [130, 131] (Table 3). Duggan et al. [130] compared enteral Gln to an isonitrogenous mix of nonessential amino acids in 20 neonates and infants younger than 12 months receiving $\mathrm{PN}$ after gastrointestinal surgery and found no apparent effect on the duration of PN (Gln: $39 \mathrm{~d}$ versus control: $21 \mathrm{~d}, \mathrm{NS}$ ) or days to achieve $80 \%$ energy requirement by EN (Gln: $24 \mathrm{~d}$ versus control: $13 \mathrm{~d}$, NS). Secondary outcomes (energy absorption, clinical infections, or growth) were also not affected by enteral Gln. Albers et al. [131] compared standard PN to isonitrogenous Gln-supplemented $\mathrm{PN}$ in 80 newborns and infants ( $<2 \mathrm{y}$ of age) after major digestive-tract surgery and concluded that parenteral Gln supplementation does not improve intestinal permeability (urinary excretion of lactulose/rhamnose), nitrogen balance, urinary 3-methyl-histidine excretion, or other outcomes (mortality, length of stay in the ICU or hospital, cultureproven sepsis, usage of antibiotics, or ICU resources). Although no adverse effects were identified, both trials as well as meta-analysis for 2 outcomes (in hospital mortality and incidence of invasive infection) [132] do not support the use of parenteral or enteral Gln supplementation in surgical infants with severe gastrointestinal disease until further research proves otherwise.

There are a number of possible explanations for the indeterminate results. Firstly, along with the small sample size, the heterogeneous nature of the infants enrolled may have contributed to the substantial variability in the primary outcome and secondary outcomes and thus limited the power of detecting differences. Whereas the target dose of $0.4 \mathrm{~g} / \mathrm{kg} / \mathrm{d}$ may have allowed Gln supplementation to have an effect, the actual cumulative intake of Gln may not have been adequate to exert its effects. For instance, in the study by Albers et al. [131], tapering of PN (and hence Gln) was allowed to begin only $2 \mathrm{~d}$ after $90 \%$ of the Gln dose had been achieved, whereas, in that by Duggan et al. [130], inadequate Gln intake may have been due to the gradual advancement of $\mathrm{EN}$ and intermittent interruption of feeds required by infants who had undergone intestinal resection. Alternatively, the dose may have been inadequate when administered by the enteral route in this population, since infants may not have absorbed the entire dose of enteral Gln due to their gastrointestinal disease and possible malabsorption [130]. Furthermore, patients fed enterally may require greater protein or amino acids to meet requirements versus those fed parenterally [133]. In addition to the potential effect of route and dose of Gln administration, total nitrogen intake may have been inadequate [131], since nitrogen intake plateaued at $90 \%$ of target $(<1.5 \mathrm{~g} / \mathrm{kg} / \mathrm{d}$ amino acids), which is lower than the recommended daily allowance for LBW infants or the minimum amount of amino acid needed to prevent protein breakdown [134]. Finally, the isonitrogenous design whereby predetermined amounts of essential and other amino acids were substituted with Gln (as in the studies with VLBW infants) may have obscured potential benefits of Gln supplementation. Large prospectively stratified trials are needed to control for these and other variables that might affect outcome and define precise indications or contraindications for Gln supplementation.

\subsubsection{Glutamine Supplementation in Short Bowel Syndrome.} Intestinal failure is the inability to maintain nutritional and fluid balance without nutritional support [135]. Short bowel syndrome (SBS) is the result of malabsorption secondary to extensive intestinal resection. The aim in the management of SBS is to enhance intestinal adaptation of the remaining gut in an attempt to achieve intestinal autonomy [135].

Although Gln reduces PN dependence when taken in combination with growth hormone in adults with SBS [136], there is a lack of data on the role of Gln in pediatric patients with this condition. Compared to adult SBS patients, pediatric patients require additional energy and nutrients for growth. Similarly, we have observed increased turnover of protein and Gln in infants compared to adults, regardless of intestinal status [137]. Importantly, previous data from our group also suggests that the infant small intestine plays a prominent role in Gln metabolism and may also be a preferential user of Gln. Specifically, we observed a lower rate of whole-body Gln production and utilization in SBS infants compared to control infants, whereas whole-body protein turnover (Leu appearance rate) was unaltered by intestinal resection [137].

Apart from isolated case reports documenting improvements in weight $[138,139]$, body composition [139], intestinal permeability [138], stool output [138], and nitrogen retention [139] after supplemental Gln, data are lacking in pediatric patients with SBS (Table 3 ). In a retrospective review of the medical records of 2 pediatric patients with SBS from neonatal gastrointestinal catastrophes, Ladd et al. [140] observed that late treatment (at $\sim 6 \mathrm{y}$ of age) with growth hormone and concurrent enteral Gln $(30 \mathrm{mg} / \mathrm{d})$ supplementation given over long periods improved growth and resulted in PN independence.

Data derived from adults and children with SBS are limited to case series $[141,142]$ reporting that supplemental Gln $(0.6 \mathrm{~g} / \mathrm{kg} / \mathrm{d})$ over long periods in combination with growth hormone and rehabilitative diet resulted in improved weight [142], plasma proteins [141, 142], intestinal absorptive capacity [141, 142], and weaning from PN [141].

In the above reports, because patients were also receiving other medical therapy, it is not clear whether Gln, growth hormone, diet, or other factors contributed to the favourable outcome. Although no side effects have been reported, data to date are solely hypothesis generating and cannot confirm any benefit of supplemental Gln in promoting 


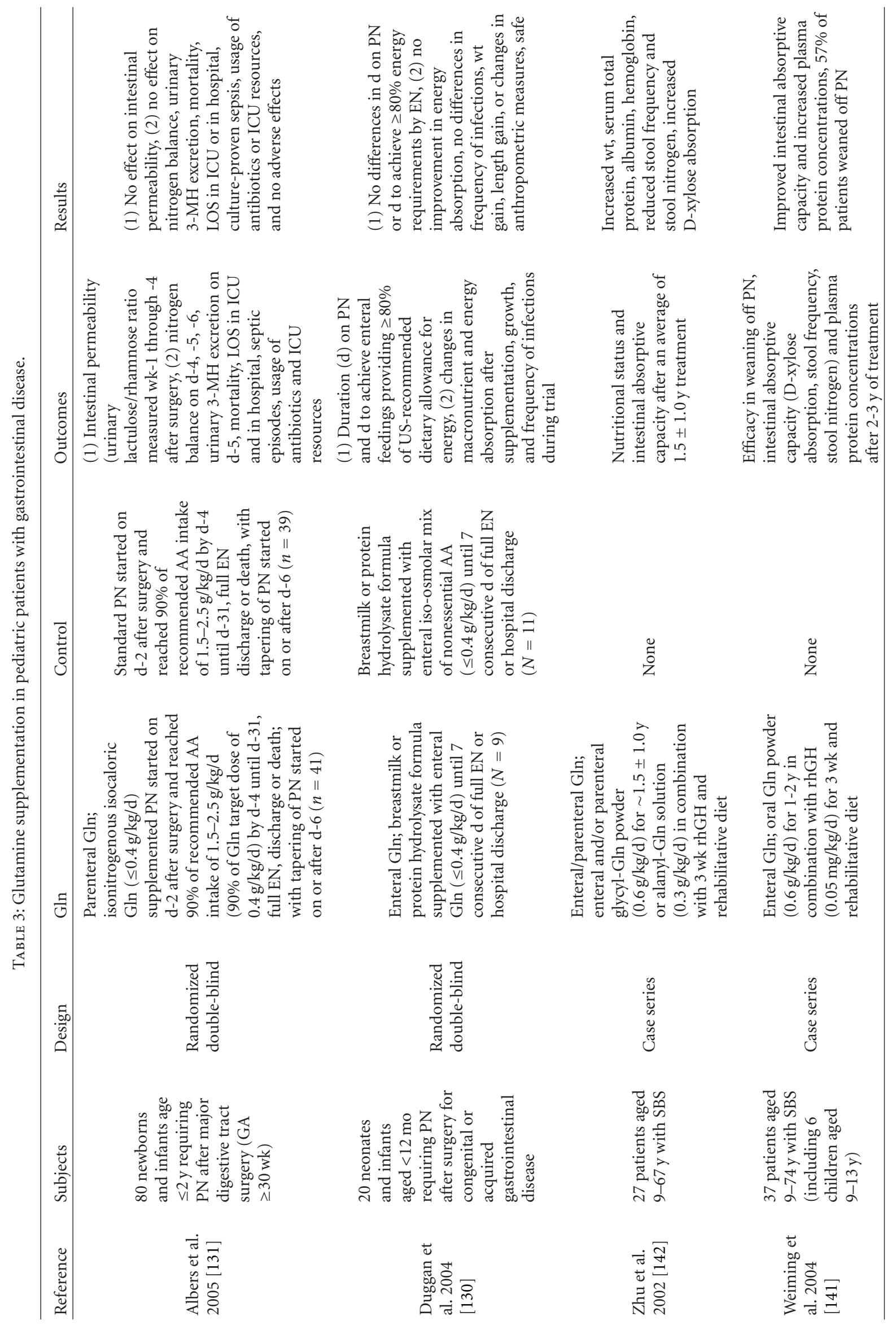




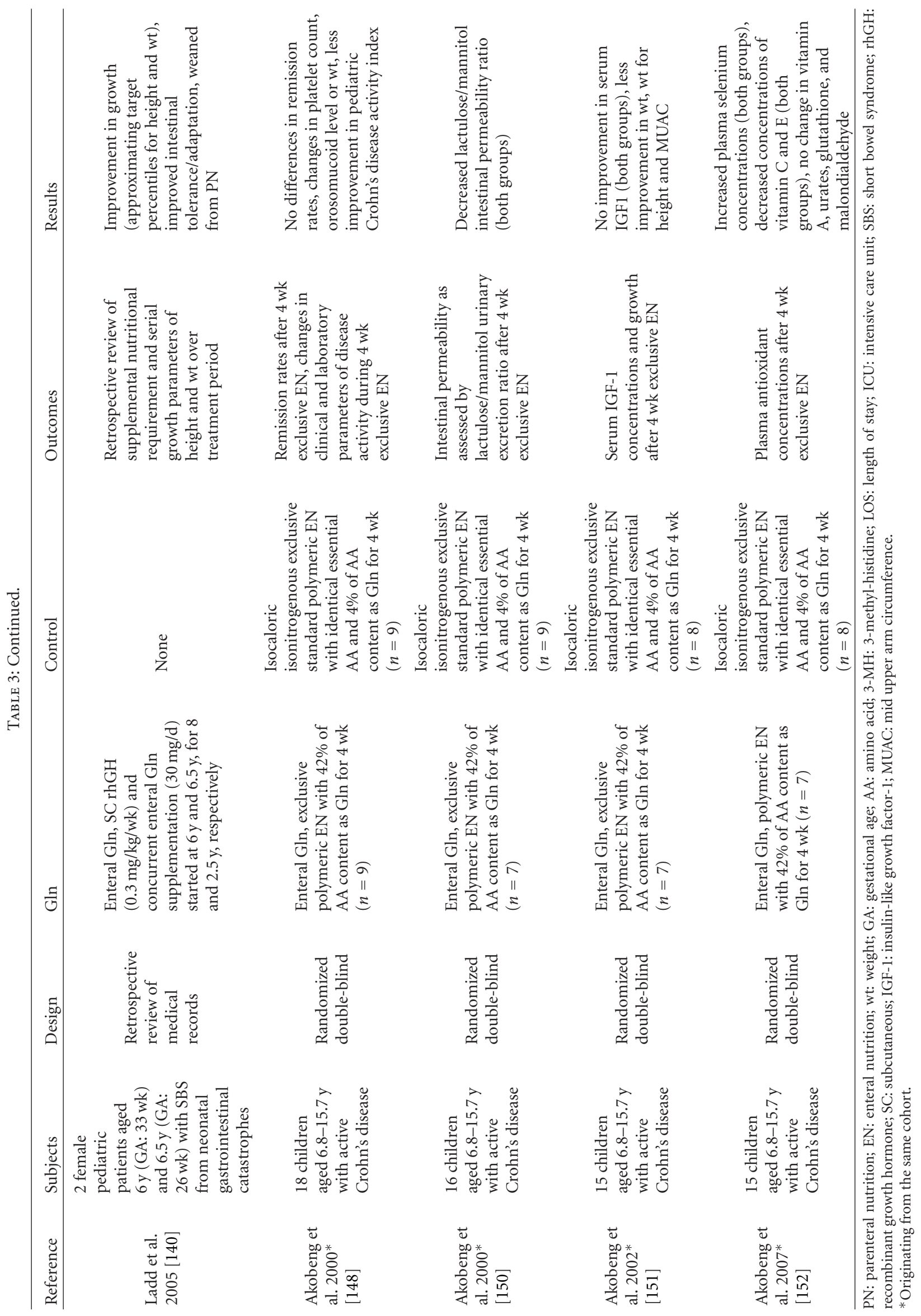


intestinal adaptation in pediatric SBS patients. Due to the small number of pediatric patients, lack of control group, and wide patient age range, larger randomized placebo controlled trials of good methodological quality are warranted, especially in children with SBS to delineate whether Gln alone or in combination with other therapies (e.g., growth hormone) is efficacious in intestinal adaptation. This highlights the need for further studies to define specific selection criteria with respect to patient age (e.g., infants or children). Consideration should also be given to the timing of treatment initiation, that is, the duration between intestinal resection and start of treatment (e.g., early versus late treatment).

3.3.3. Enteral Glutamine in Children with Crohn's Disease. Children with active Crohn's disease undergo catabolic stress, demonstrating increased rates of whole-body protein turnover [143]. Whereas animal models of IBD have indicated potentially beneficial effects of supplemental Gln [144146], clinical studies of Gln in inflammatory bowel disease (IBD) have been less encouraging [147-149].

Akobeng et al. published a series of reports $[148,150-$ 152] (Table 3) from a group of 18 children (aged 6.8-15.7 y) with active Crohn's disease who participated in a doubleblind randomized controlled trial comparing the efficacy of 4 weeks exclusive enteral Gln-enriched polymeric diet (42\% of amino acids as $\mathrm{Gln}$ ) with a standard polymeric diet ( $4 \%$ of amino acids as Gln) that was isocaloric and isonitrogenous [148]. The initial trial found no evidence that Gln-enriched polymeric EN is of any benefit over standard polymeric EN in the treatment of children with active Crohn's disease. After 4 weeks of exclusive EN, there were no differences in remission rates (4/9 in Gln versus 5/9 in control), changes in platelet count, orosomucoid level, or weight. Gln, however, was less effective in improving indices of disease activity (pediatric Crohn's disease activity index (PCDAI)) compared to standard diet.

Secondary analyses in a subset of children from the initial trial also showed that Gln was equivalent to isonitrogenous standard in attenuating increased intestinal permeability [150] or improving plasma antioxidant status [152], possible factors in the pathogenesis of Crohn's disease. Furthermore, Gln-enriched EN did not lead to any improvement in the reduced IGF1 concentrations described in children with Crohn's disease and was actually less effective than standard isonitrogenous EN in improving impaired growth in these children [151].

The inconclusive results could be explained by baseline differences in the PCDAI, which (although adjusted for in the analysis) may have contributed to the greater improvement in PCDAI with the standard diet. It is also possible that such a high concentration of Gln used in the present study may have exceeded the optimal concentration of Gln, that is, beneficial and may actually be harmful in IBD [153]. Gln might have caused excessive priming of immune cells [154], which in turn may promote inflammatory activity. This highlights the need for dose-finding studies in this population. Alternatively, substitution of $42 \%$ of amino acids with Gln may have led to an imbalance in the amino acid profile.

Results are indeterminate from this one small trial [148]. Moreover, 2 children (both from the Gln group) were withdrawn from the trial, because of nontolerance of the diet. Mechanistic data are needed to better understand how Gln interacts with disease pathogenesis and to determine whether Gln is in fact contraindicated or beneficial in children with Crohn's disease, and if so at which doses. Fundamental research is needed before any further randomized controlled trials can be conducted with larger numbers of these children.

\subsection{Enteral Glutamine in Children with}

\section{Diarrheal Disease/Malnutrition}

3.4.1. Enteral Glutamine Supplementation in Infants and Children with Diarrhea. In animal models (rat and rabbit) of secretory diarrhea induced by cholera toxin, Gln-based oral rehydration solution (ORS) was more effective in inducing the absorption of electrolytes and water versus glucosebased ORS $[155,156]$. Similarly, in experimental bacterial diarrhea using the Escherichia coli model, Gln-containing ORS corrected plasma volume and prevented significant weight loss in diarrheic calves [157]. Likewise, infected rabbits also show enhanced intestinal sodium absorption with enteral Gln treatment [158]. In children, amino acids (e.g., Gln) may have facilitating effects on fructose and sorbitol absorption [159].

Three double-blind randomized controlled trials have tested the efficacy of oral Gln in the treatment of diarrheal disease in infants and children [160-162] (Table 4). Ribeiro Jr. et al. [160] studied 118 infants (1-12 months of age) with acute noncholera diarrhea and dehydration and reported that Gln-based ORS did not provide additional benefit over the standard World Health Organization (WHO)-ORS with respect to diarrheal stool output, duration of diarrhea, or volume of ORS needed to achieve/maintain hydration. This initial trial was generally of good methodological quality; however, the addition of Gln to the standard WHO-ORS led to a higher osmolality versus standard, and osmolality could affect diarrheal symptoms. More recently, Gutierrez et al. [162] have compensated for the hyperosmolality by testing an ORS in which glucose was replaced with Gln in 147 dehydrated children (aged 1-60 mo) with acute diarrhea compared to standard glucose-based WHO-ORS. Although solutions were of similar osmolality, glucose-free Gln-based ORS did not appear to reduce stool output, volume of ORS or time required for rehydration, urine output, or vomiting. The indeterminate results of both trials could be explained by subjects being only mildly to moderately dehydrated, since ORS is more effective when given to dehydrated patients $[160,161]$. Furthermore, the early feeding just after rehydration may have blunted the effects of Gln [160]. Finally, Gln may have a lesser effect on intestinal absorption of water and sodium in noncholera diarrhea compared to when the secretory component of the diarrheal episode is more severe (i.e., when there is a relatively larger secretion of sodium and chloride) $[155,156]$. 
TABLE 4: Enteral glutamine supplementation in children with diarrheal disease/malnutrition.

\begin{tabular}{|c|c|c|c|c|c|c|}
\hline Reference & Subjects & Design & Gln & Control & Outcomes & Results \\
\hline $\begin{array}{l}\text { Ribeiro Jr. } \\
\text { et al. } 1994 \\
{[160]}\end{array}$ & $\begin{array}{l}118 \text { male infants } \\
\text { aged } 1-12 \text { mo } \\
\text { with acute } \\
\text { noncholera } \\
\text { diarrhea and } \\
\text { dehydration }\end{array}$ & $\begin{array}{l}\text { Randomized } \\
\text { double-blind }\end{array}$ & $\begin{array}{l}\text { Oral Gln } \\
(90 \mathrm{mmol} / \mathrm{L}) \\
\text { added to standard } \\
\text { glucose-based } \\
(90 \mathrm{mmol} / \mathrm{L}) \\
\text { WHO-ORS } \\
(n=59)\end{array}$ & $\begin{array}{l}\text { Standard } \\
\text { glucose-based } \\
(111 \mathrm{mmol} / \mathrm{L}) \\
\text { WHO-ORS } \\
(n=59)\end{array}$ & $\begin{array}{l}\text { (1) Duration and } \\
\text { severity (stool } \\
\text { output, stool } \\
\text { output rate) of } \\
\text { diarrhea and (2) } \\
\text { intake of ORS } \\
\text { (recorded at } 6 \mathrm{~h} \\
\text { intervals in a } \\
\text { metabolic unit), } \\
\text { urine output, } \\
\text { vomitus, body wt, } \\
\text { blood gases, and } \\
\text { electrolytes } \\
\text { monitored during } \\
\text { hospitalization }\end{array}$ & $\begin{array}{l}\text { (1) No differences in } \\
\text { diarrheal stool output, } \\
\text { stool output rate, or } \\
\text { duration of diarrhea, } \\
\text { (2) no differences in } \\
\text { volume of ORS to } \\
\text { achieve and maintain } \\
\text { hydration, amount and } \\
\text { number of vomitus, } \\
\text { urine output, wt gain, } \\
\text { safe, and well tolerated }\end{array}$ \\
\hline $\begin{array}{l}\text { Yalçin et al. } \\
2004 \text { [161] }\end{array}$ & $\begin{array}{l}128 \text { otherwise } \\
\text { healthy children } \\
\text { aged } 6-24 \text { mo } \\
\text { with acute } \\
(<10 \mathrm{~d}) \text { diarrhea }\end{array}$ & $\begin{array}{l}\text { Randomized } \\
\text { double-blind }\end{array}$ & $\begin{array}{l}\text { Oral Gln } \\
(0.1 \mathrm{~g} / \mathrm{kg} / \mathrm{d} \text { TID }) \\
\text { capsules dissolved } \\
\text { in water for } 7 \mathrm{~d} \\
(n=63)\end{array}$ & $\begin{array}{l}\text { Oral placebo } \\
\text { (cornstarch) } \\
\text { capsules dissolved } \\
\text { in water for } 7 \mathrm{~d} \\
(n=65)\end{array}$ & $\begin{array}{l}\text { (1) Duration of } \\
\text { diarrhea, (2) } \\
\text { severity of } \\
\text { diarrhea by } \\
\text { mother } \\
\text { self-report } \\
\text { followed until } \\
\text { end of diarrheal } \\
\text { episode, } \\
\text { immunologic } \\
\text { parameters } 7 \text { d } \\
\text { after treatment, } \\
\text { wt gain and } \\
\text { infectious disease } \\
\text { monitored } \\
\text { monthly until } 3 \\
\text { months after } \\
\text { treatment }\end{array}$ & $\begin{array}{l}\text { (1) Shorter duration of } \\
\text { diarrhea for entire } \\
\text { cohort and for age } \\
\geq 12 \text { mo subgroup, }(2) \\
\text { no differences in } \\
\text { frequency of persistent } \\
\text { diarrhea or vomiting, } \\
\text { no differences in serum } \\
\text { IL-8, salivary } \\
\text { immunoglobulin A, wt } \\
\text { gain or frequency of } \\
\text { infections }\end{array}$ \\
\hline $\begin{array}{l}\text { Gutierrez et } \\
\text { al. } 2007 \\
{[162]}\end{array}$ & $\begin{array}{l}147 \text { dehydrated } \\
\text { children aged } \\
1-60 \text { mo with } \\
\text { acute noncholera } \\
\text { diarrhea }\end{array}$ & $\begin{array}{l}\text { Randomized } \\
\text { double-blind }\end{array}$ & $\begin{array}{l}\text { WHO-ORS in } \\
\text { which glucose } \\
\text { was replaced with } \\
\text { Gln }(20 \mathrm{~g} / \mathrm{L}) \text { until } \\
\text { rehydration } \\
(n=73)\end{array}$ & $\begin{array}{l}\text { Standard } \\
\text { glucose-based } \\
\text { WHO-ORS until } \\
\text { rehydration } \\
(n=74)\end{array}$ & $\begin{array}{l}\text { Efficacy in } \\
\text { reducing (1) stool } \\
\text { volume and ( } 2) \\
\text { rehydratation } \\
\text { time in acute } \\
\text { diarrhea }\end{array}$ & $\begin{array}{l}\text { (1) No differences in } \\
\text { stool output during } \\
\text { first } 4 \mathrm{~h},(2) \text { no } \\
\text { differences in time to } \\
\text { successful rehydration, } \\
\text { volume of ORS } \\
\text { required for } \\
\text { rehydration, urine } \\
\text { output, or vomiting }\end{array}$ \\
\hline $\begin{array}{l}\text { Lima et al. } \\
2005 \text { [168] }\end{array}$ & $\begin{array}{l}80 \text { malnourished } \\
(\text { WAZ }<-2) \\
\text { hospitalized } \\
\text { children aged } \\
\text { 2-60 mo with or } \\
\text { without diarrhea }\end{array}$ & $\begin{array}{l}\text { Randomized } \\
\text { double-blind }\end{array}$ & $\begin{array}{l}\text { Gln- } \\
\text { supplemented } \\
(16.2 \mathrm{~g} / \mathrm{d}) \text { enteral } \\
\text { modified WHO } \\
\text { formula for } 10 \mathrm{~d} \\
(n=26)\end{array}$ & $\begin{array}{l}\text { ( } 1) \text { Modified } \\
\text { WHO enteral } \\
\text { formula standard } \\
\text { ( } n=27 \text { not } \\
\text { randomized) or } \\
\text { (2) isomolar Gly- } \\
\text { supplemented } \\
(8.3 \mathrm{~g} / \mathrm{d}) \text { enteral } \\
\text { modified WHO } \\
\text { formula for } 10 \mathrm{~d} \\
(n=27)\end{array}$ & $\begin{array}{l}\text { (1) Intestinal } \\
\text { permeability } \\
\text { (urinary lactu- } \\
\text { lose/mannitol } \\
\text { ratio), (2) wt gain } \\
\text { after } 10 \mathrm{~d} \\
\text { supplementation }\end{array}$ & $\begin{array}{l}\text { (1) Improvement in } \\
\text { intestinal barrier } \\
\text { function (decreased } \\
\text { lactulose/mannitol } \\
\text { ratio versus Gly or } \\
\text { standard), (2) no effect } \\
\text { on \% urinary excretion } \\
\text { of lactulose or } \\
\text { mannitol or on } \\
\text { duration of diarrhea, } \\
\text { no differences in wt } \\
\text { gain, no improvement } \\
\text { in WAZ, safe, and well } \\
\text { tolerated }\end{array}$ \\
\hline
\end{tabular}


Table 4: Continued.

\begin{tabular}{|c|c|c|c|c|c|c|}
\hline Reference & Subjects & Design & Gln & Control & Outcomes & Results \\
\hline $\begin{array}{l}\text { Lima et al. } \\
2007 \text { [169] }\end{array}$ & $\begin{array}{l}107 \\
\text { malnourished } \\
\text { (WAZ, HAZ, or } \\
\text { WHZ }<-1 \text { ) } \\
\text { children aged } \\
7.9-82.2 \text { mo in } \\
\text { northeastern } \\
\text { Brazil }\end{array}$ & $\begin{array}{l}\text { Randomized } \\
\text { double-blind } \\
\text { phase III }\end{array}$ & $\begin{array}{l}\text { Oral alanyl-Gln } \\
(24 \mathrm{~g} / \mathrm{d}) \text { mixed } \\
\text { with whole milk } \\
\text { for } 10 \mathrm{~d}(n=51)\end{array}$ & $\begin{array}{l}\text { Oral } \\
\text { isonitrogenous } \\
\text { Gly }(25 \mathrm{~g} / \mathrm{d}) \\
\text { mixed with whole } \\
\text { milk for } 10 \mathrm{~d} \\
(n=56)\end{array}$ & $\begin{array}{l}\text { (1) Intestinal } \\
\text { permeability } \\
\text { (urinary lactu- } \\
\text { lose/mannitol } \\
\text { ratio) } 10 \mathrm{~d} \text { after } \\
\text { supplementation, } \\
\text { (2) growth (wt } \\
\text { and height) } \\
\text { measured until } \\
\text { d120 of study, } \\
\text { diarrheal disease } \\
\text { morbidity }\end{array}$ & $\begin{array}{l}\text { (1) No effect on } \\
\text { lactulose/mannitol } \\
\text { ratio, (2) improvement } \\
\text { in barrier function } \\
\text { (decrease in \% } \\
\text { lactulose recovery), } \\
\text { reduction in absorptive } \\
\text { epithelium (decrease in } \\
\% \text { mannitol recovery), } \\
\text { improved (increased) } \\
\text { cummulative change } \\
\text { over } 120 \text { d in WHZ and } \\
\text { WAZ but not HAZ } \\
\text { (after adjustment for } \\
\text { age and season), safe } \\
\text { and well tolerated }\end{array}$ \\
\hline $\begin{array}{l}\text { Williams et } \\
\text { al. } 2007 \\
{[167]}\end{array}$ & $\begin{array}{l}93 \text { malnourished } \\
\text { growth-faltering } \\
\text { Gambian infants } \\
\text { aged } 4-11 \text { mo }\end{array}$ & $\begin{array}{l}\text { Randomized } \\
\text { double-blind }\end{array}$ & $\begin{array}{l}\text { Oral Gln } \\
0.25 \mathrm{~g} / \mathrm{kg} / \mathrm{d} \text { BID } \\
\text { mixed with } \\
\text { expressed } \\
\text { breastmilk or } \\
\text { distilled water for } \\
5-6 \text { mo (rainy } \\
\text { season) }(n=46)\end{array}$ & $\begin{array}{l}\text { Oral } \\
\text { isonitrogenous } \\
\text { isocaloric mix of } \\
\text { nonessential AA } \\
\text { (Ala, Gly, Ser, } \\
\text { Asn; } 0.25 \mathrm{~g} / \mathrm{kg} / \mathrm{d} \\
\text { BID) and fructose } \\
\text { mixed with } \\
\text { expressed } \\
\text { breastmilk or } \\
\text { distilled water for } \\
\text { 5-6 mo (rainy } \\
\text { season) ( } n=47 \text { ) }\end{array}$ & $\begin{array}{l}\text { (1) Growth and } \\
\text { intestinal barrier } \\
\text { function } \\
\text { (intestinal } \\
\text { permeability) } \\
\text { measured } \\
\text { monthly during } \\
5 \text { mo } \\
\text { supplementation } \\
\text { and } 6 \text { mo after, } \\
\text { (2) plasma } \\
\text { markers of } \\
\text { immunostimula- } \\
\text { tion } \\
\text { (immunoglobu- } \\
\text { lins and acute } \\
\text { phase proteins) } \\
\text { during } \\
\text { supplementation } \\
\text { and morbidity (as } \\
\text { reported by } \\
\text { mother) }\end{array}$ & $\begin{array}{l}\text { (1) No improvement in } \\
\text { wt gain or length gain, } \\
\text { no improvement in } \\
\text { lactulose/mannitol } \\
\text { intestinal permeability } \\
\text { ratio or \% urinary } \\
\text { lactulose or mannitol } \\
\text { recovery, (2) no effect } \\
\text { on plasma } \\
\text { concentrations of } \\
\text { immunoglobulins or } \\
\text { acute phase proteins or } \\
\text { on morbidity }\end{array}$ \\
\hline
\end{tabular}

WHO: World Health Organization; ORS: oral rehydration solution; wt: weight; TID: 3 times a day; IL: interleukin; WAZ: weight for age z-score; HAZ: height for age z-score; WHZ: weight for height z-score; BID: twice a day; AA: amino acid.

For instance, in pig rotavirus enteritis, Gln stimulates jejunal sodium and chloride absorption [163].

Yalçin et al. [161] administered oral Gln $(0.3 \mathrm{~g} / \mathrm{kg} / \mathrm{d})$ as capsules for $7 \mathrm{~d}$ in 128 otherwise healthy infants aged 6 to 24 months with acute diarrhea. Compared to cornstarch placebo, Gln reduced the duration of diarrhea (Gln: $3.40 \pm$ $1.96 \mathrm{~d}$ versus placebo: $4.57 \pm 2.48 \mathrm{~d}, P<0.01)$ for the entire cohort and among infants aged $\geq 12 \mathrm{mo}$, but not for infants $<12 \mathrm{mo}$. The frequency of persistent diarrhea (Gln: 2/63 versus placebo: 6/65) or vomiting (Gln: 24/63 versus placebo: $32 / 65$ ) was not significantly different. Serum interleukin-8 was significantly less after 7 -d treatment in both groups with no difference between groups, whereas salivary immunoglobulin A showed no change. No differences in leukocyte counts, lymphocyte counts, or lymphocyte subpopulations were observed between Gln-supplemented and placebo groups [164]. Furthermore, during the 3 months after treatment, mean weight gain and incidence of infections were similar in both groups. Thus, the reduction in diarrheal duration by Gln seems to result from its local beneficial effect on the gastrointestinal mucosa rather than a modulation of the immune response. Alternatively, the lack of immunomodulatory effect may have been partly attributed to patient selection of children with mild to moderate diarrhea, who may have responded differently to those with persistent or secretory diarrhea. It is also possible that some infants received Gln from breast milk and, thus, were not in fact truly Gln deficient, especially infants $<12$ mo (which could explain the lack of effect in this subgroup). The results, however, should be taken with caution as the primary outcome was a subjective measure based on patient self-report (i.e., clinical recovery as described by the mother 
and noted in an observation chart given to the mother). Also the small number of children may have limited the statistical power to detect changes in complications that are less frequent (e.g., frequency of persistent diarrhea).

\subsubsection{Enteral Glutamine Supplementation in Malnourished} Infants and Children. In the malnourished growing rat, Gln-enriched diet exerts trophic effects on the jejunal mucosa leading to improvements in body weight gain [165]. Similarly, feeding Gln to weaned piglets alleviates growth depression resulting from Escherichia coli challenge, via the maintenance of intestinal morphology and function [166]. Three double-blind randomized controlled trials assessed intestinal permeability using the urinary excretion of lactulose/mannitol ratio to examine whether oral Gln could improve intestinal barrier function in malnourished children and thereby enhance growth [167-169] (Table 4). Lima et al. [168] studied 80 malnourished hospitalized children aged 2 to 60 months to compare enteral formula supplemented with Gln $(16.2 \mathrm{~g} / \mathrm{d})$ versus formula supplemented with isomolar Gly $(8.3 \mathrm{~g} / \mathrm{d})$ or formula alone for $10 \mathrm{~d}$. There was a decrease in the lactulose/mannitol ratio after $10 \mathrm{~d}$ Gln supplementation, which was not observed after Gly nor standard nonsupplemented formula. However, the \% urinary excretions of lactulose or mannitol were not affected. Furthermore, the mean duration of diarrhea, weight gain, or weight-for-age $\mathrm{z}$-scores did not differ among groups; however, there was a trend for weight to increase in children supplemented with Gln or Gly, compared to nonsupplemented diet. Although the study compared Gln-supplemented formula to Glysupplemented and a nonsupplemented formula, allocation to the nonsupplemented group was not randomized, and these children were studied $2 \mathrm{y}$ prior to the randomized trial. Moreover, in the supplemented groups, the Gln and Gly consumed per d contained different amounts of nitrogen, $3.1 \mathrm{~g}$ and $1.6 \mathrm{~g}$, respectively. Thus, the effect of Gln (independent of the amount of nitrogen) cannot be confirmed.

A subsequent trial by the same group [169] also demonstrated improved barrier function, measured by decreased \% urinary lactulose excretion in 107 children (7.9 to 82.2 months of age) administered oral alanyl-Gln $(24 \mathrm{~g} / \mathrm{d})$ for $10 \mathrm{~d}$, but not with isonitrogenous Gly $(25 \mathrm{~g} / \mathrm{d})$. However, alanyl-Gln also led to a reduction in \% urinary excretion of mannitol after $10 \mathrm{~d}$, resulting in no change in the lactulose/mannitol ratio and no difference between groups. Interestingly, alanyl-Gln led to improvements in cumulative change over $120 \mathrm{~d}$ of weight-for-age and weight-for-height z-scores (but not height for age). Although it appears that oral alanyl-Gln supplement may improve intestinal barrier function and reduce wasting in malnourished children, absorptive epithelium is also reduced as determined by a decrease in mannitol recovery. The decreased urinary excretion of mannitol could be related to the high dosage used in this study $(\sim 1.79 \mathrm{~g} \mathrm{Gln} / \mathrm{kg} / \mathrm{d})$. This study [169] and the previous [168], however, may have been underpowered to detect an improvement in diarrheal disease morbidity, which was a secondary parameter (not used in the sample size calculation). Moreover, a longer supplemental period was likely necessary to demonstrate significant effects. Finally, whereas this subsequent trial used an isonitrogenous comparison group, the potential intestinal trophic effect of Gly limits its use as a control for Gln [6, 170]. This is also supported by experimental data showing that ORS containing Gln is equivalent to Gly in enhancing mucosal regeneration or maintaining hydration status in calves with viral-induced diarrhea [171].

Williams et al. [167] used a longer supplemental period of oral Gln $(0.5 \mathrm{~g} / \mathrm{kg} / \mathrm{d})$ in 93 malnourished Gambian infants (aged 4 to 11 months) during the 5-6 month rainy season but failed to demonstrate improvements in growth, intestinal barrier function, or plasma markers of immunostimulation compared to an isonitrogenous control. Growth was poor and was reflected by reductions in weightfor-age, height-for-age z-scores, and mid-upper-arm circumference during the 5-month supplemental period with no difference between groups. Furthermore, supplementation with either Gln or isonitrogenous amino acids did not improve lactulose/mannitol ratios or \% recovery of lactulose or mannitol. Plasma immunoglobulin (Ig) concentrations (IgA and $\operatorname{IgG}$ ) increased during the study, whereas IgM, albumin, antichymotrypsin, and C-reactive protein showed no change. Moreover, morbidity or plasma markers of immunostimulation were not affected by Gln. The lack of significant effect could have been due to the possible trophic effects on the intestine of nitrogen or amino acids (e.g., Gly, Glu, and Cys) in the control group [6, 170], which consisted of a mix of nonessential amino acids. Alternatively, the constant daily exposure of these infants to pathogens or the possible influence of underlying diseases may have prevented any improvement with Gln. Finally, infants may not have been truly Gln deficient as some received Gln from breast milk or other dietary sources. However, food intake data (breastfeeding in particular) was lacking.

Although apparently safe and well tolerated, results from double-blind randomized controlled trials are conflicting regarding the efficacy of oral Gln in the treatment of diarrheal disease $[160-162,168]$ or in enhancing intestinal barrier function [167-169] or growth [167-169] in children suffering from diarrhea or malnutrition. Furthermore, any beneficial effect of oral Gln does not seem to result from a modulation of the immune response $[161,167]$.

Large randomized controlled trials are needed with adequate power, treatment durations, and objective outcome measures. Also because specific subgroups of infants and children may or may not respond to supplemental Gln, patient selection criteria should be clearly defined, particularly with respect to diarrheal disease severity (e.g., secretory diarrhea), hydration status (e.g., severely dehydrated), or age (e.g., infants $\geq 12 \mathrm{mo}$ ). The choice of control (e.g., isonitrogenous) is also an important issue in the design of these studies due to a potential intestinal trophic effect of other amino acids, such as Gly $[6,170]$. Finally, consideration should be given to the possible influence of factors, such as underlying disease, complications, or systemic infections as well as food intake (particularly breastfeeding in infants). 
3.5. Glutamine Supplementation in Pediatric Oncology $\mathrm{Pa}$ tients. Some studies in adult cancer patients indicate beneficial effects of Gln supplementation after chemotherapyradiotherapy or bone marrow transplant (BMT) [172]. In the rat model of methotrexate-induced injury, specific nutrients (such as Gln) and growth factors provide protection against gastrointestinal damage and weight loss [173]. However, data are limited on the effects of Gln supplementation in pediatric oncology patients. An initial case report in a child receiving chemotherapy showed decreased costs and good tolerance with Gln-supplemented tube feedings [174]. Subsequently, Pietsch et al. [175] assessed the feasibility of administering Gln-enriched nasogastric enteral feedings for $\sim 12.7 \mathrm{~d}$ in 17 children (aged $2-19 \mathrm{y}$ ) receiving intensive chemotherapy or BMT and reported minimal complications and reduced hospital costs versus PN (Table 5). Ward et al. [176] conducted a pharmacokinetic dose-finding study in 13 pediatric oncology patients (aged 3-18y) undergoing chemotherapy and concluded that oral Gln at a single dose up to $0.65 \mathrm{~g} / \mathrm{kg}$ was well tolerated and safe to use in a clinical study in pediatric oncology patients. However, it was not feasible to assess the dose-limiting toxicity at higher doses. Apart from these preliminary studies and a case-control study that examined parenteral Gln [177], all other trials in children undergoing treatment for cancer tested oral Gln at a daily dose of $4 \mathrm{~g} / \mathrm{m}^{2}$ body surface area (BSA) [178-181] (Table 5).

\subsubsection{Glutamine Supplementation on Oral Mucositis in Chil-} dren Undergoing Chemotherapy or Bone Marrow Transplant/ Hematopoietic Stem Cell Transplant. Painful oral mucositis is a common complication after chemotherapy or BMT/ hematopoietic stem cell transplant (HSCT) resulting in reduced oral intake and frequently requiring $\mathrm{PN}$. In a small case-control study, Kuskonmaz et al. [177] matched 21 pediatric cases (mean age $8.3 \pm 5.2 \mathrm{y}$ ), who underwent allogeneic HSCT and received parenteral Gln supplementation $(0.4 \mathrm{~g} / \mathrm{kg} / \mathrm{d})$ to a group of 20 control children (comparable with respect to donor type, diagnosis, and age) and observed a trend toward reduced incidence of mucositis (29 versus $55 \%, P=0.118)$, sinusoidal obstruction syndrome (10 versus $35 \%, P=0.067$ ), and drug-related toxicity (14 versus $40 \%, P=0.085$ ) (Table 5 ). Gln supplementation was also associated with reduced duration of fever (5.7 versus $12.0 \mathrm{~d}$, $P=0.021)$; however, no differences in total parenteral nutrition (TPN) use, neutrophil engraftment, Graft Versus Host Disease, length of stay in hospital, infections, or mortality were observed.

Three double-blind randomized trials tested the efficacy of oral Gln compared to Gly placebo in reducing oral mucositis [178-180] (Table 5). Anderson et al. [179] conducted a crossover study whereby 24 patients (16 children and 8 adults) were randomly assigned to oral Gln over 2 courses of chemotherapy and Gly placebo over another 2 courses (or the reverse order). Supplementation was then continued for another $14 \mathrm{~d}$ after chemotherapy. Although the duration and severity of mucositis was reduced in the chemotherapy courses in which Gln was provided $(4.5 \mathrm{~d}$ less with Gln versus placebo, $P<0.001$ ), results were based on patient self-report by means of a calendar completed by the patients on the duration and severity of mucositis associated with each chemotherapy course. Also in addition to the small sample size, followup of recruited patients was incomplete, as only 13 patients actually completed at least 2 courses of identical chemotherapy (10 children aged $4-17 \mathrm{y}$ and 3 adults). Hence additional studies with larger numbers were needed.

These issues were addressed in a larger cohort of 193 patients (including 72 children) undergoing BMT, whereby the same group assessed mucositis by both self-report and by opiate use [180]. Patients were prospectively stratified by type of transplant (autologous, matched sibling donor or unrelated donor) and randomized to receive either oral Gln or Gly placebo during preparative chemotherapy and radiation until $28 \mathrm{~d}$ after BMT. In autologous BMT patients, Gln reduced the severity of oral mucositis assessed by selfreport and by duration of opiate use (Gln: $5.0 \pm 6.2 \mathrm{~d}$ versus control: $10.3 \pm 9.8 \mathrm{~d}, P<0.01)$. By contrast, in matched sibling BMT patients, Gln had no effect on selfreport and actually increased the duration of opiate use (Gln: $23.2 \pm 5.7 \mathrm{~d}$ versus control: $16.3 \pm 8.3 \mathrm{~d}, P<0.01$ ), whereas \% survival at d-28 was increased by Gln in allogeneic patients. Although other outcomes (TPN use, rate of relapse or progression of malignancy, antibiotic use, graft versus host disease, $\mathrm{d}$ of hospitalization, infections, or survival at d-100) were not affected, the results suggest that oral Gln is safe and effective in decreasing the severity and duration of mucositis in autologous but not allogeneic BMT patients. The study population was heterogeneous in terms of age (range: 1-62 years); subgroup analysis, however, of the 72 child participants was not reported.

Aquino et al. [178] further demonstrated the safety and benefit of oral Gln in reducing the severity of mucositis in 120 children undergoing HSCT. Compared to Gly placebo, the Gln group showed a trend toward a reduction in the mean mucositis score (Gln: $3.0 \pm 0.3$ versus Gly: $3.9 \pm 0.4$, $P=0.07)$ as well as a reduction in the number of $\mathrm{d}$ of IV narcotics use $(12.1 \pm 1.5 \mathrm{~d}$ versus Gly: $19.3 \pm 2.8 \mathrm{~d}$, $P<0.05)$ and TPN $(17.3 \pm 1.7 \mathrm{~d}$ versus Gly: $27.3 \pm 3.6 \mathrm{~d}$, $P=0.01)$. There were no differences between groups for the number of episodes of bacteremia, total number of hospital d, or mortality. Although consideration should be given to include oral Gln supplementation as part of the supportive care of HSCT, the primary endpoint (mean mucositis score) was subjectively measured by a clinical scoring scale, which is a limitation of this and other studies that assessed mucositis severity. Furthermore, the study may have been underpowered to detect a significant difference, since only 100 mucositis scoring sheets were available for analysis, whereas the estimated sample size was 120 patients. Finally the lower incidence of herpes simplex virus-positive children (a known risk factor for the development of mucositis [178]) in the Gln group at baseline may have confounded the results.

3.5.2. Glutamine on Immune Function: Implications for Children with Solid Tumors and Acute Lymphoblastic Leukaemia. In patients with solid tumors and lowered lymphocyte 


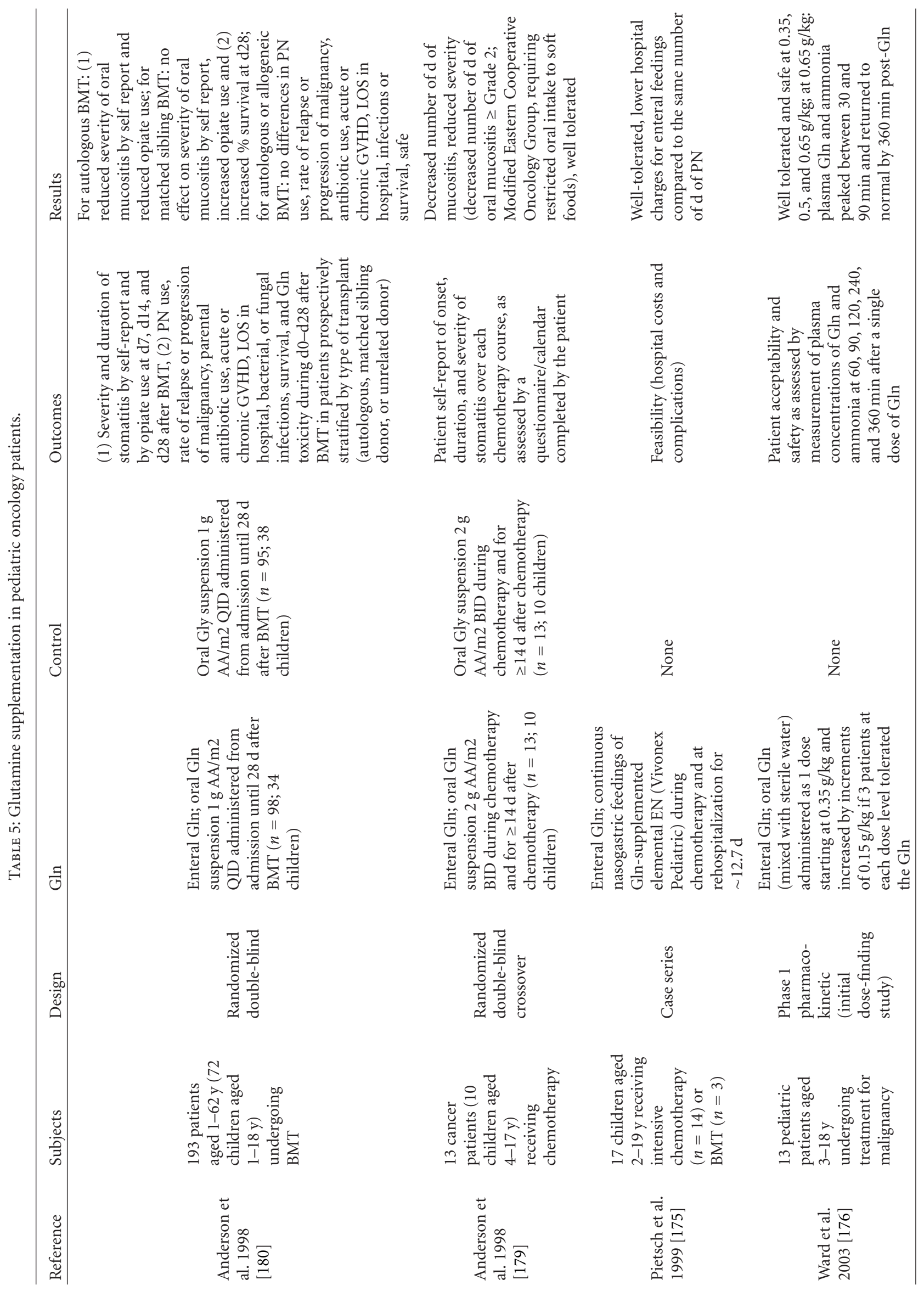




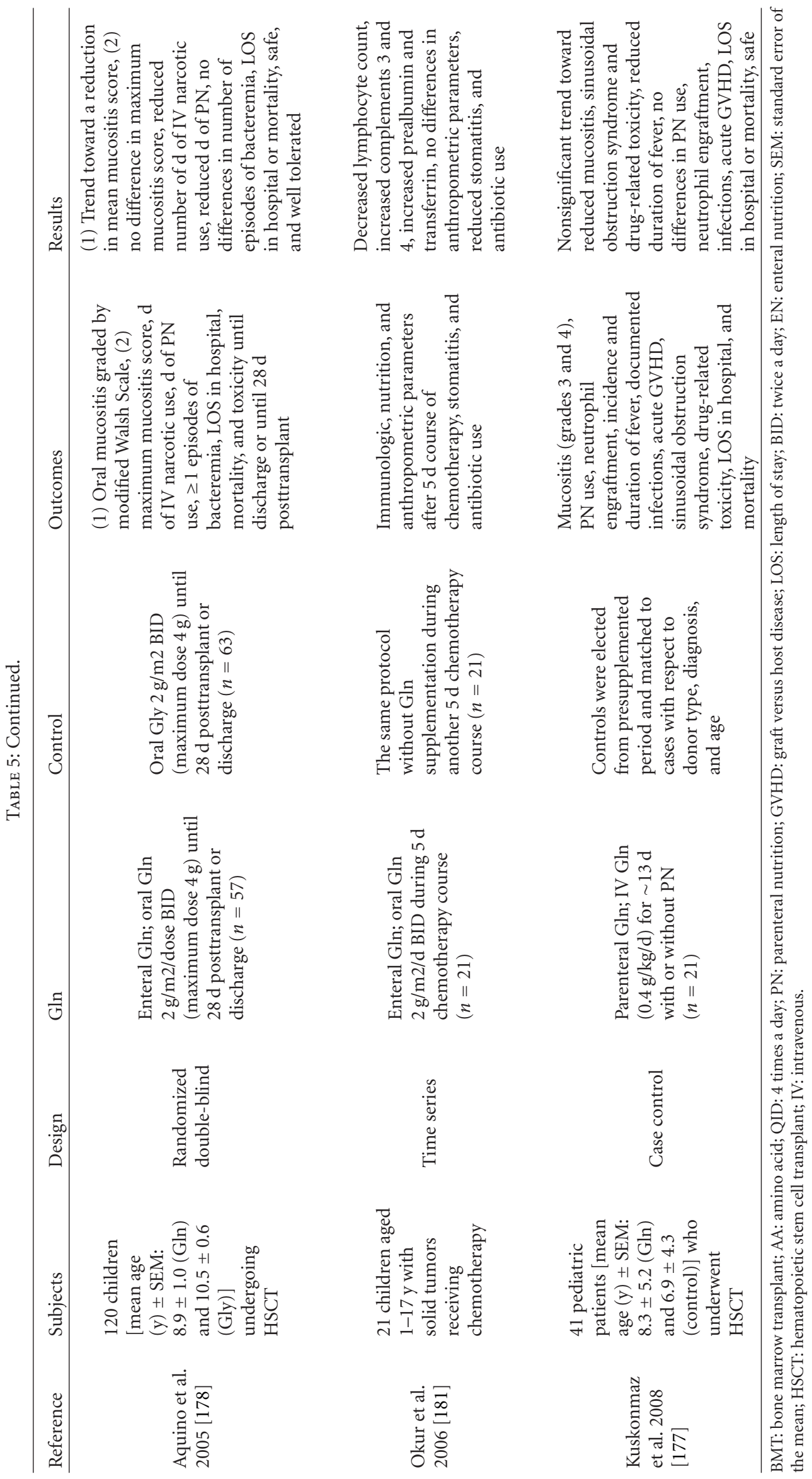


proliferative response, Gln treatment may improve immune function. Köhler et al. [182] studied the influence of Gln and glycyl-Gln on the proliferative response of lymphocytes isolated from 21 children (aged 1-17y) with solid tumors, before and after chemotherapy and observed no difference in the in vitro lymphocyte proliferation before or after chemotherapy. Although these in vitro data do not support the routine use of Gln supplementation to enhance lymphocyte function in children with solid tumors, specific subgroups of tumors showed trends that differed from the overall findings, but statistical power was inadequate to prove any differences.

An in vivo study by Okur et al. [181] examined 21 children (aged 1-17y) with solid tumors to compare the effects of oral Gln supplementation during a 5-d chemotherapy course versus another course without Gln and showed that the immune-enhancing effects of Gln could involve not only lymphocytes but also the complement pathway (Table 5). Moreover, Gln supplementation was associated with significant improvements in some nutritional parameters and reduced stomatitis severity and antibiotic necessity, suggesting that oral Gln could be considered in children with solid tumors receiving chemotherapy.

A recent report in mice has suggested that supplementation with alanyl-Gln could support the peripheral immune system and cell-mediated immunity during asparaginase chemotherapy [183]. This has implications for children since asparaginase which is used in the treatment of acute lymphoblastic leukaemia (ALL) (the most common childhood cancer) also depletes plasma asparagine and Gln [184, 185] resulting in immunosuppression. Moreover, low plasma concentrations of gluconeogenic amino acids, especially Gln and Ala have been reported during chemotherapy-related hypoglycaemia in ALL children [186], which is in contrast to the increased Gln concentrations observed in the cerebral spinal fluid of children with ALL undergoing chemotherapy or with CNS disease [187]. Future animal research is needed to test the safety and efficacy of Gln during asparaginase chemotherapy before trials in children with ALL.

Results from 3 randomized trials suggest that oral Gln supplementation is safe and may reduce the severity and duration of oral mucositis in patients undergoing treatment for cancer, including chemotherapy, autologous BMT, and HSCT [178-180]. Although trials were methodologically sound, sample sizes were small, and 2 trials included both pediatric and adult patients. Moreover, outcome (mucositis severity) was assessed subjectively by the patient rather than objectively by an independent observer.

The data from nonrandomized preliminary clinical studies demonstrate safety [176] and suggest that supplemental Gln may lead to reduced hospital costs in children receiving chemotherapy or BMT [175], reduced fever duration in children undergoing HSCT [177], and improvements in nutritional and immunological parameters in children with solid tumors receiving chemotherapy [181]. However, in vitro data do not support the routine use of Gln supplementation to enhance lymphocyte function in children with solid tumors [182].
Due to the lack of data in children, additional randomized controlled trials are needed with adequate numbers of pediatric oncology patients to confirm any benefit of supplemental Gln. Future trials should define the patient populations for which Gln may or may not be of benefit, by using clearly defined selection criteria with respect to age (e.g., pediatric versus adult), specific cancer treatments (e.g., autologous versus allogeneic BMT), or subgroups of malignancies (e.g., specific subgroups of solid tumors) and evaluate efficacy using objective outcome measures that are both valid and reliable.

3.6. Glutamine in Pediatric Patients with Severe Burns/Trauma. In situations of abnormal muscle protein metabolism (e.g., severe burns or trauma), endogenous Gln production could be impaired [188]. Gore and Jahoor [188] observed decreased arterial Gln concentrations and decreased rates of Gln turnover, in 5 severely burned children compared to control children, whereas net efflux of Gln did not differ. Thus, suggesting that reduced plasma Gln, observed in burned children, results from a deficiency in peripheral Gln production and increased central consumption. This supports the notion that Gln supplementation may be needed in pediatric burn patients because of an inadequate skeletal muscle response.

The reduced plasma Gln concentrations observed after major burns could also in part contribute to the immunosuppression, that is, seen in these patients. An in vitro study by Ogle et al. [189] isolated neutrophils from 12 pediatric burn patients (aged 4-18y) at various postburn times to determine their ability to kill Staphylococcus aureus in the presence or absence of $\mathrm{Gln}(20 \mathrm{mmol} / \mathrm{L})$ and compared this with normal subjects. At all but 2 postburn times, Gln improved the observed abnormal neutrophil bactericidal function, restoring it to normal levels. Although Gln had no effect on $\mathrm{C} 3 \mathrm{~b}$ receptors (CR1) or on phagocytosis, the restoration of the impaired bactericidal function shown in this in vitro study provided additional evidence for Gln supplementation in the diets of pediatric burn patients.

There exists, however, limited clinical data demonstrating efficacy of supplemental Gln in burn and other trauma patients (Table 6). Sheridan et al. [190] conducted the only randomized double-blind trial of supplemental Gln using a crossover design in 9 pediatric burn patients (aged 1.3-15.8 y) who received in a random order: $48 \mathrm{~h}$ of standard enteral feedings (control phase) and $48 \mathrm{~h}$ of enteral feedings with Gln $(0.6 \mathrm{~g} / \mathrm{kg} / \mathrm{d})$ replacing $20 \%$ of essential and nonessential amino acids. Whole-body protein kinetics, determined in the fed state at the end of each study phase, revealed that Leu flux and Leu oxidation were lower during Gln supplemental period versus control period. However, no significant differences were observed in net balance of Leu accretion into protein, nitrogen balance, or plasma Gln concentrations. The lack of beneficial effect on protein accretion could have resulted from a number of reasons. Firstly, the use of an isonitrogenous control tests 
TABLE 6: Glutamine in pediatric patients with severe burns/trauma.

\begin{tabular}{|c|c|c|c|c|c|c|}
\hline Reference & Subjects & Design & Gln & Control & Outcomes & Results \\
\hline $\begin{array}{l}\text { Sheridan et } \\
\text { al. } 2004 \text { [190] }\end{array}$ & $\begin{array}{l}7 \text { pediatric } \\
\text { patients aged } \\
1.3-15.8 \text { y with } \\
\text { serious burns } \\
\text { ( } \geq 20 \% \text { of BSA) } \\
\text { tolerating enteral } \\
\text { feedings }\end{array}$ & $\begin{array}{l}\text { Randomized } \\
\text { double-blind } \\
\text { crossover }\end{array}$ & $\begin{array}{l}\text { Enteral Gln; EN } \\
\text { (Pediasure and/or } \\
\text { Jevity) with Gln } \\
(0.6 \mathrm{~g} / \mathrm{kg} / \mathrm{d}) \\
\text { replacing } 20 \% \text { of } \\
\text { essential and } \\
\text { nonessential AA } \\
\text { for } 48-72 \mathrm{~h} \\
(n=7)\end{array}$ & $\begin{array}{l}\text { Isocaloric } \\
\text { isonitrogenous } \\
\text { standard EN } \\
\text { (Pediasure and/or } \\
\text { Jevity) } \\
\text { supplemented } \\
\text { with modular } \\
\text { protein (Promod) } \\
\text { for } 48-72 \mathrm{~h} \\
(n=7)\end{array}$ & $\begin{array}{l}\text { Whole-body } \\
\text { protein kinetics } \\
\text { (IV infusion of } \\
\text { L-[1-13C]Leu, } \\
\text { NaH13CO3) after } \\
48 \text { h enteral } \\
\text { feeding (fed } \\
\text { state), nitrogen } \\
\text { balance, plasma } \\
\text { Gln } \\
\text { concentrations }\end{array}$ & $\begin{array}{l}\text { Decreased Leu flux and } \\
\text { Leu oxidation rate, no } \\
\text { differences in net } \\
\text { balance of Leu } \\
\text { accretion into proteins, } \\
\text { nitrogen balance or } \\
\text { plasma Gln } \\
\text { concentrations, well } \\
\text { tolerated }\end{array}$ \\
\hline $\begin{array}{l}\text { Chuntrasakul } \\
\text { et al. } 2003 \\
\text { [195] }\end{array}$ & $\begin{array}{l}36 \text { trauma } \\
\text { patients aged } \\
15-60 \text { y }(n=16 \\
\text { severe trauma; } \\
n=20 \text { burn BSA } \\
30-60 \%)\end{array}$ & $\begin{array}{l}\text { Randomized } \\
\text { controlled }\end{array}$ & $\begin{array}{l}\text { Enteral Gln; } \\
\text { exclusive EN } \\
\text { enriched with } \\
\text { Arg, Gln, } \\
\text { omega-3 fatty } \\
\text { acids (Neomune) } \\
\text { started on } \\
\text { postinjury d-2 } \\
\text { until d-10 } \\
(\leq 0.15 \mathrm{~g} / \mathrm{kg} / \mathrm{d} \\
\text { Gln })(n=18)\end{array}$ & $\begin{array}{l}\text { Standard } \\
\text { exclusive EN for } \\
\text { trauma patients } \\
\text { (traumacal) } \\
\text { started on } \\
\text { postinjury d-2 } \\
\text { until d-10 } \\
(\leq 0.07 \mathrm{~g} / \mathrm{kg} / \mathrm{d} \\
\text { Gln })(n=18)\end{array}$ & $\begin{array}{l}\text { Biochemical and } \\
\text { immune } \\
\text { parameters after } \\
10 \mathrm{~d} \\
\text { supplementation, } \\
\text { morbidity, and } \\
\text { mortality }\end{array}$ & $\begin{array}{l}\text { No differences in } \\
\text { immunologic or } \\
\text { biochemical } \\
\text { parameters (except } \\
\text { increased serum total } \\
\text { protein, decreased } \\
\text { serum triglycerides), } \\
\text { no significant } \\
\text { differences in nitrogen } \\
\text { balance, LOS in } \\
\text { ICU/hospital, d to } \\
\text { wean off ventilator, or } \\
\text { mortality, well } \\
\text { tolerated }\end{array}$ \\
\hline $\begin{array}{l}\text { Yang and } \mathrm{Xu} \text {, } \\
2007 \text { [196] }\end{array}$ & $\begin{array}{l}46 \text { patients aged } \\
7-68 \text { y with severe } \\
\text { traumatic brain } \\
\text { injury }\end{array}$ & $\begin{array}{l}\text { Randomized } \\
\text { controlled }\end{array}$ & $\begin{array}{l}\text { Enteral or } \\
\text { parenteral Gln; } \\
\text { Gln-Ala dipeptide } \\
(n=23)\end{array}$ & $\begin{array}{l}\text { Routine } \\
\text { nutritional } \\
\text { therapy }(n=23)\end{array}$ & $\begin{array}{l}\text { LOS in } \\
\text { neurosurgical } \\
\text { ICU, mortality, } \\
\text { lymphocyte } \\
\text { count, and related } \\
\text { complications }\end{array}$ & $\begin{array}{l}\text { No significant } \\
\text { differences in } \\
\text { mortality, LOS in } \\
\text { neurosurgical ICU, } \\
\text { lung infection or } \\
\text { alimentary tract } \\
\text { hemorrhage or } \\
\text { lymphocyte count }\end{array}$ \\
\hline
\end{tabular}

BSA: body surface area; EN: enteral nutrition; AA: amino acid; IV: intravenous; LOS: length of stay; ICU: intensive care unit.

the specificity of Gln but also results in a reduction in both essential and nonessential amino acids in the Gln diet, which may have counterbalanced any beneficial effect of Gln. Furthermore, the risk of type II error cannot be ruled out, since only 7 out of the 9 children enrolled actually completed the study. Finally, the Gln feeding period may have been too short to replenish the depleted Gln pools in stressed pediatric burn patients. Hence, a longer supplemental period may be required to restore plasma Gln concentrations and stimulate protein accretion in this population.

Microdialysis and magnetic resonance spectroscopy observations in children indicate that the Gln/Glu balance in the injured brain may play a significant role in the pathophysiology of traumatic head injury in children [191193]. Moreover, higher brain Glu/Gln ratio correlates with increased tissue damaging procedures in asphyxiated term neonates [194]. The efficacy of supplemental Gln in severe trauma was tested in 2 small trials that included both pediatric and adult patients $[195,196]$ (Table 6). Yang and Xu [196] compared Gln-Ala dipeptide versus routine nutritional therapy in 46 patients aged $7-68 \mathrm{y}$ with severe traumatic brain injury. Chuntrasakul et al. [195] compared immunonutrient formula enriched with Gln versus standard EN in 36 patients aged $15-60$ y with severe burns/trauma. Results were inconclusive since studies were underpowered to detect statistically significant differences, particularly for nonspecific, multifactorial outcomes, such as length of stay and mortality. Also the clinical heterogeneity (wide age range) of subjects included limits application to children. Apart from methodological issues (e.g., incomplete description of blinding and randomization procedures), the study by Chuntrasakul et al. [195] used a commercial product that combined Gln with added Arg and omega- 3 fatty acids. As such, it is difficult to assess the effects of Gln apart from the effects of other nutrients. Furthermore, the actual intake of Gln was not significantly greater in the study group versus control ( $\leq 0.15$ versus $\leq 0.07 \mathrm{~g} / \mathrm{kg} / \mathrm{d}$, resp.). Thus, any effect of Gln may have been blunted.

In summary, although in vitro data suggest beneficial effects of supplemental Gln in pediatric burn patients [189], clinical data are less encouraging [190]. Short-term enteral Gln is apparently well tolerated but does not result 
in an immediate whole body protein gain in pediatric burn patients [190]. Moreover, studies showing benefits of supplemental Gln in pediatric and adult patients with severe trauma are inconclusive, and methodological problems have been noted [195, 196]. Larger well-designed studies are needed, especially in children to test any clinical benefit. Protein kinetic studies should consider the duration of administration, for example, testing enteral Gln administered over longer periods on protein metabolism as well as on its own metabolism to determine whether Gln's protein-sparing effect also applies to burned children. Such studies might also consider the route of administration, as no study has yet tested the efficacy of parenteral Gln on protein metabolism or on clinical outcome in pediatric burn patients.

\subsection{Enteral Glutamine Supplementation in Chronic Diseases of Childhood}

3.7.1. Enteral Glutamine Supplementation in Children with Duchenne Muscular Dystrophy. Duchenne muscular dystrophy (DMD) is an X-linked disease caused by a defect in the gene encoding for dystrophin (a cytoskeletal protein) [197]. The absence of dystrophin expression is associated with a progressive and severe loss of muscle mass and function. Studies on protein metabolism suggest that muscle wasting in DMD could result from a reduction in muscle protein synthesis or an increase in protein degradation or both [198200]. Because skeletal muscle is the body's main producer and exporter of Gln and muscle mass is drastically reduced in DMD, the need for Gln may be increased in persons who have this disease. Furthermore, in DMD as in other proteinwasting conditions, the intramuscular Gln concentration is low [201, 202]. And Sharma et al. [202] suggested that this may be an underlying reason for muscle wasting in DMD. Additionally, we have demonstrated that compared to normal boys, the dramatic muscle mass loss observed in DMD boys aged $10 \mathrm{y}$ was associated with a decrease in wholebody Gln availability in the postabsorptive state, resulting from a decrease in Gln de novo synthesis [203]. Thus, in DMD as in other catabolic stress conditions, Gln might be considered a conditionally essential amino acid.

We conducted 2 separate studies using stable isotope methodology [204, 205] (Table 7), to test the effect of oral Gln on whole-body protein and Gln metabolism in DMD children during the postabsorptive state. In the initial study [204], Leu and Gln kinetics were measured in 6 DMD boys aged $8-13$ y on 2 consecutive days while children received a 5-h oral administration of flavoured water (Kool-Aid) on the first study day followed by Gln $(0.6 \mathrm{~g} / \mathrm{kg})$ dissolved in the same flavoured water on study day-2. During Gln administration, Leu release from protein breakdown and Leu oxidation rate both decreased by $8 \%$ and $35 \%$, respectively $(P<0.01)$, resulting in no change in nonoxidative Leu disposal (an index of protein synthesis). Whereas, whole body Gln exchange in the plasma doubled $(P<0.01)$, Gln from protein degradation and Gln de novo synthesis both decreased during oral Gln administration. These preliminary data suggested that acute oral Gln might have an acute protein-sparing effect in children with DMD resulting from a decrease in whole-body protein degradation and Gln de novo synthesis. However, results should be taken with caution due to the small sample size. Additionally, the order of treatment allocation was not randomized, and participants and assessors were not blinded to treatment. Moreover, the specificity of Gln's effect on protein metabolism could not be tested as measurements were not performed using an isonitrogenous control group as well.

We addressed these shortcomings more recently by conducting a double-blind randomized controlled trial [205] in 26 DMD boys (aged 7-15y) to test whether the acute protein-sparing effect of Gln persisted when oral Gln $(0.5 \mathrm{~g} / \mathrm{kg} / \mathrm{d})$ was given for $10 \mathrm{~d}$ and whether the effect was specific to Gln, by comparing the Gln-supplemented group to an isonitrogenous control (amino acid mixture). Whereas plasma Gln concentrations were not altered this time (since kinetic studies were performed $24 \mathrm{~h}$ after Gln or amino acid administration $)$, the $9 \%(P<0.05)$ decrease in Leu release from protein breakdown persisted after $10 \mathrm{~d}$ Gln supplementation and endogenous Gln from protein degradation also decreased. Similar effects were observed after $10 \mathrm{~d}$ amino acid supplementation; however, the magnitude of the decrease in whole-body proteolysis was less $(-4 \%, P<$ 0.05). There were no significant effects on other estimates of Leu and Gln turnover or on body composition (fatfree mass, \% fat mass, muscle mass, and weight) after $10 \mathrm{~d}$ supplementation in either group. The lack of significant difference between Gln and isonitrogenous control could be explained by the variability in disease progression among the study population, since Gln treatment in DMD may have different effects depending on the stage of the disease process [206]. It is also possible that a higher dose or longer treatment duration may be necessary to demonstrate the specific effect of Gln, separate from its role of providing nitrogen. This highlights the need for dose and time course data on Gln administration in DMD. Alternatively, the route of administration (enteral versus parenteral) could partly explain the lack of significant difference, since Gln's protein-sparing effect may be less dramatic when it is given enterally $[125,127]$ as opposed to parenterally $[80,105]$, as demonstrated in studies on protein metabolism in premature infants of LBW [126].

Based on experimental data showing that Gln improved performance in the $m d x$ mouse model of DMD [207], Escolar et al. [206] conducted a randomized double-blind placebo-controlled multicentre study to test the efficacy and safety of 6-month oral Gln $(0.6 \mathrm{~g} / \mathrm{kg} / \mathrm{d})$ in 35 ambulant steroid naïve boys with DMD aged 4-10 y (Table 7). Whereas there were no significant differences in the primary outcome (manual muscle testing score) or on quantitative measurements of muscle strength, subgroup analysis showed that in younger boys $(<7 \mathrm{y})$ the Gln group had significantly less deterioration over 6 months in timed functional tests versus placebo. Although there was a trend toward less deterioration in quantitative and functional measures of muscle strength with Gln treatment over 6 months, the effect did not reach significance for the cohort as a whole. The inability to detect 


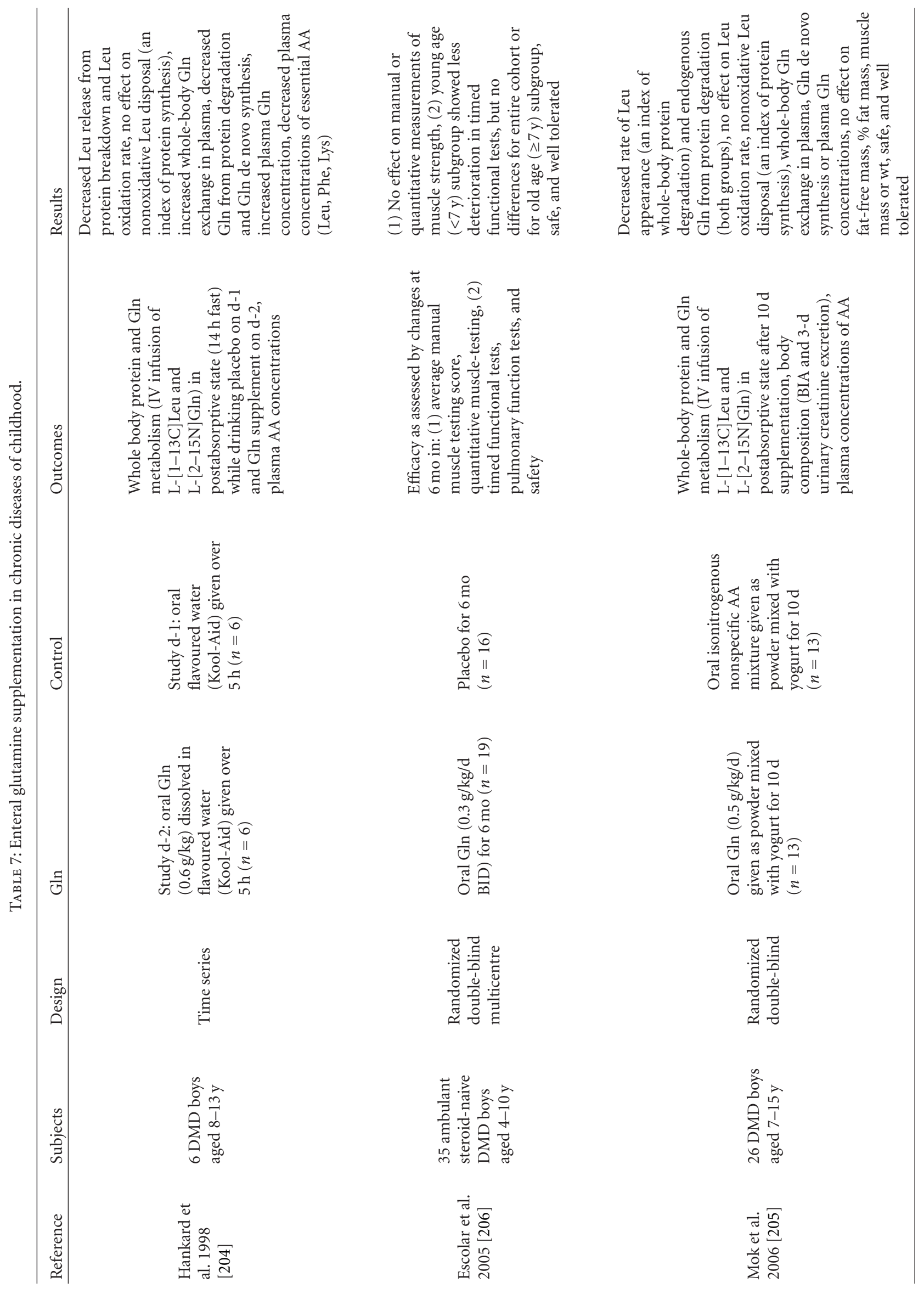




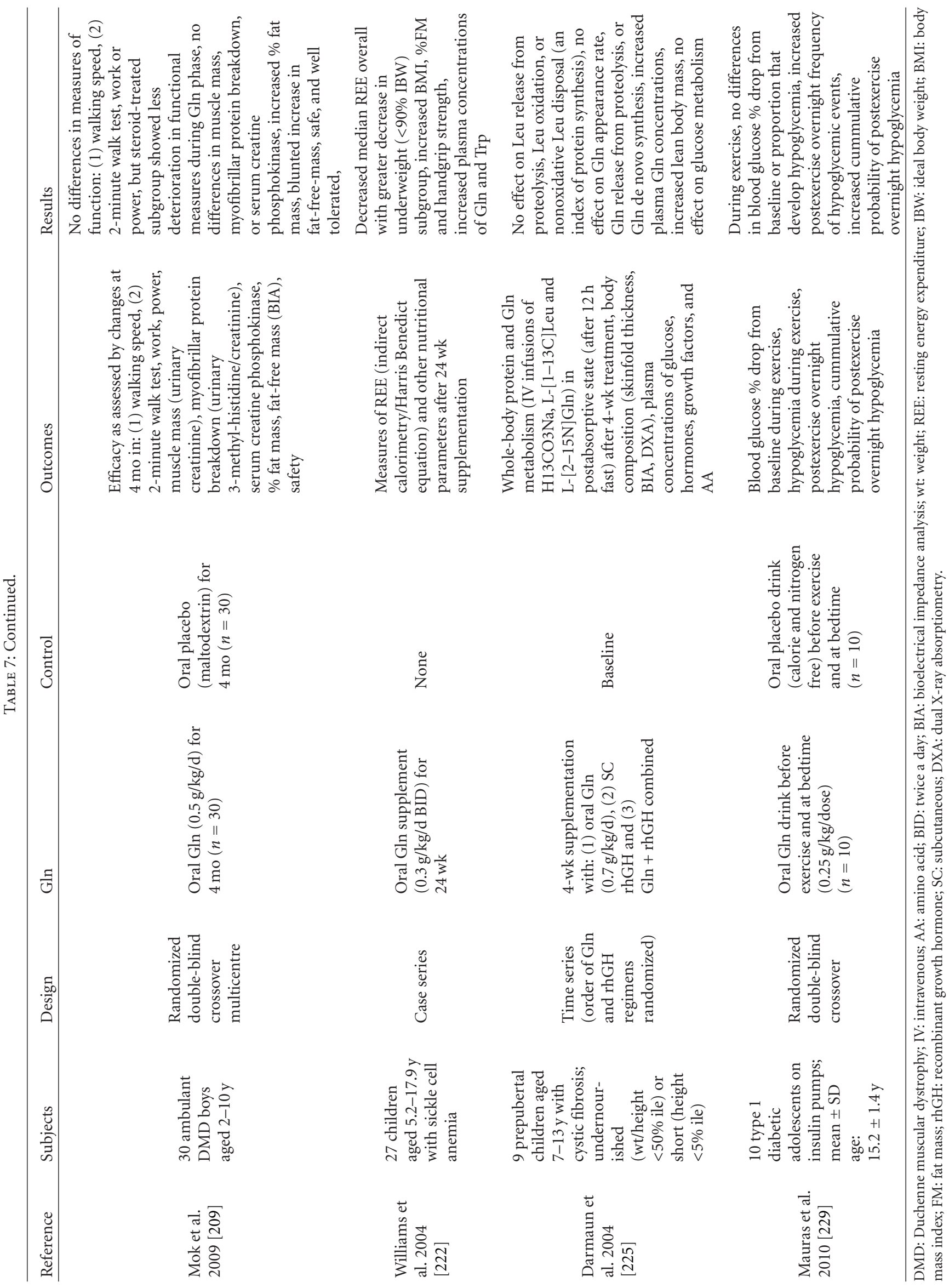


a significant difference in the primary outcome could be explained by the unexpected lack of strength deterioration (measured by manual muscle testing) in the placebo group over the 6-month trial. Thus, the study may have been underpowered since power calculations were based on previous natural history data of DMD [208]. The significant age-related results must be interpreted with caution as they were based on an unplanned subgroup analyses in a small group of patients. Larger trials incorporating a priori age stratification are required to test the disease-modifying effect of long-term Gln supplementation in DMD.

Our group has recently completed a multicentre randomized controlled crossover trial in 30 prepubertal DMD boys aged $2-10 y$ to test whether 4 -month oral Gln can slow the progressive loss in muscle mass and function that occurs in these children [209]. Subjects received 4-month Gln separated by a 1-month washout, followed by 4-month placebo (maltodextrin) or vice versa. The order of treatment allocation was randomized. Overall, there was no apparent functional benefit as tested by comparing Gln versus placebo on change in walking speed at 4 months (primary outcome) or in secondary measures of muscle function (2-minute walk test, work, and power). We observed no differences in muscle mass (urinary creatinine), markers of protein breakdown (urinary 3-methyl-histidine/creatinine), or serum creatine phosphokinase in the Gln group compared with placebo, except for a blunted increase in fat free mass in the Gln group which led to a greater increase in fat-mass percentage. Our findings that functional measures did not deteriorate during the 4-month placebo phase or over the course of the 9 -month trial were not as expected. Based on natural history data [208], the trial was powered to detect a $10 \%$ difference in walking speed after 4-month Gln compared to placebo. However, we did not consider the greater placebo effect reported in children [210] which could have narrowed the expected effect size of Gln treatment. Interestingly, subgroup analysis revealed a significant effect of Gln treatment on functional measures in boys taking corticosteroids $(P<$ 0.05). Specifically, boys taking corticosteroids showed a significant decline in walking speed during the placebo phase $(-40 \%, P<0.05)$, whereas walking speed remained stable when corticosteroid-treated boys received Gln treatment for 4 months. Although the findings must be interpreted with caution, because they derive from an unplanned analysis in a small subgroup of boys $(n=5)$, they might suggest a rationale for Gln supplementation in conjunction with corticosteroid therapy which needs investigation.

In summary, studies on protein metabolism in DMD children suggest a protein-sparing effect of Gln, resulting from a decrease in whole-body proteolysis [204, 205]. Moreover, we have identified a potential antioxidant protective mechanism for Gln's antiproteolytic effect in dystrophic muscle of young $m d x$ mice [35]. Although safe, supplemental Gln does not appear to improve muscle strength [206] or function in DMD children [209]. Better targeting of specific subgroups (younger DMD children or DMD children under stress, e.g., corticosteroid treatment) is necessary to fully evaluate the presence (or absence) of benefits. Fundamental research is also needed to elucidate potential mechanisms whereby therapies such as Gln target events downstream of the genetic defect in the progressive dystrophic pathology.

\subsubsection{Enteral Glutamine Supplementation in Children with} Sickle Cell Anemia. Children with sickle cell anemia often have decreased height and weight and reduced muscle mass when compared with healthy children $[211,212]$. This may be partly due to increased metabolism, since prepubertal children with sickle cell disease have been shown to use approximately 19\% more energy, 58\% more protein, and $47 \%$ more Gln compared with age-, sex-, and race-matched controls [213], even in the absence of sickling, vaso-occlusive disease or intercurrent illness, suggesting that sickle cell children may have greater protein and energy needs than healthy children, and this could lead to impaired growth. The increased protein and energy needs could be due in part to the increased erythrocyte production as a result of the chronic hemolysis and anemia that leads to increased cardiac output [213]. In adult sickle cell disease patients, oral Gln has been shown to improve NAD redox potential of sickle red blood cells and may result in reduced oxidative stress susceptibility [214]. Moreover, low erythrocyte Gln may contribute to alterations in the erythrocyte redox environment and may play a role in hemolysis and pulmonary hypertension in patients with sickle cell disease [215]. As well, reduced concentrations of plasma Gln have been reported in children with sickle cell disease [216], malaria [217, 218], and $\beta$ Thalassemia [219], which may be related to the growth impairment in height and weight also observed in these children.

Whereas previous data suggest positive physiological effects of Gln in sickle cell disease [214, 220, 221], Williams et al. [222] were the only group to have examined the role of Gln in children who have this disease (Table 7). They studied 27 children with sickle cell anemia (aged 5.2-17.9y) and observed that oral $\mathrm{Gln}(0.6 \mathrm{~g} / \mathrm{kg} / \mathrm{d})$ administration for 24 weeks was associated with a decrease in resting energy expenditure and increased body mass index, \% fat mass, muscle strength, and plasma concentrations of Gln compared to baseline. Subgroup analysis in underweight children showed an even greater decrease in resting energy expenditure which was not observed in normal weight sickle cell children. While it is possible that lowering resting energy expenditure with supplemental Gln may be an effective way to improve growth of children with sickle cell disease, the study design (i.e., lack of control group) underscores the need for large randomized controlled trials to test this hypothesis. Future studies should also focus on specific subgroups of sickle cell disease children, in whom Gln utilization may exceed endogenous Gln de novo synthesis or exogenous supply, resulting in Gln depletion, for example, when sickle cell disease children suffer from acute intercurrent illness or malnutrition.

3.7.3. Enteral Glutamine Supplementation in Children with Cystic Fibrosis. Cystic fibrosis in children is often associated with malnutrition and poor growth. Chronic malnutrition in combination with frequent infections that are linked with 
acute stress may lead to depletion of body Gln stores in cystic fibrosis. Compared with normal children, neutrophil Gln deficiency has been observed in cystic fibrosis children [223]. Moreover, cystic fibrosis children with severe mutations showed even lower neutrophil Gln content compared to those with mild mutations [223]. Because Gln is a free amino acid, Darmaun et al. [224, 225] hypothesized that Gln should be readily absorbed in cystic fibrosis children with malabsorption secondary to exocrine pancreatic insufficiency and maybe of potential benefit.

In this one trial [225] (Table 7), Leu and Gln kinetics were measured in the postabsorptive state in 9 prepubertal (age $9.6 \pm 0.5 \mathrm{y}$ ) children with cystic fibrosis who were either malnourished or short stature to test whether 4 weeks of oral Gln $(0.7 \mathrm{~g} / \mathrm{kg} / \mathrm{d})$, subcutaneous human recombinant growth hormone (rhGH; $0.3 \mathrm{mg} / \mathrm{kg} /$ week), or a combination of both agents (given in a random order) altered protein and Gln metabolism. Compared to baseline, 4-week oral Gln increased plasma Gln concentrations, whereas protein or Gln metabolism was not affected. In contrast, rhGH (as well as the combination of $\mathrm{Gln}+\mathrm{rhGH}$ ) reduced Leu oxidation and increased nonoxidative Leu disposal (an index of protein synthesis) with no change in Leu release from proteolysis. rhGH did not alter whole-body Gln metabolism (rate of Gln appearance, Gln release from proteolysis, or Gln de novo synthesis). Gln or rhGH given individually were associated with slight increases in lean body mass. Whereas Gln alone did not alter glucose metabolism, the increase in glucose and insulin/glucose ratio after rhGH treatment were blunted when rhGH was combined with oral Gln. Although oral Gln had no measurable protein anabolic effects in the fasting state in prepubertal cystic fibrosis children who are either malnourished or short, it is worth noting that Leu oxidation decreased in 6 out of 9 patients after Gln supplementation. Moreover, only 9 patients (of the12 recruited) completed the study. Hence, in addition to the limited statistical power, the wide intersubject variability of this heterogeneous population may have precluded the detection of Gln's effect.

Data from this one small study is not sufficient to determine whether Gln supplementation provides any benefit in cystic fibrosis children. Further study is needed. In addition to outcomes such as protein metabolism, glucose metabolism, and body composition, it may be worthwhile to test the effect of Gln on other outcomes, for example, immune function. Future studies should also focus on specific subgroups of this heterogeneous population, who may be Gln deficient, for example, children with severe cystic fibrosis mutations.

\subsubsection{Enteral Glutamine Supplementation in Children with} Type 1 Diabetes. Although Gln is thought to be a major source of carbon for gluconeogenesis [66], results are conflicting on whether Gln impairs or accelerates recovery from hypoglycaemia [226-228]. A recent randomized crossover pilot study in children with type 1 diabetes has investigated whether oral Gln could improve hypoglycaemia during exercise and overnight after exercise [229]. Ten adolescents (mean age $15.2 \pm 1.4 \mathrm{y}$ ) on insulin pumps were randomized to receive a drink containing Gln or placebo preexercise and at bedtime $(0.25 \mathrm{~g} / \mathrm{kg} / \mathrm{dose})$. Blood glucose was monitored hourly overnight. Fasting plasma Gln and ammonia concentrations were measured the following morning $16 \mathrm{~h}$ postexercise. Subjects returned within 3 weeks for an identical study with the reverse treatment. Blood glucose concentrations showed a similar \% drop from baseline during exercise in Gln and placebo groups. Although a comparable number of subjects developed hypoglycaemia during exercise on Gln or placebo, postexercise overnight hypoglycaemia was more frequent after Gln than after placebo ( $\leq 70 \mathrm{mg} / \mathrm{dL}$ : Gln, 19\%; placebo, $15 \% ; P<0.05 ; \leq 60 \mathrm{mg} / \mathrm{dL}: \mathrm{Gln}, 7.7 \%$; placebo, $3.6 \% ; P<0.05)$. The cumulative probability of overnight hypoglycaemia was increased on the Gln day versus the placebo day $(80 \%$ versus $50 \%, P<0.05)$. Whereas plasma Gln concentrations were higher than the morning after Gln administration as compared with placebo $(316 \mu \mathrm{mol} / \mathrm{L}$ versus $200 \mu \mathrm{mol} / \mathrm{L}, P<0.001)$, plasma ammonia concentrations were similar. This pilot data suggests that Gln supplementation increases the likelihood of postexercise overnight hypoglycaemia in adolescents with type 1 diabetes. Results, however, are limited given the small sample size and lack of direct measurement of insulin sensitivity. Further study is needed in larger numbers of children with type 1 diabetes to determine whether Gln affects peripheral or hepatic insulin sensitivity.

\section{Conclusions}

4.1. Premature Neonates. Although parenteral Gln appears to have a protein-sparing effect in premature infants of LBW $[80,105]$, randomized trials and a meta-analysis of 7 high quality trials cannot confirm any consistent benefit(s) of enteral or parenteral Gln on clinical outcomes (e.g., mortality, length of stay, feeding tolerance, infections/sepsis, NEC, ventilator use, growth, or neurological sequelae) [99, $100,102,107,111,113,129]$. Further, the beneficial effects of parenteral Gln on protein metabolism were not reported with enteral Gln supplementation [125, 127], likely because the majority of enteral Gln is used in first pass in premature infants [126]. Although several high quality trials have studied the effects of enteral and parenteral Gln in premature neonates, results remain indeterminate. There are a number of explanations for this. Firstly, the choice of clinically relevant outcomes (e.g., rare events, like mortality) that are not influenced by other factors is challenging in a population of infants with rapidly changing clinical status. Furthermore, the differences in nutritional support regimens; different effects of enteral versus parenteral Gln supplementation could also contribute to the conflicting results. In addition to the route of administration (enteral versus parenteral), differences in Gln dose, supplement duration, studies varied with respect to initiation, advancement, and tapering of parenteral amino acids as well as the total daily intake. This in combination with the different practices for introducing or withholding EN and the variable breast milk intake limits comparisons between studies and could represent sources of confounding within a particular study. For example, advancement of amino acids (and hence Gln) may be less aggressive in sicker infants, the subgroup that may be 
more likely to benefit from exogenous Gln. Finally, the heterogeneous study population of premature neonates with different gestational age, birth weight, and varying degrees of acute illness may also affect outcome.

4.2. Older Infants and Children with Disease. In older infants and children with disease, fewer high-quality randomized trials have studied the effects of supplemental Gln in any one specific population. In infants with surgical gastrointestinal disease, data from 2 randomized trials and a meta-analysis are insufficient to determine whether enteral or parenteral Gln confers clinically significant benefits (feeding tolerance or intestinal permeability) [130-132]. Apart from this one trial [131], the effects of parenteral Gln supplementation have not been studied in older children with disease. In children suffering from diarrhea or malnutrition, results from 6 randomized trials are conflicting regarding the efficacy of oral Gln in the treatment of diarrheal disease or in improving intestinal barrier function or growth [160162, 167-169]. In pediatric cancer patients undergoing chemotherapy, autologous BMT, and HSCT, results from 3 randomized trials suggest that oral Gln may reduce the severity and duration of oral mucositis [178-180]. However, preliminary studies in children with solid tumors are conflicting $[181,182]$. Finally in DMD children, oral Gln inhibits whole-body proteolysis but does not appear to improve muscle strength or function (based on results from 3 small randomized trials) $[205,206,209]$.

Studies in other childhood diseases are limited. In older children with gastrointestinal disease, firm conclusions cannot be made from 1 small randomized trial on the efficacy of enteral Gln on remission rates in pediatric patients with active Crohn's disease [148]. Furthermore, there is a lack of good quality data specific to pediatric patients with SBS to suggest any benefit of supplemental Gln in promoting intestinal adaptation, since studies are limited to case series [140-142]. Except for 1 small randomized trial in severely burned children showing no beneficial effects of enteral Gln on whole-body protein accretion [190], the 2 trials in pediatric and adult patients with severe burns/trauma had significant methodological limitations (high risk of bias) $[195,196]$. And insufficient evidence is available to confer any beneficial effect(s) of Gln supplementation in chronic diseases of childhood. Other than one small randomized crossover in diabetic adolescents [229], data are limited to time series studies in cystic fibrosis and sickle cell anemia [222, 225].

Given the conflicting results (e.g., in premature infants) and insufficient data in other childhood conditions, the routine use of supplemental Gln cannot be recommended in any one pediatric population as a whole. It seems that the benefits of Gln supplementation are limited to specific subgroups of pediatric patients who may suffer from Gln deficiency, whereby Gln utilization exceeds the body's synthetic capacity or exogenous supply. Although mechanisms of Gln action have been proposed, there is still a need for fundamental research to better define the role of Gln in different life stages of childhood and to determine how Gln modulates cell-specific functions during health and disease processes.
A better understanding of the mechanisms of Gln will help to eventually identify the subpopulations of pediatric patients for which Gln may (or may not) be beneficial. Given the abundant evidence demonstrating safety in all conditions studied so far, eventual evaluation in specific subgroups of children is warranted. However, the methodological issues noted from previous trials should be seriously considered in any future large randomized controlled trial involving Gln supplementation in sick children.

\section{Conflict of Interests}

The authors had no conflict of interests to report.

\section{Acknowledgments}

This research is sponsored by the Assistance PubliqueHôpitaux de Paris and supported by a grant from the Programme Hospitalier de Recherche Clinique National 2003 (to RH) and by Les Fonds de la Recherche en Santé Québec PhD Training Award (to EM) and Le Prix de Nutrition de la Fédération Association Nationale pour les Traitements A Domicile, les Innovations et la Recherche awarded by La Société Francophone de Nutrition Entérale et Parentérale (to EM).

\section{References}

[1] J. Bergstrom, P. Furst, L. O. Noree, and E. Vinnars, "Intracellular free amino acid concentration in human muscle tissue," Journal of Applied Physiology, vol. 36, no. 6, pp. 693-697, 1974.

[2] H. Eagle, V. I. Oyama, M. Levy, C. L. Horton, and R. Fleischman, "The growth response of mammalian cells in tissue culture to L-glutamine and L-glutamic acid," Journal of Biological Chemistry, vol. 218, no. 2, pp. 607-616, 1956.

[3] E. A. Newsholme, B. Crabtree, and M. S. M. Ardawi, "Glutamine metabolism in lymphocytes: its biochemical, physiological and clinical importance," Quarterly Journal of Experimental Physiology, vol. 70, no. 4, pp. 473-489, 1985.

[4] J. Neu, "Glutamine in the fetus and critically III low birth weight neonate: metabolism and mechanism of action," Journal of Nutrition, vol. 131, no. 9, supplement, pp. 2585S2589S, 2001.

[5] G. C. Ligthart-Melis, M. C. G. Van De Poll, P. G. Boelens, C. H. C. Dejong, N. E. P. Deutz, and P. A. M. Van Leeuwen, "Glutamine is an important precursor for de novo synthesis of arginine in humans," American Journal of Clinical Nutrition, vol. 87, no. 5, pp. 1282-1289, 2008.

[6] C. Duggan, J. Gannon, and W. Allan Walker, "Protective nutrients and functional foods for the gastrointestinal tract," American Journal of Clinical Nutrition, vol. 75, no. 5, pp. 789808, 2002.

[7] H. G. Windmueller and A. E. Spaeth, "Respiratory fuels and nitrogen metabolism in vivo in small intestine of fed rats. Quantitative importance of glutamine, glutamate, and aspartate," Journal of Biological Chemistry, vol. 255, no. 1, pp. 107-112, 1980.

[8] S. Rapoport, J. Rost, and M. Schultze, "Glutamine and glutamate as respiratory substrates of rabbit reticulocytes," European Journal of Biochemistry, vol. 23, no. 1, pp. 166-170, 1971. 
[9] D. Darmaun, D. E. Matthews, J. F. Desjeux, and D. M. Bier, "Glutamine and glutamate nitrogen exchangeable pools in cultured fibroblasts: a stable isotope study," Journal of Cellular Physiology, vol. 134, no. 1, pp. 143-148, 1988.

[10] J. M. Lacey and D. W. Wilmore, "Is glutamine a conditionally essential amino acid?" Nutrition Reviews, vol. 48, no. 8, pp. 297-309, 1990.

[11] N. Nurjhan, A. Bucci, G. Perriello et al., "Glutamine: a major gluconeogenic precursor and vehicle for interorgan carbon transport in man," Journal of Clinical Investigation, vol. 95, no. 1, pp. 272-277, 1995.

[12] G. Mithieux, "New data and concepts on glutamine and glucose metabolism in the gut," Current Opinion in Clinical Nutrition and Metabolic Care, vol. 4, no. 4, pp. 267-271, 2001.

[13] T. C. Welbourne, D. Childress, and G. Givens, "Renal regulation of interorgan glutamine flow in metabolic acidosis," American Journal of Physiology, vol. 251, no. 5, pp. R859R866, 1986.

[14] R. Curi, C. J. Lagranha, S. Q. Doi et al., "Molecular mechanisms of glutamine action," Journal of Cellular Physiology, vol. 204, no. 2, pp. 392-401, 2005.

[15] J. Neu, V. Shenoy, and R. Chakrabarti, "Glutamine nutrition and metabolism: where do we go from here?" FASEB Journal, vol. 10, no. 8, pp. 829-837, 1996.

[16] B. I. Labow, S. F. Abcouwer, C. M. Lin, and W. W. Souba, "Glutamine synthetase expression in rat lung is regulated by protein stability," American Journal of Physiology, vol. 275, no. 5, pp. L877-L886, 1998.

[17] B. I. Labow, W. W. Souba, and S. F. Abcouwer, "Glutamine synthetase expression in muscle is regulated by transcriptional and posttranscriptional mechanisms," American Journal of Physiology, vol. 276, no. 6, pp. E1136-E1145, 1999.

[18] B. I. Labow, W. W. Souba, and S. F. Abcouwer, "Mechanisms governing the expression of the enzymes of glutamine metabolism-glutaminase and glutamine synthetase," Journal of Nutrition, vol. 131, no. 9, supplement, pp. 2467S-2474S, 2001.

[19] J. Haberle, B. Gorg, F. Rutsch et al., "Congenital glutamine deficiency with glutamine synthetase mutations," New England Journal of Medicine, vol. 353, no. 18, pp. 1926-1933, 2005.

[20] J. Neu, V. DeMarco, and N. Li, "Glutamine: clinical applications and mechanisms of action," Current opinion in clinical nutrition and metabolic care, vol. 5, no. 1, pp. 69-75, 2002.

[21] P. E. Wischmeyer, "Glutamine: mode of action in critical illness," Critical Care Medicine, vol. 35, no. 9, pp. S541-S544, 2007.

[22] G. Wu, Y. Z. Fang, S. Yang, J. R. Lupton, and N. D. Turner, "Glutathione metabolism and its implications for health," Journal of Nutrition, vol. 134, no. 3, pp. 489-492, 2004.

[23] E. Roth, R. Oehler, N. Manhart et al., "Regulative potential of glutamine-relation to glutathione metabolism," Nutrition, vol. 18, no. 3, pp. 217-221, 2002.

[24] J. Wernerman, J. L. Luo, and F. Hammarqvist, "Glutathione status in critically-ill patients: possibility of modulation by antioxidants," Proceedings of the Nutrition Society, vol. 58, no. 3, pp. 677-680, 1999.

[25] S. Thomas, R. Prabhu, and K. A. Balasubramanian, "Surgical manipulation of the intestine and distant organ damageprotection by oral glutamine supplementation," Surgery, vol. 137, no. 1, pp. 48-55, 2005.

[26] P. E. Wischmeyer, D. Jayakar, U. Williams et al., "Single dose of glutamine enhances myocardial tissue metabolism, glutathione content, and improves myocardial function after ischemia-reperfusion injury," Journal of Parenteral and Enteral Nutrition, vol. 27, no. 6, pp. 396-403, 2003.

[27] R. Babu, S. Eaton, D. P. Drake, L. Spitz, and A. Pierro, "Glutamine and glutathione counteract the inhibitory effects of mediators of sepsis in neonatal hepatocytes," Journal of Pediatric Surgery, vol. 36, no. 2, pp. 282-286, 2001.

[28] U. B. Flaring, O. E. Rooyackers, J. Wernerman, and F. Hammarqvist, "Glutamine attenuates post-traumatic glutathione depletion in human muscle," Clinical Science, vol. 104, no. 3, pp. 275-282, 2003.

[29] R. Oehler and E. Roth, "Regulative capacity of glutamine," Current Opinion in Clinical Nutrition and Metabolic Care, vol. 6, no. 3, pp. 277-282, 2003.

[30] E. Kefaloyianni, C. Gaitanaki, and I. Beis, "ERK1/2 and p38-MAPK signalling pathways, through MSK1, are involved in NF- $\kappa \mathrm{B}$ transactivation during oxidative stress in skeletal myoblasts," Cellular Signalling, vol. 18, no. 12, pp. 2238-2251, 2006.

[31] S. K. Powers, A. N. Kavazis, and J. M. McClung, "Oxidative stress and disuse muscle atrophy," Journal of Applied Physiology, vol. 102, no. 6, pp. 2389-2397, 2007.

[32] M. E. Tischler, "Is regulation of proteolysis associated with redox-state changes in rat skeletal muscle?" Biochemical Journal, vol. 192, no. 3, pp. 963-966, 1980.

[33] J. M. Fagan and M. E. Tischler, "Reduction-oxidation state and protein degradation in skeletal muscle of fasted and refed rats," Journal of Nutrition, vol. 116, no. 10, pp. 2028-2033, 1986.

[34] R. W. Jackman and S. C. Kandarian, "The molecular basis of skeletal muscle atrophy," American Journal of Physiology, vol. 287, no. 4, pp. C834-C843, 2004.

[35] E. Mok, B. Constantin, F. Favreau et al., "L-glutamine administration reduces oxidized glutathione and MAP kinase signaling in dystrophic muscle of $\mathrm{mdx}$ mice," Pediatric Research, vol. 63, no. 3, pp. 268-273, 2008.

[36] P. E. Wischmeyer, J. Riehm, K. D. Singleton et al., "Glutamine attenuates tumor necrosis factor- $\alpha$ release and enhances heat shock protein 72 in human peripheral blood mononuclear cells," Nutrition, vol. 19, no. 1, pp. 1-6, 2003.

[37] P. E. Wischmeyer, M. Kahana, R. Wolfson, H. Ren, M. M. Musch, and E. B. Chang, "Glutamine induces heat shock protein and protects against endotoxin shock in the rat," Journal of Applied Physiology, vol. 90, no. 6, pp. 2403-2410, 2001.

[38] M. Coëffier, F. L. Pessot, A. Leplingard et al., "Acute enteral glutamine infusion enhances heme oxygenase-1 expression in human duodenal mucosal," Journal of Nutrition, vol. 132, no. 9, pp. 2570-2573, 2002.

[39] T. R. Ziegler, L. G. Ogden, K. D. Singleton et al., "Parenteral glutamine increases serum heat shock protein 70 in critically ill patients," Intensive Care Medicine, vol. 31, no. 8, pp. 10791086, 2005.

[40] R. Oehler, E. Pusch, P. Dungel et al., "Glutamine depletion impairs cellular stress response in human leucocytes," British Journal of Nutrition, vol. 87, no. 1, pp. S17-S21, 2002.

[41] K. D. Singleton and P. E. Wischmeyer, "Glutamine's protection against sepsis and lung injury is dependent on heat shock protein 70 expression," American Journal of Physiology, vol. 292, no. 5, pp. R1839-R1845, 2007.

[42] Y. Hayashi, Y. Sawa, N. Fukuyama, H. Nakazawa, and H. Matsuda, "Preoperative glutamine administration induces heatshock protein 70 expression and attenuates cardiopulmonary bypass-induced inflammatory response by regulating nitric 
oxide synthase activity," Circulation, vol. 106, no. 20, pp. 2601-2607, 2002.

[43] R. Marion, M. Coëffier, A. Leplingard, L. Favennec, P. Ducrotte, and P. Dechelotte, "Cytokine-stimulated nitric oxide production and inducible NO-synthase mRNA level in human intestinal cells: lack of modulation by glutamine," Clinical Nutrition, vol. 22, no. 6, pp. 523-528, 2003.

[44] H. T. Papaconstantinou, D. H. Chung, W. Zhang et al., "Prevention of mucosal atrophy: role of glutamine and caspases in apoptosis in intestinal epithelial cells," Journal of Gastrointestinal Surgery, vol. 4, no. 4, pp. 416-423, 2000.

[45] R. Exner, G. Weingartmann, M. M. Eliasen et al., "Glutamine deficiency renders human monocytic cells more susceptible to specific apoptosis triggers," Surgery, vol. 131, no. 1, pp. 7580, 2002.

[46] Y. G. Ko, E. K. Kim, T. Kim et al., "Glutamine-dependent antiapoptotic interaction of human glutaminyl-tRNA synthetase with apoptosis signal-regulating kinase 1," Journal of Biological Chemistry, vol. 276, no. 8, pp. 6030-6036, 2001.

[47] T. C. Pithon-Curi, R. I. Schumacher, J. J. S. Freitas et al., "Glutamine delays spontaneous apoptosis in neutrophils," American Journal of Physiology, vol. 284, no. 6, pp. C1355C1361, 2003.

[48] W. K. Chang, K. D. Yang, H. Chuang, J. T. Jan, and M. F. Shaio, "Glutamine protects activated human $\mathrm{T}$ cells from apoptosis by up-regulating glutathione and Bcl-2 levels," Clinical Immunology, vol. 104, no. 2, pp. 151-160, 2002.

[49] G. C. Melis, N. T. Wengel, P. G. Boelens, and P. A. M. Van Leeuwen, "Glutamine: recent developments in research on the clinical significance of glutamine," Current Opinion in Clinical Nutrition and Metabolic Care, vol. 7, no. 1, pp. 5970, 2004.

[50] S. D. Smith, M. A. Cardona, S. A. Wishnev, A. G. Kurkchubasche, and M. I. Rowe, "Unique characteristics of the neonatal intestinal mucosal barrier," Journal of Pediatric Surgery, vol. 27, no. 3, pp. 333-338, 1992.

[51] N. Li, K. Liboni, M. Z. Fang et al., "Glutamine decreases lipopolysaccharide-induced intestinal inflammation in infant rats," American Journal of Physiology, vol. 286, no. 6, pp. G914-G921, 2004.

[52] D. G. Burrin, R. J. Shulman, C. Langston, and M. C. Storm, "Supplemental alanylglutamine, organ growth, and nitrogen metabolism in neonatal pigs fed by total parenteral nutrition," Journal of Parenteral and Enteral Nutrition, vol. 18, no. 4, pp. 313-319, 1994.

[53] P. Panigrahi, I. H. Gewolb, P. Bamford, and K. Horvath, "Role of glutamine in bacterial transcytosis and epithelial cell injury," Journal of Parenteral and Enteral Nutrition, vol. 21, no. 2, pp. 75-80, 1997.

[54] M. Akisu, M. Baka, A. Huseyinov, and N. Kultursay, "The role of dietary supplementation with L-glutamine in inflammatory mediator release and intestinal injury in hypoxia/reoxygenation-induced experimental necrotizing enterocolitis," Annals of Nutrition and Metabolism, vol. 47, no. 6, pp. 262-266, 2003.

[55] A. Dilsiz, I. Çiftçi, T. M. Aktan, M. Gürbilek, and E. Karagözoğlu, "Enteral glutamine supplementation and dexamethasone attenuate the local intestinal damage in rats with experimental necrotizing enterocolitis," Pediatric Surgery International, vol. 19, no. 8, pp. 578-582, 2003.

[56] C. Domeneghini, A. Di Giancamillo, G. Bosi, and S. Arrighi, "Can nutraceuticals affect the structure of intestinal mucosa? Qualitative and quantitative microanatomy in L-glutamine diet-supplemented weaning piglets," Veterinary Research Communications, vol. 30, no. 3, pp. 331-342, 2006.

[57] J. Wang, L. Chen, P. Li et al., "Gene expression is altered in piglet small intestine by weaning and dietary glutamine supplementation," Journal of Nutrition, vol. 138, no. 6, pp. 1025-1032, 2008.

[58] G. Wu, S. A. Meier, and D. A. Knabe, "Dietary glutamine supplementation prevents jejunal atrophy in weaned pigs," Journal of Nutrition, vol. 126, no. 10, pp. 2578-2584, 1996.

[59] B. Potsic, N. Holliday, P. Lewis, D. Samuelson, V. DeMarco, and J. Neu, "Glutamine supplementation and deprivation: effect on artificially reared rat small intestinal morphology," Pediatric Research, vol. 52, no. 3, pp. 430-436, 2002.

[60] N. Li, P. Lewis, D. Samuelson, K. Liboni, and J. Neu, "Glutamine regulates Caco-2 cell tight junction proteins," American Journal of Physiology, vol. 287, no. 3, pp. G726G733, 2004.

[61] Y. Huang, N. Li, K. Liboni, and J. Neu, "Glutamine decreases lipopolysaccharide-induced IL-8 production in Caco-2 cells through a non-NF- $\kappa$ B p50 mechanism," Cytokine, vol. 22, no. 3-4, pp. 77-83, 2003.

[62] K. C. Liboni, N. Li, P. O. Scumpia, and J. Neu, "Glutamine modulates LPS-induced IL-8 production through $\mathrm{I} \kappa \mathrm{B} / \mathrm{NF}-\kappa \mathrm{B}$ in human fetal and adult intestinal epithelium," Journal of Nutrition, vol. 135, no. 2, pp. 245-251, 2005.

[63] K. Liboni, N. Li, and J. Neu, "Mechanism of glutaminemediated amelioration of lipopolysaccharide-induced IL-8 production in Caco-2 cells," Cytokine, vol. 26, no. 2, pp. 5765, 2004.

[64] C. L. Yeh, C. S. Hsu, S. L. Yeh, and W. J. Chen, "Dietary glutamine supplementation modulates Th1/Th2 cytokine and interleukin-6 expressions in septic mice," Cytokine, vol. 31, no. 5, pp. 329-334, 2005.

[65] J. L. Lelli Jr., L. L. Becks, M. I. Dabrowska, and D. B. Hinshaw, "ATP converts necrosis to apoptosis in oxidantinjured endothelial cells," Free Radical Biology and Medicine, vol. 25, no. 6, pp. 694-702, 1998.

[66] R. G. Hankard, M. W. Haymond, and D. Darmaun, "Role of glutamine as a glucose precursor in fasting humans," Diabetes, vol. 46, no. 10, pp. 1535-1541, 1997.

[67] T. Bongers, R. D. Griffiths, and A. McArdle, "Exogenous glutamine: the clinical evidence," Critical Care Medicine, vol. 35, no. 9, supplement, pp. S545-S552, 2007.

[68] C. Li, C. Buettger, J. Kwagh et al., "A signaling role of glutamine in insulin secretion," Journal of Biological Chemistry, vol. 279, no. 14, pp. 13393-13401, 2004.

[69] P. O. Prada, S. M. Hirabara, C. T. D. Souza et al., "Lglutamine supplementation induces insulin resistance in adipose tissue and improves insulin signalling in liver and muscle of rats with diet-induced obesity," Diabetologia, vol. 50, no. 9, pp. 1949-1959, 2007.

[70] X. Zhou and J. R. Thompson, "Regulation of protein turnover by glutamine in heat-shocked skeletal myotubes," Biochimica et Biophysica Acta, vol. 1357, no. 2, pp. 234-242, 1997.

[71] M. Kadowaki and T. Kanazawa, "Amino acids as regulators of proteolysis," Journal of Nutrition, vol. 133, no. 6, supplement, pp. 2052S-2056S, 2003.

[72] S. C. Kalhan and J. M. Edmison, "Effect of intravenous amino acids on protein kinetics in preterm infants," Current Opinion in Clinical Nutrition and Metabolic Care, vol. 10, no. 1, pp. 69-74, 2007.

[73] Y. Xia, H. Y. Wen, M. E. Young, P. H. Guthrie, H. Taegtmeyer, and R. E. Kellems, "Mammalian target of rapamycin and 
protein kinase A signaling mediate the cardiac transcriptional response to glutamine," Journal of Biological Chemistry, vol. 278, no. 15, pp. 13143-13150, 2003.

[74] L. Deldicque, C. Sanchez Canedo, S. Horman et al., "Antagonistic effects of leucine and glutamine on the mTOR pathway in myogenic C2C12 cells," Amino Acids, vol. 35, no. 1, pp. 147-155, 2008.

[75] E. Ogier-Denis, S. Pattingre, J. El Benna, and P. Codogno, "Erk1/2-dependent phosphorylation of $\mathrm{G} \alpha$-interacting protein stimulates its GTPase accelerating activity and autophagy in human colon cancer cells," Journal of Biological Chemistry, vol. 275, no. 50, pp. 39090-39095, 2000.

[76] S. Y. Low, M. J. Rennie, and P. M. Taylor, "Signaling elements involved in amino acid transport responses to altered muscle cell volume," FASEB Journal, vol. 11, no. 13, pp. 1111-1117, 1997.

[77] D. Haussinger, F. Schliess, F. Dombrowski, and S. Vom Dahl, "Involvement of p38(MAPK) in the regulation of proteolysis by liver cell hydration," Gastroenterology, vol. 116, no. 4, pp. 921-935, 1999.

[78] M. Coëffier, S. Claeyssens, B. Hecketsweiler, A. Lavoinne, P. Ducrotté, and P. Déchelotte, "Enteral glutamine stimulates protein synthesis and decreases ubiquitin mRNA level in human gut mucosa," American Journal of Physiology, vol. 285, no. 2, pp. G266-G273, 2003.

[79] Y. F. Huang, Y. Wang, and M. Watford, "Glutamine directly downregulates glutamine synthetase protein levels in mouse C2C12 skeletal muscle myotubes," Journal of Nutrition, vol. 137, no. 6, pp. 1357-1362, 2007.

[80] S. C. Kalhan, P. S. Parimi, L. L. Gruca, and R. W. Hanson, "Glutamine supplement with parenteral nutrition decreases whole body proteolysis in low birth weight infants," Journal of Pediatrics, vol. 146, no. 5, pp. 642-647, 2005.

[81] M. M. Kadrofske, P. S. Parimi, L. L. Gruca, and S. C. Kalhan, "Effect of intravenous amino acids on glutamine and protein kinetics in low-birth-weight preterm infants during the immediate neonatal period," American Journal of Physiology, vol. 290, no. 4, pp. E622-E630, 2006.

[82] P. S. Parimi, M. M. Kadrofske, L. L. Gruca, R. W. Hanson, and S. C. Kalhan, "Amino acids, glutamine, and protein metabolism in very low birth weight infants," Pediatric Research, vol. 58, no. 6, pp. 1259-1264, 2005.

[83] F. C. Battaglia and T. R. H. Regnault, "Placental transport and metabolism of amino acids," Placenta, vol. 22, no. 2-3, pp. 145-161, 2001.

[84] A. Pierro, "Basic science review: metabolism and nutritional support in the surgical neonate," Journal of Pediatric Surgery, vol. 37, no. 6, pp. 811-822, 2002.

[85] J. Neu, "Glutamine supplements in premature infants: why and how," Journal of Pediatric Gastroenterology and Nutrition, vol. 37, no. 5, pp. 533-535, 2003.

[86] Y. Huang, X. M. Shao, and J. Neu, "Immunonutrients and neonates," European Journal of Pediatrics, vol. 162, no. 3, pp. 122-128, 2003.

[87] F. Pohlandt, "Plasma amino acid concentrations in newborn infants breast-fed ad libitum," Journal of Pediatrics, vol. 92, no. 4, pp. 614-616, 1978.

[88] R. M. Becker, G. Wu, J. A. Galanko et al., "Reduced serum amino acid concentrations in infants with necrotizing enterocolitis," Journal of Pediatrics, vol. 137, no. 6, pp. 785793, 2000.

[89] K. M. Bernt and W. A. Walker, "Human milk as a carrier of biochemical messages," Acta Paediatrica, vol. 88, no. 430, supplement, pp. 27-41, 1999.
[90] B. R. Vohr, B. B. Poindexter, A. M. Dusick et al., "Beneficial effects of breast milk in the neonatal intensive care unit on the developmental outcome of extremely low birth weight infants at 18 months of age," Pediatrics, vol. 118, no. 1, pp. e115-e123, 2006.

[91] B. R. Vohr, B. B. Poindexter, A. M. Dusick et al., "Persistent beneficial effects of breast milk ingested in the neonatal intensive care unit on outcomes of extremely low birth weight infants at 30 months of age," Pediatrics, vol. 120, no. 4, pp. e953-e959, 2007.

[92] C. Agostoni, B. Carratu, C. Boniglia, E. Riva, and E. Sanzini, "Free amino acid content in standard infant formulas: comparison with human milk," Journal of the American College of Nutrition, vol. 19, no. 4, pp. 434-438, 2000.

[93] T. A. Davis, H. V. Nguyen, R. Garcia-Bravo et al., "Amino acid composition of human milk is not unique," Journal of Nutrition, vol. 124, no. 7, pp. 1126-1132, 1994.

[94] C. Y. Yeung, H. C. Lee, S. P. Lin, Y. C. Yang, F. Y. Huang, and C. K. Chuang, "Negative effect of heat sterilization on the free amino acid concentrations in infant formula," European Journal of Clinical Nutrition, vol. 60, no. 1, pp. 136-141, 2006.

[95] C. Agostoni, B. Carratù, C. Boniglia, A. M. Lammardo, E. Riva, and E. Sanzini, "Free glutamine and glutamic acid increase in human milk through a three-month lactation period," Journal of Pediatric Gastroenterology and Nutrition, vol. 31, no. 5, pp. 508-512, 2000.

[96] F. Jochum, S. Colling, P. Meinardus, B. Alteheld, P. Stehle, and C. Fusch, "Total glutamine content in human milk is not influenced by gestational age," Acta Paediatrica, International Journal of Paediatrics, vol. 95, no. 8, pp. 985-990, 2006.

[97] G. Harzer, V. Franzke, and J. G. Bindels, "Human milk nonprotein nitrogen components: changing patterns of free amino acids and urea in the course of early lactation," American Journal of Clinical Nutrition, vol. 40, no. 2, pp. 303309, 1984.

[98] M. Pamblanco, M. Portoles, C. Paredes, A. Ten, and J. Comin, "Free amino acids in preterm and term milk from mothers delivering appropriate- or small-for-gestational-age infants," American Journal of Clinical Nutrition, vol. 50, no. 4, pp. 778781, 1989.

[99] J. M. Lacey, J. B. Crouch, K. Benfell et al., "The effects of glutamine-supplemented parenteral nutrition in premature infants," Journal of Parenteral and Enteral Nutrition, vol. 20, no. 1, pp. 74-80, 1996.

[100] S. W. Thompson, B. G. McClure, and T. R. J. Tubman, "A randomized, controlled trial of parenteral glutamine in ill, very low birth-weight neonates," Journal of Pediatric Gastroenterology and Nutrition, vol. 37, no. 5, pp. 550-553, 2003.

[101] Z. H. Li, D. H. Wang, and M. Dong, "Effect of parenteral glutamine supplementation in premature infants," Chinese Medical Journal, vol. 120, no. 2, pp. 140-144, 2007.

[102] B. B. Poindexter, R. A. Ehrenkranz, B. J. Stoll et al., "Parenteral glutamine supplementation does not reduce the risk of mortality or late-onset sepsis in extremely low birth weight infants," Pediatrics, vol. 113, no. 5 I, pp. 1209-1215, 2004.

[103] B. B. Poindexter, R. A. Ehrenkranz, B. J. Stoll et al., "Effect of parenteral glutamine supplementation on plasma amino acid concentrations in extremely low-birth-weight infants," American Journal of Clinical Nutrition, vol. 77, no. 3, pp. 737743, 2003.

[104] Y. Wang, Y. X. Tao, W. Cai, Q. Y. Tang, Y. Feng, and J. Wu, "Protective effect of parenteral glutamine supplementation 
on hepatic function in very low birth weight infants," Clinical Nutrition, vol. 29, no. 3, pp. 307-311, 2010.

[105] C. Des Robert, O. L. Bacquer, H. Piloquet, J. C. Roze, and D. Darmaun, "Acute effects of intravenous glutamine supplementation on protein metabolism in very low birth weight infants: a stable isotope study," Pediatric Research, vol. 51, no. 1, pp. 87-93, 2002.

[106] P. J. Thureen, D. Melara, P. V. Fennessey, and W. W. Hay Jr., "Effect of low versus high intravenous amino acid intake on very low birth weight infants in the early neonatal period," Pediatric Research, vol. 53, no. 1, pp. 24-32, 2003.

[107] J. Neu, J. C. Roig, W. H. Meetze et al., "Enteral glutamine supplementation for very low birth weight infants decreases morbidity," Journal of Pediatrics, vol. 131, no. 5, pp. 691-699, 1997.

[108] J. C. Roig, W. H. Meetze, N. Auestad et al., "Enteral glutamine supplementation for the very low birthweight infant: plasma amino acid concentrations," Journal of Nutrition, vol. 126, no. 4, supplement, pp. 1115S-1120S, 1996.

[109] M. J. Dallas, D. Bowling, J. C. Roig, N. Auestad, and J. Neu, "Enteral glutamine supplementation for very-lowbirth-weight infants decreases hospital costs," Journal of Parenteral and Enteral Nutrition, vol. 22, no. 6, pp. 352-356, 1998.

[110] E. Barbosa, E. A. Moreira, J. E. Goes, and J. Faintuch, "Pilot study with a glutamine-supplemented enteral formula in critically ill infants," Revista do Hospital das Clínicas, vol. 54, no. 1, pp. 21-24, 1999.

[111] P. Vaughn, P. Thomas, R. Clark, and J. Neu, "Enteral glutamine supplementation and morbidity in low birth weight infants," Journal of Pediatrics, vol. 142, no. 6, pp. 662668, 2003.

[112] A. Mercier, D. Eurin, V. Poulet-Young, S. Marret, and P. Dechelotte, "Effect of enteral supplementation with glutamine on mesenteric blood flow in premature neonates," Clinical Nutrition, vol. 22, no. 2, pp. 133-137, 2003.

[113] A. Van Den Berg, R. M. Van Elburg, E. A. M. Westerbeek, J. W. R. Twisk, and W. P. F. Fetter, "Glutamine-enriched enteral nutrition in very-low-birth-weight infants and effects on feeding tolerance and infectious morbidity: a randomized controlled trial," American Journal of Clinical Nutrition, vol. 81, no. 6, pp. 1397-1404, 2005.

[114] A. Van Den Berg, R. M. Van Elburg, T. Teerlink, H. N. Lafeber, J. W. R. Twisk, and W. P. F. Fetter, "A randomized controlled trial of enteral glutamine supplementation in very low birth weight infants: plasma amino acid concentrations," Journal of Pediatric Gastroenterology and Nutrition, vol. 41, no. 1, pp. 66-71, 2005.

[115] A. van den Berg, R. M. van Elburg, E. A. M. Westerbeek et al., "The effect of glutamine-enriched enteral nutrition on intestinal microflora in very low birth weight infants: a randomized controlled trial," Clinical Nutrition, vol. 26, no. 4, pp. 430-439, 2007.

[116] A. Van Den Berg, W. P. F. Fetter, E. A. M. Westerbeek, I. M. Van Der Vegt, H. R. A. Van Der Molen, and R. M. Van Elburg, "The effect of glutamine-enriched enteral nutrition on intestinal permeability in very-low-birth-weight infants: a randomized controlled trial," Journal of Parenteral and Enteral Nutrition, vol. 30, no. 5, pp. 408-414, 2006.

[117] A. Van Den Berg, A. Van Zwol, H. A. Moll, W. P. F. Fetter, and R. M. Van Elburg, "Glutamine-enriched enteral nutrition in very low-birth-weight infants: effect on the incidence of allergic and infectious diseases in the first year of life,"
Archives of Pediatrics and Adolescent Medicine, vol. 161, no. 11, pp. 1095-1101, 2007.

[118] A. Van Zwol, H. A. Moll, W. P. F. Fetter, and R. M. Van Elburg, "Glutamine-enriched enteral nutrition in very low birthweight infants and allergic and infectious diseases at 6 years of age," Paediatric and Perinatal Epidemiology, vol. 25, no. 1, pp. 60-66, 2011.

[119] A. Van Zwol, A. Van Den Berg, E. E. S. Nieuwenhuis, J. W. R. Twisk, W. P. F. Fetter, and R. M. Van Elburg, "Cytokine profiles in 1-yr-old very low-birth-weight infants after enteral glutamine supplementation in the neonatal period," Pediatric Allergy and Immunology, vol. 20, no. 5, pp. 467-470, 2009.

[120] A. Van Den Berg, R. M. Van Elburg, L. Vermeij et al., "Cytokine responses in very low birth weight infants receiving glutamine-enriched enteral nutrition," Journal of Pediatric Gastroenterology and Nutrition, vol. 48, no. 1, pp. 94-101, 2009.

[121] A. Van Zwol, A. Van Den Berg, J. Knol, J. W. R. Twisk, W. P. F. Fetter, and R. M. Van Elburg, "Intestinal microbiota in allergic and nonallergic 1-year-old very low birth weight infants after neonatal glutamine supplementation," Acta Paediatrica, International Journal of Paediatrics, vol. 99, no. 12, pp. 1868-1874, 2010.

[122] A. Van Zwol, A. Van Den Berg, J. Huisman et al., "Neurodevelopmental outcomes of very low-birth-weight infants after enteral glutamine supplementation in the neonatal period," Acta Paediatrica, International Journal of Paediatrics, vol. 97, no. 5, pp. 562-567, 2008.

[123] A. Korkmaz, M. Yurdakök, Ş. Yiğit, and G. Tekinalp, "Longterm enteral glutamine supplementation in very low birth weight infants: effects on growth parameters," Turkish Journal of Pediatrics, vol. 49, no. 1, pp. 37-44, 2007.

[124] B. B. Poindexter, J. C. Langer, A. M. Dusick, and R. A. Ehrenkranz, "Early provision of parenteral amino acids in extremely low birth weight infants: relation to growth and neurodevelopmental outcome," Journal of Pediatrics, vol. 148, no. 3, pp. 300-305, 2006.

[125] D. Darmaun, J. C. Roig, N. Auestad, B. K. Sager, and J. Neu, "Glutamine metabolism in very low birth weight infants," Pediatric Research, vol. 41, no. 3, pp. 391-396, 1997.

[126] S. R. D. Van Der Schoor, H. Schierbeek, P. M. Bet et al., "Majority of dietary glutamine is utilized in first pass in preterm infants," Pediatric Research, vol. 67, no. 2, pp. 194199, 2010.

[127] P. S. Parimi, S. Devapatla, L. L. Gruca, S. B. Amini, R. W. Hanson, and S. C. Kalhan, "Effect of enteral glutamine or glycine on whole-body nitrogen kinetics in very-low-birthweight infants," American Journal of Clinical Nutrition, vol. 79, no. 3, pp. 402-409, 2004.

[128] P. S. Parimi, S. Devapatla, L. Gruca, A. M. O’Brien, R. W. Hanson, and S. C. Kalhan, "Glutamine and leucine nitrogen kinetics and their relation to urea nitrogen in newborn infants," American Journal of Physiology, vol. 282, no. 3, pp. E618-E625, 2002.

[129] T. R. Tubman, S. W. Thompson, and W. McGuire, "Glutamine supplementation to prevent morbidity and mortality in preterm infants," Cochrane Database of Systematic Reviews, no. 1, Article ID CD001457, 2008.

[130] C. Duggan, A. R. Stark, N. Auestad et al., "Glutamine supplementation in infants with gastrointestinal disease: a randomized, placebo-controlled pilot trial," Nutrition, vol. 20, no. 9, pp. 752-756, 2004.

[131] M. J. Albers, E. W. Steyerberg, F. W. J. Hazebroek et al., "Glutamine supplementation of parenteral nutrition does 
not improve intestinal permeability, nitrogen balance, or outcome in newborns and infants undergoing digestive-tract surgery: results from a double-blind, randomized, controlled trial," Annals of Surgery, vol. 241, no. 4, pp. 599-606, 2005.

[132] Z. Grover, R. Tubman, and W. McGuire, "Glutamine supplementation for young infants with severe gastrointestinal disease," Cochrane Database of Systematic Reviews, no. 1, Article ID CD005947, 2007.

[133] D. G. Burrin and T. A. Davis, "Proteins and amino acids in enteral nutrition," Current Opinion in Clinical Nutrition and Metabolic Care, vol. 7, no. 1, pp. 79-87, 2004.

[134] W. W. Hay Jr. and P. J. Thureen, "Early postnatal administration of intravenous amino acids to preterm, extremely low birth weight infants," Journal of Pediatrics, vol. 148, no. 3, pp. 291-294, 2006.

[135] K. Soondrum and R. Hinds, "Management of intestinal failure," Indian journal of pediatrics, vol. 73, no. 10, pp. 913918, 2006.

[136] T. A. Byrne, D. W. Wilmore, K. Iyer et al., "Growth hormone, glutamine, and an optimal diet reduces parenteral nutrition in patients with short bowel syndrome: a prospective, randomized, placebo-controlled, double-blind clinical trial," Annals of Surgery, vol. 242, no. 5, pp. 655-661, 2005.

[137] R. Hankard, O. Goulet, C. Ricour, M. Rongier, V. Colomb, and D. Darmaun, "Glutamine metabolism in children with short-bowel syndrome: a stable isotope study," Pediatric Research, vol. 36, no. 2, pp. 202-206, 1994.

[138] D. Brewster, R. Kukuruzovic, A. Haase, J. Bines, D. Francis, and D. Hill, "Short bowel syndrome, intestinal permeability and glutamine," Journal of Pediatric Gastroenterology and Nutrition, vol. 27, no. 5, pp. 614-616, 1998.

[139] C. Cukier, D. L. Waitzberg, V. C. Borges, M. L. Silva, J. Gama-Rodrigues, and H. W. Pinotti, "Clinical use of growth hormone and glutamine in short bowel syndrome," Revista do Hospital das Clínicas, vol. 54, no. 1, pp. 29-34, 1999.

[140] A. P. Ladd, J. L. Grosfeld, O. H. Pescovitz, and N. B. Johnson, "The effect of growth hormone supplementation on late nutritional independence in pediatric patients with short bowel syndrome," Journal of Pediatric Surgery, vol. 40, no. 2, pp. 442-445, 2005.

[141] Z. Weiming, L. Ning, and L. Jieshou, "Effect of recombinant human growth hormone and enteral nutrition on short bowel syndrome," Journal of Parenteral and Enteral Nutrition, vol. 28, no. 6, pp. 377-381, 2004.

[142] W. Zhu, N. Li, J. Ren, J. Gu, J. Jiang, and J. Li, "Rehabilitation therapy for short bowel syndrome," Chinese Medical Journal, vol. 115, no. 5, pp. 776-778, 2002.

[143] A. G. Thomas, V. Miller, F. Taylor, P. Maycock, C. M. Scrimgeour, and M. J. Rennie, "Whole body protein turnover in childhood Crohn's disease," Gut, vol. 33, no. 5, pp. 675677, 1992.

[144] M. Vicario, C. Amat, M. Rivero, M. Moretó, and C. Pelegrí, "Dietary glutamine affects mucosal functions in rats with mild DSS-induced colitis," Journal of Nutrition, vol. 137, no. 8, pp. 1931-1937, 2007.

[145] B. Sido, C. Seel, A. Hochlehnert, R. Breitkreutz, and W. Droge, "Low intestinal glutamine level and low glutaminase activity in Crohn's disease: a rational for glutamine supplementation?" Digestive diseases and sciences, vol. 51, no. 12, pp. 2170-2179, 2006.

[146] T. Fujita and K. Sakurai, "Efficacy of glutamine-enriched enteral nutrition in an experimental model of mucosal ulcerative colitis," British Journal of Surgery, vol. 82, no. 6, pp. 749-751, 1995.
[147] E. Den Hond, M. Hiele, M. Peeters, Y. Ghoos, and P. Rutgeerts, "Effect of long-term oral glutamine supplements on small intestinal permeability in patients with Crohn's disease," Journal of Parenteral and Enteral Nutrition, vol. 23, no. 1, pp. 7-11, 1999.

[148] A. K. Akobeng, V. Miller, J. Stanton, A. M. Elbadri, and A. G. Thomas, "Double-blind randomized controlled trial of glutamine-enriched polymeric diet in the treatment of active Crohn's disease," Journal of Pediatric Gastroenterology and Nutrition, vol. 30, no. 1, pp. 78-84, 2000.

[149] J. Ockenga, K. Borchert, E. Stüber, H. Lochs, M. P. Manns, and S. C. Bischoff, "Glutamine-enriched total parenteral nutrition in patients with inflammatory bowel disease," European Journal of Clinical Nutrition, vol. 59, no. 11, pp. 1302-1309, 2005.

[150] A. K. Akobeng, V. Miller, A. G. Thomas, and K. Richmond, "Glutamine supplementation intestinal permeability in Crohn's disease," Journal of Parenteral and Enteral Nutrition, vol. 24, no. 3, p. 196, 2000.

[151] A. K. Akobeng, P. E. Clayton, V. Miller, C. M. Hall, and A. G. Thomas, "Low serum concentrations of insulin-like growth factor-I in children with active crohn disease effect of enteral nutritional support and glutamine supplementation," Scandinavian Journal of Gastroenterology, vol. 37, no. 12, pp. 1422-1427, 2002.

[152] A. K. Akobeng, K. Richmond, V. Miller, and A. G. Thomas, "Effect of exclusive enteral nutritional treatment on plasma antioxidant concentrations in childhood Crohn's disease," Clinical Nutrition, vol. 26, no. 1, pp. 51-56, 2007.

[153] M. Shinozaki, H. Saito, and T. Muto, "Excess glutamine exacerbates trinitrobenzenesulfonic acid-induced colitis in rats," Diseases of the Colon and Rectum, vol. 40, no. 10, pp. S59-S63, 1997.

[154] J. Omata, K. Fukatsu, C. Ueno, Y. Maeshima, D. Saitoh, and H. Mochizuki, "Intraluminal glutamine administration during ischemia worsens survival after gut ischemiareperfusion," Journal of Surgical Research, vol. 143, no. 2, pp. 260-264, 2007.

[155] A. A. M. Lima, G. Carvalho, A. A. Figueiredo et al., "Effects of an alanyl-glutamine-based oral rehydration and nutrition therapy solution on electrolyte and water absorption in a rat model of secretory diarrhea induced by cholera toxin," Nutrition, vol. 18, no. 6, pp. 458-462, 2002.

[156] A. C. Silva, M. S. Santos-Neto, A. M. Soares, M. C. Fonteles, R. L. Guerrant, and A. A. M. Lima, "Efficacy of a glutaminebased oral rehydration solution on the electrolyte and water absorption in a rabbit model of secretory diarrhea induced by cholera toxin," Journal of Pediatric Gastroenterology and Nutrition, vol. 26, no. 5, pp. 513-519, 1998.

[157] H. W. Brooks, D. G. White, A. J. Wagstaff, and A. R. Michell, "Evaluation of a glutamine-containing oral rehydration solution for the treatment of calf diarrhoea using an Escherichia coli model," Veterinary Journal, vol. 153, no. 2, pp. 163-170, 1997.

[158] S. K. Nath, P. Dechelotte, D. Darmaun, M. Gotteland, M. Rongier, and J. F. Desjeux, "[15N]- and [14C]glutamine fluxes across rabbit ileum in experimental bacterial diarrhea," American Journal of Physiology, vol. 262, no. 2, pp. G312G318, 1992.

[159] J. H. Hoekstra and J. H. L. Van Den Aker, "Facilitating effect of amino acids on fructose and sorbitol absorption in children," Journal of Pediatric Gastroenterology and Nutrition, vol. 23, no. 2, pp. 118-124, 1996. 
[160] H. Ribeiro Jr., T. Ribeiro, A. Mattos et al., "Treatment of acute diarrhea with oral rehydration solutions containing glutamine," Journal of the American College of Nutrition, vol. 13, no. 3, pp. 251-255, 1994.

[161] S. S. Yalçin, K. Yurdakök, I. Tezcan, and L. Oner, "Effect of glutamine supplementation on diarrhea, interleukin-8 and secretory immunoglobulin A in children with acute diarrhea," Journal of Pediatric Gastroenterology and Nutrition, vol. 38, no. 5, pp. 494-501, 2004.

[162] C. Gutierrez, S. Villa, F. R. Mota, and J. J. Calva, "Does an L-glutamine-containing, glucose-free, oral rehydration solution reduce stool output and time to rehydrate in children with acute diarrhoea? A double-blind randomized clinical trial," Journal of Health, Population and Nutrition, vol. 25, no. 3, pp. 278-284, 2007.

[163] J. M. Rhoads, E. O. Keku, J. Quinn, J. Woosely, and J. G. Lecce, "L-glutamine stimulates jejunal sodium and chloride absorption in pig rotavirus enteritis," Gastroenterology, vol. 100, no. 3, pp. 683-691, 1991.

[164] S. S. Yalçin, K. Yurdakök, I. Tezcan, and M. Tuncer, "Effect of glutamine supplementation on lymphocyte subsets in children with acute diarrhea," Turkish Journal of Pediatrics, vol. 52, no. 3, pp. 262-266, 2010.

[165] U. Tannuri, F. R. Carrazza, and K. Iriya, "The effects of glutamine-supplemented diet on the intestinal mucosa of the malnourished growing rat," Revista do Hospital das Clinicas de Faculdade de Medicina da Universidade de Sao Paulo, vol. 55, no. 3, pp. 87-92, 2000.

[166] G. F. Yi, J. A. Carroll, G. L. Allee et al., "Effect of glutamine and spray-dried plasma on growth performance, small intestinal morphology, and immune responses of Escherichia coli K88 +-challenged weaned pigs," Journal of Animal Science, vol. 83, no. 3, pp. 634-643, 2005.

[167] E. A. Williams, M. Elia, and P. G. Lunn, "A doubleblind, placebo-controlled, glutamine-supplementation trial in growth-faltering Gambian infants," American Journal of Clinical Nutrition, vol. 86, no. 2, pp. 421-427, 2007.

[168] A. A. M. Lima, L. F. B. Brito, H. B. Ribeiro et al., "Intestinal barrier function and weight gain in malnourished children taking glutamine supplemented enteral formula," Journal of Pediatric Gastroenterology and Nutrition, vol. 40, no. 1, pp. 28-35, 2005.

[169] N. L. Lima, A. M. Soares, R. M. S. Mota, H. S. A. Monteiro, R. L. Guerrant, and A. A. M. Lima, "Wasting and intestinal barrier function in children taking alanylglutamine-supplemented enteral formula," Journal of Pediatric Gastroenterology and Nutrition, vol. 44, no. 3, pp. 365374, 2007.

[170] A. A. M. Lima and R. L. Guerrant, "Glutamine for childhood malnutrition: is it needed?" Journal of Pediatric Gastroenterology and Nutrition, vol. 40, no. 4, pp. 526-527, 2005.

[171] J. M. Naylor, T. Leibel, and D. M. Middleton, "Effect of glutamine or glycine containing oral electrolyte solutions on mucosal morphology, clinical and biochemical findings, in calves with viral induced diarrhea," Canadian Journal of Veterinary Research, vol. 61, no. 1, pp. 43-48, 1997.

[172] T. R. Ziegler, L. S. Young, K. Benfell et al., "Clinical and metabolic efficacy of glutamine-supplemented parenteral nutrition after bone marrow transplantation. A randomized, double-blind, controlled study," Annals of Internal Medicine, vol. 116, no. 10, pp. 821-828, 1992.

[173] W. T. F. Harsha, E. Kalandarova, P. McNutt, R. Irwin, and J. Noel, "Nutritional supplementation with transforming growth factor- $\beta$, glutamine, and short chain fatty acids minimizes methotrexate-induced injury," Journal of Pediatric Gastroenterology and Nutrition, vol. 42, no. 1, pp. 53-58, 2006.

[174] C. Ford, J. A. Whitlock, and J. B. Pietsch, "Glutaminesupplemented tube feedings versus total parenteral nutrition in children receiving intensive chemotherapy," Journal of Pediatric Oncology Nursing, vol. 14, no. 2, pp. 68-72, 1997.

[175] J. B. Pietsch, C. Ford, and J. A. Whitlock, "Nasogastric tube feedings in children with high-risk cancer: a pilot study," Journal of Pediatric Hematology/Oncology, vol. 21, no. 2, pp. 111-114, 1999.

[176] E. Ward, S. Picton, U. Reid et al., "Oral glutamine in paediatric oncology patients: a dose finding study," European Journal of Clinical Nutrition, vol. 57, no. 1, pp. 31-36, 2003.

[177] B. Kuskonmaz, S. Yalcin, O. Kucukbayrak et al., "The effect of glutamine supplementation on hematopoietic stem cell transplant outcome in children: a case-control study," Pediatric Transplantation, vol. 12, no. 1, pp. 47-51, 2008.

[178] V. M. Aquino, A. R. Harvey, J. H. Garvin et al., "A doubleblind randomized placebo-controlled study of oral glutamine in the prevention of mucositis in children undergoing hematopoietic stem cell transplantation: a pediatric blood and marrow transplant consortium study," Bone Marrow Transplantation, vol. 36, no. 7, pp. 611-616, 2005.

[179] P. M. Anderson, G. Schroeder, and K. M. Skubitz, "Oral glutamine reduces the duration and severity of stomatitis after cytotoxic cancer chemotherapy," Cancer, vol. 83, no. 7, pp. 1433-1429, 1998.

[180] P. M. Anderson, N. K. C. Ramsay, X. O. Shu et al., "Effect of low-dose oral glutamine on painful stomatitis during bone marrow transplantation," Bone Marrow Transplantation, vol. 22, no. 4, pp. 339-344, 1998.

[181] A. Okur, F. S. Ezgü, L. Tümer et al., "Effects of oral glutamine supplementation on children with solid tumors receiving chemotherapy," Pediatric Hematology and Oncology, vol. 23, no. 4, pp. 277-285, 2006.

[182] H. Köhler, M. Klowik, O. Brand, U. Göbel, and H. Schroten, "Influence of glutamine and glycyl-glutamine on in vitro lymphocyte proliferation in children with solid tumors," Supportive Care in Cancer, vol. 9, no. 4, pp. 261-266, 2001.

[183] P. Bunpo, B. Murray, J. Cundiff, E. Brizius, C. J. Aldrich, and T. G. Anthony, "Alanyl-glutamine consumption modifies the suppressive effect of L-asparaginase on lymphocyte populations in mice," Journal of Nutrition, vol. 138, no. 2, pp. 338-343, 2008.

[184] R. S. Grigoryan, E. H. Panosyan, N. L. Seibel, P. S. Gaynon, I. A. Avramis, and V. I. Avramis, "Changes of amino acid serum levels in pediatrics patients with higher-risk acute lymphoblastic leukemia (CCG-1961)," In Vivo, vol. 18, no. 2, pp. 107-112, 2004.

[185] A. S. D. Spiers and H. E. Wade, "Bacterial glutaminase in treatment of acute leukaemia," British Medical Journal, vol. 1, no. 6021, pp. 1317-1319, 1976.

[186] P. Halonen, M. K. Salo, K. Schmiegelow, and A. Makipernaa, "Investigation of the mechanisms of therapy-related hypoglycaemia in children with acute lymphoblastic leukaemia," Acta Paediatrica, vol. 92, no. 1, pp. 37-42, 2003.

[187] C. T. Peng, K. H. Wu, S. J. Lan, J. J. P. Tsai, F. J. Tsai, and C. H. Tsai, "Amino acid concentrations in cerebrospinal fluid in children with acute lymphoblastic leukemia undergoing chemotherapy," European Journal of Cancer, vol. 41, no. 8, pp. 1158-1163, 2005. 
[188] D. C. Gore and F. Jahoor, "Deficiency in peripheral glutamine production in pediatric patients with burns," Journal of Burn Care and Rehabilitation, vol. 21, no. 2, pp. 171-177, 2000.

[189] C. K. Ogle, J. D. Ogle, J. X. Mao et al., "Effect of glutamine on phagocytosis and bacterial killing by normal and pediatric burn patient neutrophils," Journal of Parenteral and Enteral Nutrition, vol. 18, no. 2, pp. 128-133, 1994.

[190] R. L. Sheridan, K. Prelack, Y. M. Yu et al., "Short-term enteral glutamine does not enhance protein accretion in burned children: a stable isotope study," Surgery, vol. 135, no. 6, pp. 671-678, 2004.

[191] S. Ashwal, B. Holshouser, K. Tong et al., "Proton MR spectroscopy detected glutamate/glutamine is increased in children with traumatic brain injury," Journal of Neurotrauma, vol. 21, no. 11, pp. 1539-1552, 2004.

[192] D. A. Richards, C. M. Tolias, S. Sgouros, and N. G. Bowery, "Extracellular glutamine to glutamate ratio may predict outcome in the injured brain: a clinical microdialysis study in children," Pharmacological Research, vol. 48, no. 1, pp. 101109, 2003.

[193] C. M. Tolias, D. A. Richards, N. G. Bowery, and S. Sgouros, "Extracellular glutamate in the brains of children with severe head injuries: a pilot microdialysis study," Child's Nervous System, vol. 18, no. 8, pp. 368-374, 2002.

[194] D. M. Angeles, S. Ashwal, N. D. Wycliffe et al., "Relationship between opioid therapy, tissue-damaging procedures, and brain metabolites as measured by proton MRS in asphyxiated term neonates," Pediatric Research, vol. 61, no. 5, pp. 614621, 2007.

[195] C. Chuntrasakul, S. Siltham, S. Sarasombath et al., "Comparison of a immunonutrition formula enriched arginine, glutamine and omega-3 fatty acid, with a currently highenriched enteral nutrition for trauma patients," Journal of the Medical Association of Thailand, vol. 86, no. 6, pp. 552-561, 2003.

[196] D. L. Yang and J. F. Xu, "Effect of dipeptide of glutamine and alanine on severe traumatic brain injury," Chinese Journal of Traumatology, vol. 10, no. 3, pp. 145-149, 2007.

[197] E. P. Hoffman, K. H. Fischbeck, R. H. Brown et al., "Characterization of dystrophin in muscle-biopsy specimens from patients with Duchenne's or Becker's muscular dystrophy," New England Journal of Medicine, vol. 318, no. 21, pp. 1363 1368, 1988.

[198] M. Goldstein, S. Meyer, and H. R. Freund, "Effects of overfeeding in children with muscle dystrophies," Journal of Parenteral and Enteral Nutrition, vol. 13, no. 6, pp. 603-607, 1989.

[199] R. C. Griggs and M. J. Rennie, "Muscle wasting in muscular dystrophy: decreased protein synthesis or increased degradation?" Annals of Neurology, vol. 13, no. 2, pp. 125-132, 1983.

[200] M. J. Rennie, R. H. T. Edwards, and D. J. Millward, "Effects of Duchenne muscular dystrophy on muscle protein synthesis," Nature, vol. 296, no. 5853, pp. 165-167, 1982.

[201] M. J. Rennie, P. A. MacLennan, H. S. Hundal et al., "Skeletal muscle glutamine transport, intramuscular glutamine concentration, and muscle-protein turnover," Metabolism, vol. 38 , no. 8, pp. 47-51, 1989.

[202] U. Sharma, S. Atri, M. C. Sharma, C. Sarkar, and N. R. Jagannathan, "Skeletal muscle metabolism in Duchenne muscular dystrophy (DMD): an in-vitro proton NMR spectroscopy study," Magnetic Resonance Imaging, vol. 21, no. 2, pp. 145$153,2003$.

[203] R. Hankard, N. Mauras, D. Hammond, M. Haymond, and D. Darmaun, "Is glutamine a "conditionally essential" amino acid in Duchenne muscular dystrophy?" Clinical Nutrition, vol. 18, no. 6, pp. 365-369, 1999.

[204] R. G. Hankard, D. Hammond, M. W. Haymond, and D. Darmaun, "Oral glutamine slows down whole body protein breakdown in Duchenne muscular dystrophy," Pediatric Research, vol. 43, no. 2, pp. 222-226, 1998.

[205] E. Mok, C. Eleouet-Da Violante, C. Daubrosse et al., "Oral glutamine and amino acid supplementation inhibit whole-body protein degradation in children with Duchenne muscular dystrophy," American Journal of Clinical Nutrition, vol. 83, no. 4, pp. 823-828, 2006.

[206] D. M. Escolar, G. Buyse, E. Henricson et al., "CINRG randomized controlled trial of creatine and glutamine in Duchenne muscular dystrophy," Annals of Neurology, vol. 58, no. 1, pp. 151-155, 2005.

[207] J. A. Granchelli, C. Pollina, and M. S. Hudecki, "Pre-clinical screening of drugs using the mdx mouse," Neuromuscular Disorders, vol. 10, no. 4-5, pp. 235-239, 2000.

[208] M. H. Brooke, G. M. Fenichel, and R. C. Griggs, "Clinical investigation in Duchenne dystrophy: II. Determination of the "power" of therapeutic trials based on the natural history," Muscle and Nerve, vol. 6, no. 2, pp. 91-103, 1983.

[209] E. Mok, G. Letellier, J. M. Cuisset et al., "Lack of functional benefit with glutamine versus placebo in Duchenne muscular dystrophy: a randomized crossover trial," PLoS ONE, vol. 4, no. 5, Article ID e5448, 2009.

[210] S. Rheims, M. Cucherat, A. Arzimanoglou, and P. Ryvlin, "Greater response to placebo in children than in adults: a systematic review and meta-analysis in drug-resistant partial epilepsy," PLoS Medicine, vol. 5, no. 8, pp. 1223-1237, 2008.

[211] M. C. G. Stevens, G. H. Maude, and L. Cupidore, "Prepubertal growth and skeletal maturation in children with sickle cell disease," Pediatrics, vol. 78, no. 1, pp. 124-132, 1986.

[212] C. K. Phebus, M. F. Gloninger, and B. J. Maciak, "Growth patterns by age and sex in children with sickle cell disease," Journal of Pediatrics, vol. 105, no. 1, pp. 28-33, 1984.

[213] E. K. Salman, M. W. Haymond, E. Bayne et al., "Protein and energy metabolism in prepubertal children with sickle cell anemia," Pediatric Research, vol. 40, no. 1, pp. 34-40, 1996.

[214] Y. Niihara, C. R. Zerez, D. S. Akiyama, and K. R. Tanaka, "Oral L-glutamine therapy for sickle cell anemia: I. Subjective clinical improvement and favorable change in red cell NAD redox potential," American Journal of Hematology, vol. 58, no. 2, pp. 117-121, 1998.

[215] C. R. Morris, J. H. Suh, W. Hagar et al., "Erythrocyte glutamine depletion, altered redox environment, and pulmonary hypertension in sickle cell disease," Blood, vol. 111, no. 1, pp. 402-410, 2008.

[216] D. J. VanderJagt, G. J. Kanellis, C. Isichei, A. Pastuszyn, and R. H. Glew, "Serum and urinary amino acid levels in sickle cell disease," Journal of Tropical Pediatrics, vol. 43, no. 4, pp. 220-225, 1997.

[217] T. Planche, A. Dzeing, A. C. Emmerson et al., "Plasma glutamine and glutamate concentrations in Gabonese children with Plasmodium falciparum infection," QJM, vol. 95, no. 2, pp. 89-97, 2002.

[218] G. Cowan, T. Planche, T. Agbenyega et al., "Plasma glutamine levels and falciparum malaria," Transactions of the Royal Society of Tropical Medicine and Hygiene, vol. 93, no. 6, pp. 616-618, 1999.

[219] Y. M. Abdulrazzaq, A. Ibrahim, A. I. Al-Khayat, and K. Dawson, " $\beta$-thalassemia major and its effect on amino acid 
metabolism and growth in patients in the United Arab Emirates," Clinica Chimica Acta, vol. 352, no. 1-2, pp. 183190, 2005.

[220] Y. Niihara, N. M. Matsui, Y. M. Shen et al., "L-glutamine therapy reduces endothelial adhesion of sickle red blood cells to human umbilical vein endothelial cells," BMC Blood Disorders, vol. 5, article 4, 2005.

[221] N. M. Rumen, "Inhibition of sickling in erythrocytes by amino acids," Blood, vol. 45, no. 1, pp. 45-48, 1975.

[222] R. Williams, S. Olivi, C.-S. Li et al., "Oral glutamine supplementation decreases resting energy expenditure in children and adolescents with sickle cell anemia," Journal of Pediatric Hematology/Oncology, vol. 26, no. 10, pp. 619-625, 2004.

[223] P. D’Eufemia, R. Finocchiaro, M. Celli et al., "Neutrophil glutamine deficiency in relation to genotype in children with cystic fibrosis," Pediatric Research, vol. 59, no. 1, pp. 13-16, 2006.

[224] V. Hayes, D. Schaeffer, N. Mauras, J. Punati, and D. Darmaun, "Can glutamine and growth hormone promote protein anabolism in children with cystic fibrosis?" Hormone Research, vol. 58, no. 1, pp. 21-23, 2002.

[225] D. Darmaun, V. Hayes, D. Schaeffer, S. Welch, and N. Mauras, "Effects of glutamine and recombinant human growth hormone on protein metabolism in prepubertal children with cystic fibrosis," The Journal of Clinical Endocrinology and Metabolism, vol. 89, no. 3, pp. 1146-1152, 2004.

[226] H. M. Souza, G. R. Borba-Murad, R. Curi, R. Galletto, and R. B. Bazotte, "Combined administration of glucose precursors is more efficient than that of glucose itself in recovery from hypoglycemia," Research Communications in Molecular Pathology and Pharmacology, vol. 110, no. 3-4, pp. 264-272, 2001.

[227] R. F. Garcia, V. A. F. G. Gazola, H. C. Barrena et al., "Blood amino acids concentration during insulin induced hypoglycemia in rats: the role of alanine and glutamine in glucose recovery," Amino Acids, vol. 33, no. 1, pp. 151-155, 2007.

[228] A. Battezzati, S. Benedini, A. Fattorini, L. P. Sereni, and L. Luzi, "Effect of hypoglycemia on amino acid and protein metabolism in healthy humans," Diabetes, vol. 49, no. 9, pp. 1543-1551, 2000.

[229] N. Mauras, D. Xing, L. A. Fox, K. Englert, and D. Darmaun, "Effects of glutamine on glycemic control during and after exercise in adolescents with type 1 diabetes: a pilot study," Diabetes Care, vol. 33, no. 9, pp. 1951-1953, 2010. 


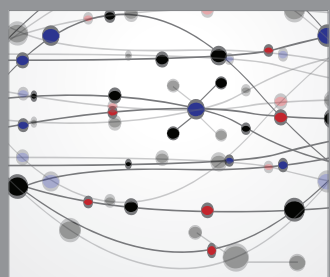

The Scientific World Journal
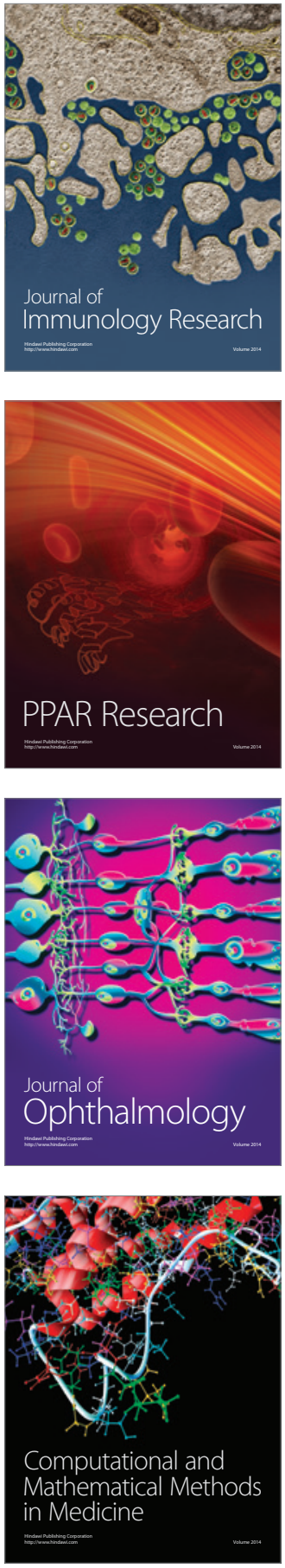

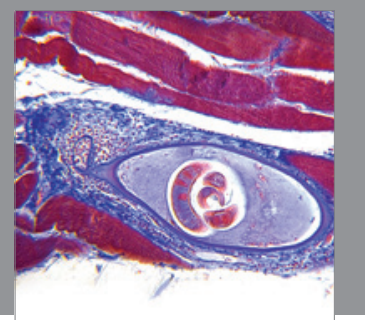

Gastroenterology

Research and Practice
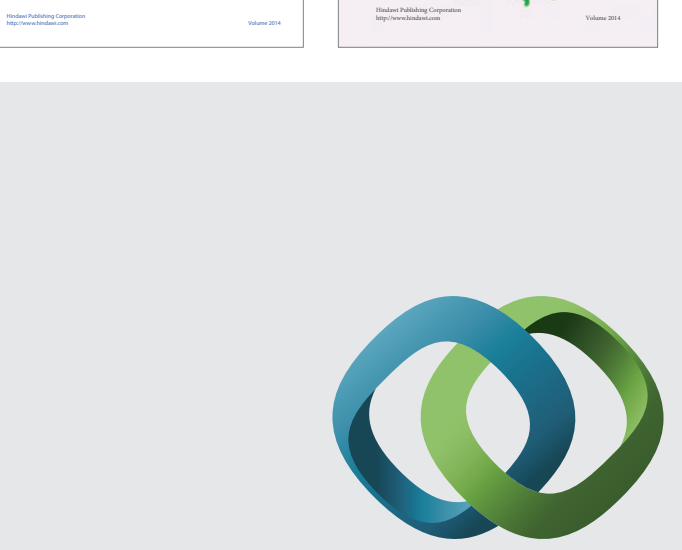

\section{Hindawi}

Submit your manuscripts at

http://www.hindawi.com
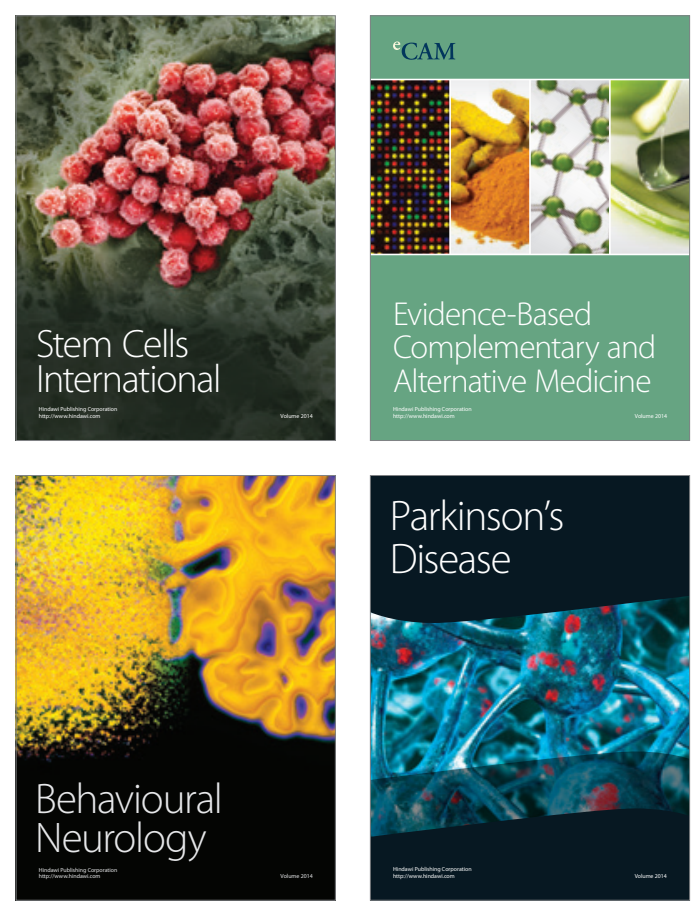

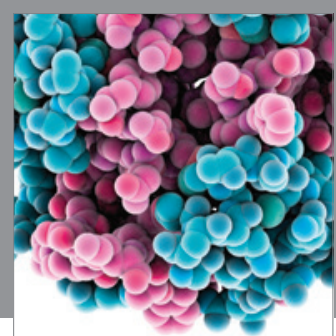

Journal of
Diabetes Research

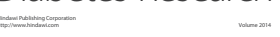

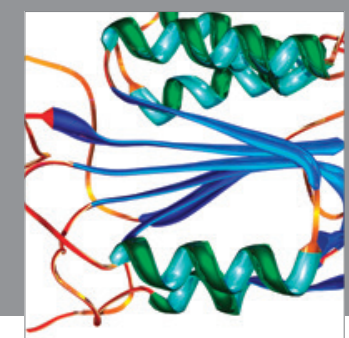

Disease Markers
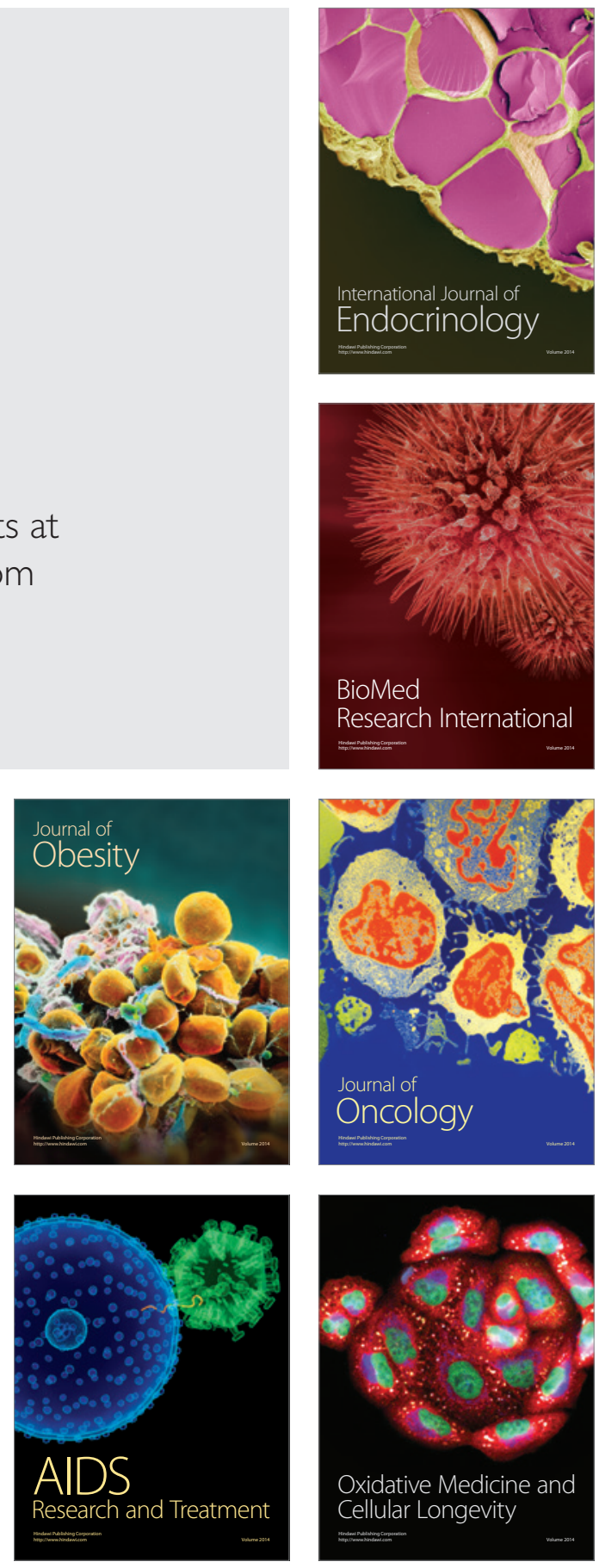